\title{
Un sanctuaire rural antique au cœur d'une boucle de la Seine : le Sablon à Yville-sur-Seine (Seine- Maritime)
}

A rural sanctuary of the 1st to 4th centuries AD situated in a loop of the river Seine : le Sablon at Yville-sur-Seine (Seine-Maritime)

Gérard Guillier, Claire Beurion, Lénaïg Féret et Fabien Pilon

\section{OpenEdition Journals}

Édition électronique

URL : https://journals.openedition.org/rao/6102

DOI : 10.4000/rao.6102

ISSN : 1775-3732

Éditeur

Presses universitaires de Rennes

\section{Édition imprimée}

Date de publication : 18 décembre 2020

Pagination : 147-190

ISBN : 978-2-7535-8232-3

ISSN : 0767-709X

\section{Référence électronique}

Gérard Guillier, Claire Beurion, Lénaïg Féret et Fabien Pilon, « Un sanctuaire rural antique au cœur d'une boucle de la Seine : le Sablon à Yville-sur-Seine (Seine-Maritime) », Revue archéologique de l'Ouest [En ligne], 36 | 2020, mis en ligne le 18 décembre 2020, consulté le 18 août 2022. URL : http:// journals.openedition.org/rao/6102; DOI : https://doi.org/10.4000/rao.6102 


\title{
Un sanctuaire rural antique au cœur d'une boucle de la Seine : le Sablon à Yville-sur-Seine (Seine-Maritime)
}

\author{
A rural sanctuary of the 1st to 4th centuries $A D$ situated in a loop \\ of the river Seine : le Sablon at Yville-sur-Seine \\ (Seine-Maritime)
}

\author{
Gérard Guillier $^{a}$, Claire Beurion ${ }^{b}$, Lénaïg FÉret ${ }^{\mathrm{b}}$ \\ et Fabien PILON ${ }^{c}$
}

Résumé : Une partie d'un vaste sanctuaire antique localisé au cœur d'une boucle de la Seine entre Calètes et Véliocasses, à l'ouest de Rouen, montre après une première occupation peu caractérisée, une succession de temples ceinte au sud d'un péribole fossoyé ( $\mathrm{I}^{\mathrm{er}}$ et $\mathrm{II}^{\mathrm{e}}$ s. apr. J.-C.). La chronologie des différents éléments constitutifs du sanctuaire reste cependant peu assurée. Au sud du péribole, s’installe un établissement (II ${ }^{\mathrm{e}} \mathrm{s}$. au milieu du $\mathrm{III}^{\mathrm{e}}$ s. apr. J.-C.), vraisemblablement contemporain d'une phase d'occupation du sanctuaire, matérialisé par un petit bâtiment maçonné et deux fossés en forme de " U », emboîtés, ceignant un bâti élevé sur poteaux. Ce serait un habitat, un lieu de commerce, de restauration ou de repos. Un semis de fosses-dépotoirs vient ensuite percer ces derniers éléments (première moitié au milieu du III ${ }^{\mathrm{e}}$ s. apr. J.-C.). Le temple est abandonné et détruit entre le milieu du $\mathrm{III}^{\mathrm{e}}$ s. apr. J.-C. et le Ive s. apr. J.-C.

\begin{abstract}
A$ vast sanctuary dating from the 1st to 4 th centuries AD, located in a loop of the river Seine between Calètes and Veliocasses not far to the west of Rouen, includes a succession of temple enclosures, built to the south of a ditch or moat that delimits a peribolos ( 1 st and $2 n d c$. AD). It is preceded by an occupation that was not characterised. The chronological relationship between the various components of the sanctuary are missing. A settlement was established (2nd c. to middle of the $3 r d c$. AD) to the south of the peribolos, probably contemporary to one of the sanctuary's occupation phases, represented by a small building and two u-shaped ditches fitted together, surrounding a wooden construction. This would have been a settlement or trading centre, or some type of inn. A scattering of refuse pits were later dug through these levels (first half to the middle of the $3 \mathrm{rd} c$. AD). The temple was abandoned and knocked down between the middle of the $3 r d \mathrm{c}$. AD and the 4 th $c . A D$.
\end{abstract}

Mots clés : Normandie, Haut-Empire, Véliocasses, Calètes, temple, péribole, céramique, monnaies, enclos, habitat, instrumentum.

Keywords: Normandy, Roman Empire, Veliocasses, Caletes, temple, peribol, pottery, coins, enclosure, settlement, small finds.

\footnotetext{
a Inrap Grand Ouest, Le Mans, AOrOc UMR 8546, CNRS/ENS (gerard.guillier@inrap.fr)

b Inrap Grand Ouest, Le Grand-Quevilly (claire.beurion@inrap.fr) (lenaig.feret@inrap.fr)

c UMR 7041-ArScAn, équipe GAMA (fabien.pilon@wanadoo.fr)
} 


\section{GÉNÉralités}

Le site du Sablon ${ }^{1}$ est localisé dans un méandre de la basse vallée de la Seine, à $15 \mathrm{~km}$ à l'ouest de Rouen, sur la commune d'Yville-sur-Seine et dans le département de la Seine-Maritime (fig. 1). Il est placé au cœur de la plaine alluviale de la boucle d'Anneville-Ambourville, où les sables et graviers sont exploités de façon extensive depuis plusieurs décennies. La fouille de ce site fait suite à une opération de diagnostic archéologique (Beurion, 2013). La parcelle fouillée en février 2014 (Guillier et al., 2016) est localisée en limite nord du territoire de la commune et à $2 \mathrm{~km}$ à l'est du cours actuel du fleuve, à une altitude d'environ +6 m NGF. Le site recouvre la limite entre la plaine alluviale moderne $(\mathrm{Fz})$ et la basse terrasse quaternaire (Fyd). La plaine alluviale moderne correspond à l'extension des grandes crues avec des dépôts de limons, sables, argiles et graves et recouvre les alluvions grossières rattachées à la terrasse quaternaire la plus récente. Ce sont des sables, gravillons, graviers et galets, disposés en stratifications entrecroisées (Sangnier, 1968). La zone décapée obéit à une double pente, qui descend d'est $(+6,40 \mathrm{~m} \mathrm{NGF})$ en ouest (+5,57 $\mathrm{m} \mathrm{NGF})$, mais aussi du nord (+6,40 $\mathrm{m} \mathrm{NGF)} \mathrm{vers}$ le sud $(+5,83 \mathrm{~m} \mathrm{NGF})$.

\section{Le contexte archéologique}

L'occupation du méandre d'Anneville-Ambourville est peu documentée aux époques anciennes. La Protohistoire est représentée par des découvertes ponctuelles. À une échelle large, pendant la période antique, le site du Sablon serait localisé au sud-est de la cité des Calètes, entre Juliobona, l'actuelle Lillebonne, et Rotomagus, l'actuelle Rouen. Une carte, basée sur les travaux de L. Guyard et T. Lepert (1999, p. 22), présente quelques variantes où le site du Sablon est situé sur la frontière entre Calètes et Véliocasses (Guyard et al., 2015, p. 192) (fig. 2). D’autres auteurs définissent des limites de cité où le site du Sablon relèverait des Éburovices (Aubin et al., 2014, p. 220-222). Le bourg d'Anneville-surSeine (Seine-Maritime), localisé à $3 \mathrm{~km}$ au nord du Sablon, recouvre une petite agglomération gallo-romaine où de nombreux vestiges ont été exhumés sur environ $1 \mathrm{~km}^{2}$. Les éléments nécessaires à la compréhension du paysage antique

1. Ce site est référencé sous les codes patriarche 76.759.0010 et 76.759.00.12. Son numéro d'Entité Archéologique est le suivant : 17-2278. La parcelle fouillée porte le $\mathrm{n}^{\circ} \mathrm{B} 427$. Lopération archéologique du Sablon fait suite à un projet d'extension d'une carrière par la société des Carrières et Balastières de Normandie (CBN), société qui a financé l'opération, ainsi que la mise à disposition d'engins pour le décapage du site, la réalisation de sondages dans les fosses et fossés, et qui a grandement facilité sur le terrain nos opérations de fouille. environnant le sanctuaire (réseau viaire, habitats, parcellaire, espaces funéraires...) sont à l'heure actuelle absents.

Enfin, le Sablon n'est éloigné que de $5 \mathrm{~km}$ environ à l'ouest-sud-ouest du temple romain de l'abbaye SaintGeorges à Saint-Martin-de-Boscherville (Le Maho, 1995).

En 1972, dans une carrière proche de la zone d'étude, des remblais de terre noire recelant de la céramique, un fragment de Vénus anadyomène et des fondations furent observés. En novembre 1981, trois portions de murs gallo-romains furent mises au jour dans la carrière jouxtant immédiatement au nord le terrain aujourd'hui exploré et les archives du Service Régional d'Archéologie conservent un relevé et une description des maçonneries réalisés par Éric Follain de la direction des Antiquités de l'époque. Des murs en petit appareil de moellons de calcaire liés au mortier jaune reposent sur une semelle en bloc de silex. L'un d'eux est renforcé dans un angle par des rangs de briques et de blocs de calcaire sciés; du torchis brûlé et des tuiles à rebord accompagnent ces maçonneries.

\section{La stratigraphie générale du terrain}

En dehors des zones archéologiques (fig. 3, $\log 1$; d'après Beurion, 2013, p. 29), la sédimentation est restreinte, avec $0,50 \mathrm{~m}$ de sédiments sableux chargés en galets (US 1 et 2) reposant directement sur la grave (US 4 : relevant probablement de la plaine alluviale moderne $\mathrm{Fz}$ ), alors que de faibles dépressions conservent des séquences plus développées, où ont pu être piégés des éléments mobiliers anciens. Dans la zone d'occupation antique, les limons sableux supérieurs, de teinte brun foncé, presque noire, sont chargés de matériaux de construction, de céramique et de charbon de bois (US 3), notamment au sud des temples, au niveau des couches de destruction 1056 et 1086 (fig. 3, $\log 2$; ibid., p. 29).

\section{L'occupation du SITE du SABLON}

En premier lieu, évoquons l'état lacunaire de ce site. En effet, seule une partie du sanctuaire a été mise au jour lors des fouilles menées en 2014 et une part importante du monument, notamment les temples, est sous la voirie actuelle, au nord de la zone fouillée (fig. 4), tandis que plus au nord encore, l'exploitation ancienne des carrières a détruit la moitié nord du temenos. Une partie du sanctuaire se développe aussi à l'ouest, sous la bande de sécurité séparant la route départementale 45 de l'actuelle zone d'exploitation.

En second lieu, d'intenses phases de récupération de matériaux à l'époque antique, voire plus tardivement, ont été menées. Soulignons aussi l'absence de tout niveau de sol ou de couche d'occupation comme souvent en Normandie (Éloy-Épailly, 2008). 

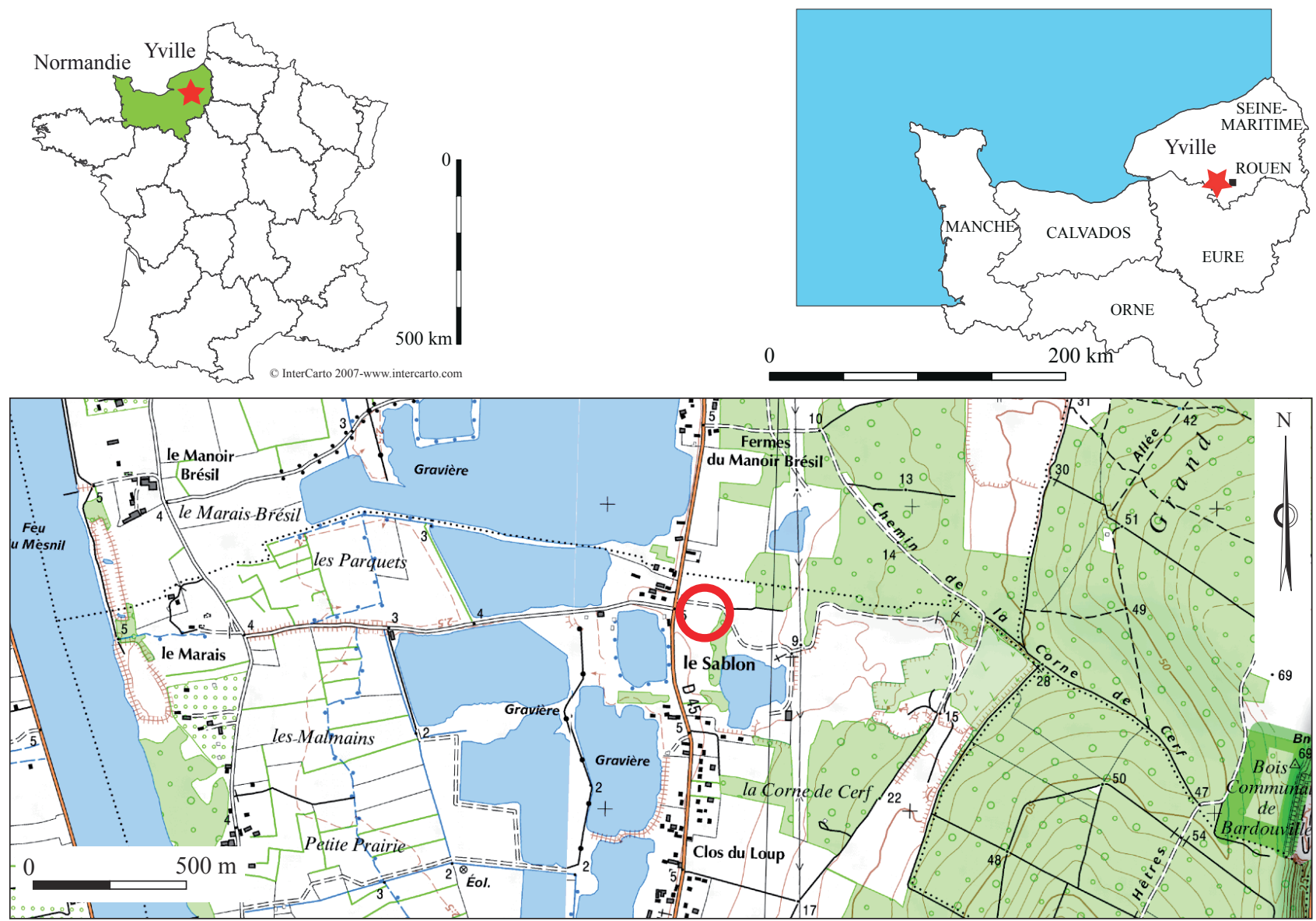

(C) IGN 2012 - www.geoportail.gouv.fr

Figure 1 : Yville-sur-Seine (Seine-Maritime), Le Sablon, localisation de l'opération archéologique.

Figure 1: Yville-sur-Seine (Seine-Maritime), Le Sablon, location of the archaeological operation.

Ce site ${ }^{2}$ présente plusieurs phases d'occupation, pas toujours bien datées ni caractérisées (fig. 4). Mais il est possible de proposer, dans ses grandes lignes, la chronologie suivante :

- Les premières occupations, dont la datation recouvre la fin de la période gauloise et le début du $\mathrm{I}^{\text {er }}$ s. apr. J.-C.;

- Un sanctuaire des $\mathrm{I}^{\mathrm{er}}$-III ${ }^{\mathrm{e}}$ s. apr. J.-C., largement incomplet au nord, est implanté sur les éléments précédents;

- En limite sud du sanctuaire, un établissement, constitué d'un bâti élevé sur poteaux et d'enclos emboîtés vient, aux $\mathrm{II}^{\mathrm{e}}$-III ${ }^{\mathrm{e}}$ s. apr. J.-C., s'appuyer contre le fossé sud du péribole;

- Un semis de fosses, attribuable au III $^{\mathrm{e}}$ s. apr. J.-C., est creusé sur cette dernière limite;

- Les couches de destruction du sanctuaire sont localisées au cœur des temples tandis que celles dispersées par l'érosion se situent en contrebas et au sud de celui-ci. Le numéraire

2. Des appels dans le texte font référence à l'instrumentum (par exemple : inv. 1077-2), ou au numéro de monnaie dans le catalogue de l'étude numismatique (par exemple : cat. $\mathrm{n}^{\circ} 55$ ). issu de ces couches semble dater sa destruction du courant du IV s. apr. J.-C.

\section{Les rares témoins des premières occupations}

Les vestiges de la première phase d'occupation, peu caractérisés, sont aussi mal datés (fig. 4 et 5). Ceux localisés en limite nord de l'emprise des fouilles sont très incomplets puisque morcelés par le sanctuaire édifié à partir du milieu $\mathrm{du} \mathrm{I}^{\mathrm{er}}$ s. apr. J.-C. et n'ont livré aucun mobilier archéologique datant. Parmi les autres vestiges de cette première occupation, le fossé 1068 et la fosse 1075 sont identifiés par le mobilier céramique associé.

\section{Les vestiges localisés en limite nord de l'emprise}

À l'ouest ont été observés les segments de fossés 1137 et 1138 et les trous de poteaux 1139,1140 et 1141 (fig. 5). À l'est, la fosse 1134 au comblement sableux de teinte noire recelait de rares fragments de tuiles. Ce sont aussi une 


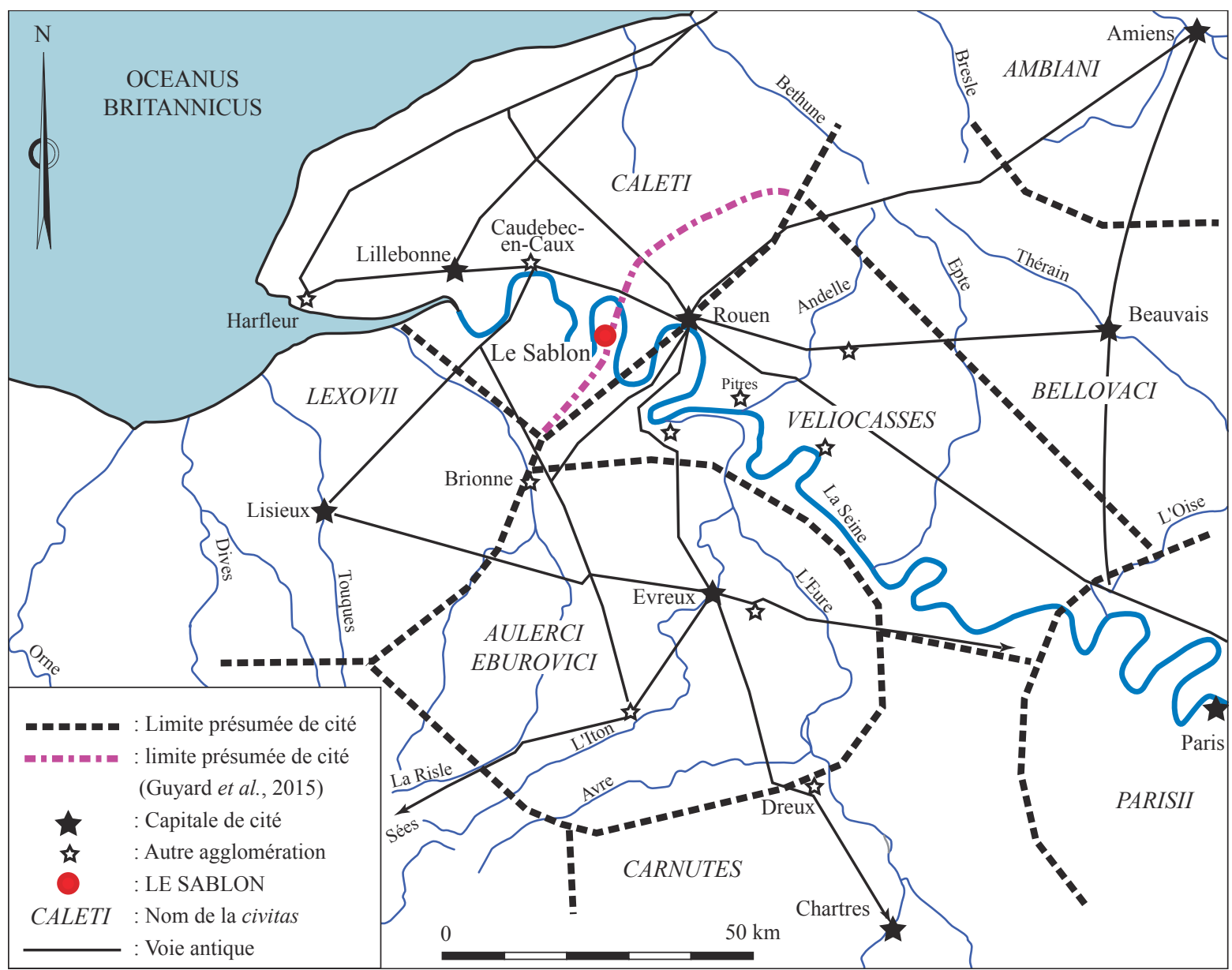

Figure 2 : Yville-sur-Seine (76), situation du site du Sablon dans la cité des Calètes ou des Véliocasses (d'après Guyard et Lepert, 1999; Guyard et al., 2015).

Figure 2: Situation of the site of Sablon in relation to Calètes and Véliocasses (after Guyard, Lepert, 1999; Guyard et al., 2015).

courte portion d'un éventuel fossé ou sablière, 1135, ainsi que les segments de murs maçonnés 1136, 1143 et 1146. Si ces éléments sont largement incomplets, des orientations comparables suggèrent un ou plusieurs états primitifs d'un éventuel sanctuaire antérieur à celui édifié à partir du milieu du $\mathrm{I}^{\mathrm{er}}$ s. apr. J.-C., mieux caractérisé, aux orientations identiques (fig. 4). La petite sablière (?) 1135 permet d'évoquer cette hypothèse puisqu' elle est placée exactement sous le mur 1117, qui marque au sud l'ensemble E3 du sanctuaire édifié plus tardivement. Ces vestiges formeraient les ultimes témoins d'un ou plusieurs temples, très lacunaires mais aussi très mal datés. Notons que cette fosse ou sablière 1135 présentait dans son comblement un fragment de dallage en calcaire.

\section{La fosse 1075 et les deux fossés 1068 et 1073}

Au sud des éléments précédemment décrits sont localisés la fosse 1075 et les fossés 1068 et 1073.
La fosse 1075 datée de la fin de la période gauloise et du début de l'époque augustéenne (fig. 5), la plus ancienne sur le site, est isolée chronologiquement sur la surface décapée. De forme grossièrement ovale, elle mesure $4,7 \times 10,5 \mathrm{~m}$, ses bords sont très évasés et elle est profonde de 0,10 à $0,20 \mathrm{~m}$. Son comblement, un sable de teinte noire à gris foncé, recelait 31 tessons de céramique, où ont été décomptés huit vases, dont cinq sont figurés (fig. 6). On remarque une jatte tournée $\left(\mathrm{n}^{\circ} 1\right)$ avec des traces de suie, l'élément le mieux conservé est un pot ( $\left.\mathrm{n}^{\circ} 2\right)$ dont le haut de panse striée délimite une partie basse laissée brute; sa face interne, très abîmée, est peut-être due à un contenu agressif (sel, saumure), ce pot servant d'ustensile de stockage et non de cuisson.

Les formes non tournées renvoient à des pots de gabarit et de finition divers puisque si l'un montre un façonnage fruste $\left(\mathrm{n}^{\circ} 3\right)$, les bords des deux autres exemplaires ( $\mathrm{n}^{\text {os }} 4$ et 5) seraient repris au tour. Ces deux derniers ont une pâte proche des productions de type "Veauvillaise», reconnues au 
Log 1 : stratigraphie générale du terrain

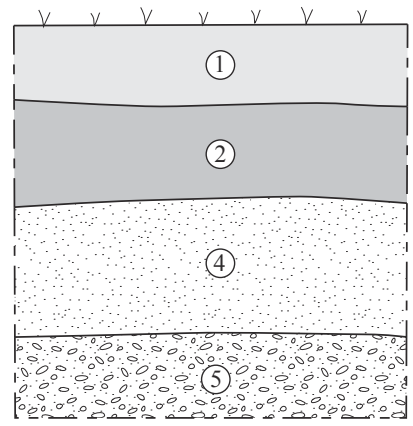

1 - Sable humifère brun gris

2 - Sable grossier brun clair à brun orangé légèrement pédogénéisé et cailloutis

3 - Sable organique fin homogène sans cailloutis, d'aspect lessivé : brun à brun noir en partie supérieure à grisâtre en partie inférieure, abondant mobilier
Log 2 : au niveau de ST 1086

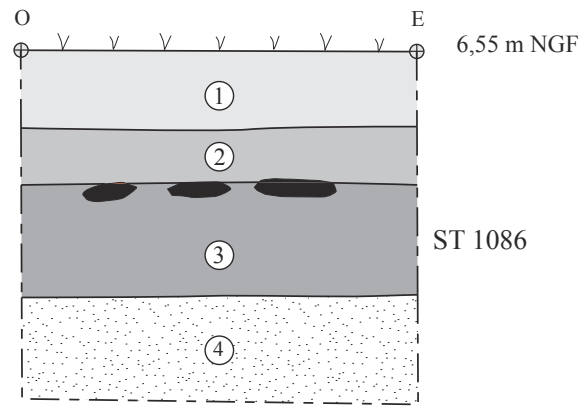

4 - Sable beige à orangé, nombreux cailloutis issu de la grave, avec parfois des passées argileuses orangées et des accumulations ferrro-manganiques à la base

5 - Grave sableuse très caillouteuse, jaune clair

Terre cuite architecturale

Figure 3 : Yville-sur-Seine (76), Le Sablon, les différentes séquences stratigraphiques observées sur le terrain (C. Beurion, Inrap).

Figure 3: The different stratigraphic sequences observed in the field (C. Beurion, Inrap).

nord de la Seine à la fin du second âge du Fer (Blancquaert et al., 1996). Un fragment d'anse d'une amphore vinaire de type Dressel 1 complète ce lot. Les profils de ces vases de " tradition indigène " sont comparables à ceux contemporains de la vallée de Seine, à l'exemple de Val-de-Reuil (Eure) Le Chemin aux Errants, zone A (Lukas, 2014, fig. 169) ou encore Le Clos Saint-Cyr / La Cerisaie (Beurion, 2012). Plus proche d'Yville-sur-Seine, des comparaisons sont probantes avec le site de Jumièges (Seine-Maritime) Le Camp des Vieux (fouille B. Houdusse, étude H. Delnef, Inrap, notamment le fossé 221).

Le fossé 1068 , daté du premier tiers du $\mathrm{I}^{\mathrm{er}}$ s. apr. J.-C., localisé à quelques mètres au sud de la fosse précédente, est constitué de deux segments perpendiculaires, longs de 42 et de $9 \mathrm{~m}$ (fig. 5). Il est large de 0,70 à $1,30 \mathrm{~m}$ et profond de $0,30 \mathrm{~m}(\mathrm{C} 1)$ à $0,60 \mathrm{~m}(\mathrm{C} 2)$ (fig. 5). Ce fossé présente un comblement de sable gris (US 4), puis de sable noir avec quelques silex épars (US 3). Au niveau du seul sondage C2, ont été décelés en surface des fragments de tuiles à rebord.

Le lot de céramique issu du fossé 1068, au caractère homogène (fig. 7), compte 67 tessons où sont décomptés 18 vases. Le seul tesson de sigillée, une assiette, est une importation italique des années 20 av. J.-C. à 20 apr. J.-C. (identification R. Delage/Inrap). De probables productions champenoises sont matérialisées par des assiettes de type Deru A41 $\left(\mathrm{n}^{\circ} 1\right)$ en terra nigra et Gose $296\left(\mathrm{n}^{\circ} 2\right)$ en terra rubra; du Centre de la Gaule proviennent deux coupes de type Menez $110\left(\mathrm{n}^{\circ} 3\right)$ en terra nigra. Des deux pots en céramique dorée au mica ( $\mathrm{n}^{\text {os }} 4$ et 5 ), le plus grand, par sa pâte grossière relève du type "Besançon " stricto sensu. Les pâtes sombres, fréquentes avec un tiers de l'ensemble, présentent un caractère "romanisé » ou de tradition indigène. Est identifié un gobelet en pâte grise fine, au décor à peine soigné de "pastilles " moulées $\left(n^{\circ} 6\right)$, peu représenté régionalement. D'autres formes sont plus habituelles, ainsi la jatte à profil en " $S$ " $\left(n^{\circ} 7\right)$ ou le pot trapu $\left(n^{\circ} 8\right)$. Des deux pots $\left(n^{\text {os }} 9\right.$ et 10$)$ à la pâte "sandwich ", de teinte rose à cœur gris et surface enfumée, le second a une face interne corrodée, témoignant d'un contenu agressif et de son usage en tant que poterie de stockage. La céramique non tournée de " tradition indigène " concentre la moitié des restes et un tiers des individus recensés. Se distinguent deux jattes à profil en « $S$ » bien marqué ( $\left.{ }^{\circ} 11\right)$, ou au profil plus affadi $\left(n^{\circ} 12\right)$, montrant une reprise autour du bord. Un bord de pot de grand module conserve des traces de suie témoignant de son passage sur le feu et de son usage en tant que pot à cuire $\left(\mathrm{n}^{\circ} 13\right)$.

Le segment de fossé 1073 (fig. 5), très érodé, localisé à quelques mètres au nord du précédent, est long de $16 \mathrm{~m}$, large de $0,80 \mathrm{~m}$ et profond de $0,10 \mathrm{~m}$. Son extrémité orientale légèrement incurvée vers le nord, amorcerait un angle. Son comblement, peu différent du substrat, a livré de rares fragments de tuiles et aucun tesson de céramique. 

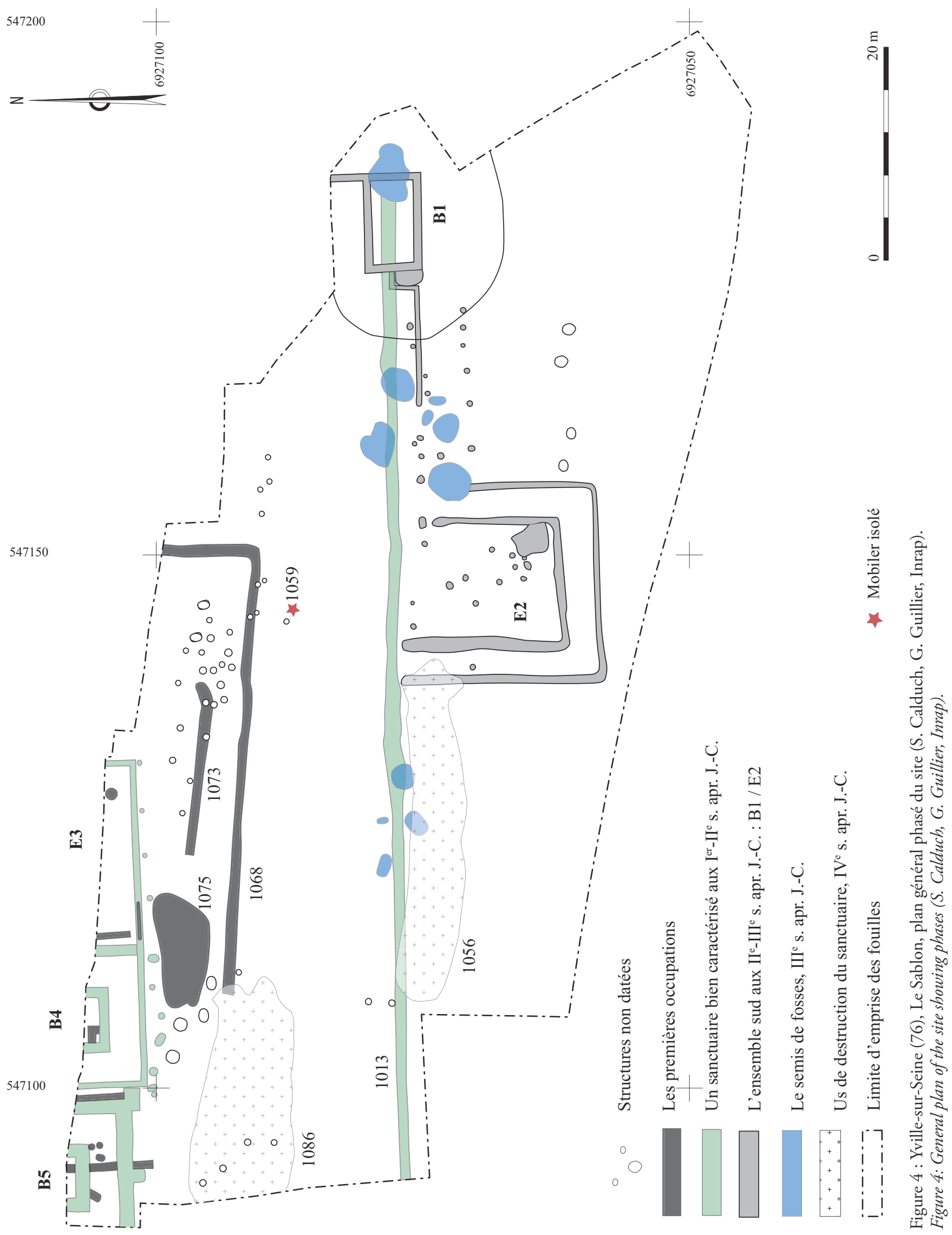


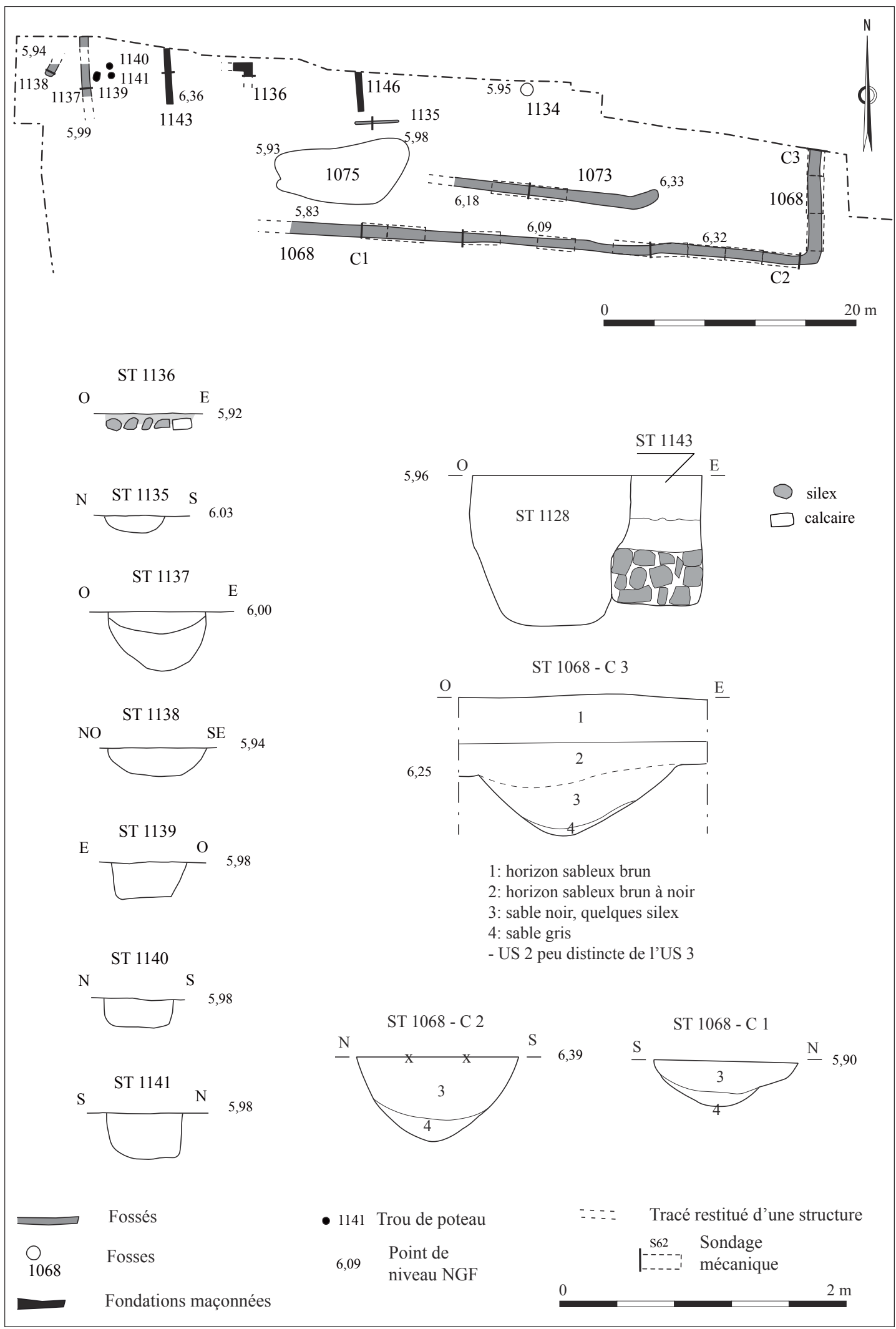

Figure 5 : Yville-sur-Seine (76), Le Sablon, plan des vestiges les plus anciens, avec localisation des coupes et choix de relevés de coupes (L. Brossard, G. Guillier, Inrap).

Figure 5: Detailed plan of the earliest structures on the site, with locations and selected drawings of sections (L. Brossard, G. Guillier, Inrap). 


\section{$?$}

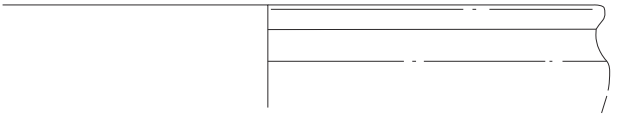

1075-1 (c.s. ind.)

Figure 6 : Yvillesur-Seine (76), Le Sablon, le mobilier céramique de la fosse 1075 , La Tène D2 / époque augustéenne (L. Féret, Inrap).

Figure 6: The pottery from pit 1075 (La Tène D2 / Augustan period) (L. Féret, Inrap).
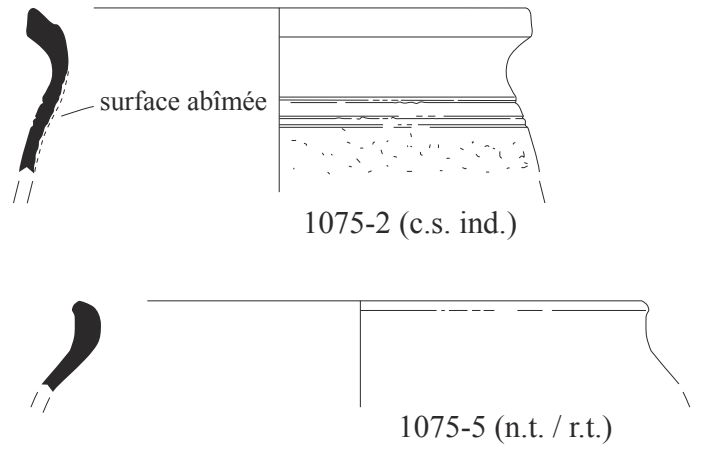

1075
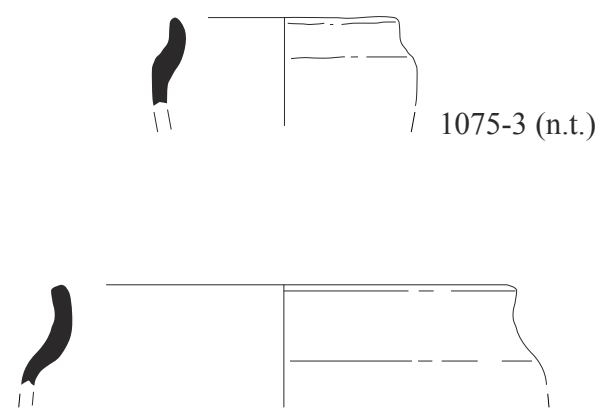

1075-4 (n.t. / r.t.)

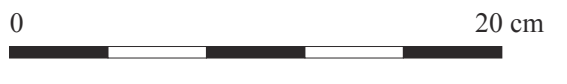

\section{La première occupation du site, un sanctuaire?}

Ces éléments (fig. 5), mal datés à l'exception du fossé 1068 et de la fosse 1075, sont déconnectés stratigraphiquement et regroupent des fosses, des fossés et des fondations maçonnées plus ou moins marquées, formant un ensemble hétérogène allant de La Tène $\mathrm{D} 2$ au premier tiers du $\mathrm{I}^{\mathrm{er}}$ s. apr. J.-C. L'hypothèse d'un ou plusieurs états primitifs d'un ou plusieurs temples se fonde sur des orientations comparables à celles du sanctuaire postérieur et sur l'observation de leur succession en un même lieu (fig. 4). Les fondations 1143, 1136 et 1146 formeraient les ultimes vestiges d'un ou plusieurs bâtiments maçonnés, très lacunaires et nettement différents morphologiquement. Au sud de cet ensemble, la fosse 1075 marque la première occupation du site, mais sans qu'il soit possible de la relier à un sanctuaire d'origine laténienne; en outre, elle ne présente aucun mobilier caractéristique de possibles rejets cultuels. En revanche, les fossés 1068 et 1073 sembleraient pouvoir être interprétés comme limites au sud d'une première aire sacrée.

\section{Un sanctuaire bien caractérisé aux $\mathrm{I}^{\mathrm{er}}$-IIII $s$.}

Aux éléments précédents, possiblement issus d'un premier temple, succède vers le milieu du $\mathrm{I}^{\text {er }}$ s. et occupé tout au long $\mathrm{du} \mathrm{II}^{\mathrm{e}}$ s., voire au siècle suivant, un ensemble un peu plus complet, au plan plus cohérent, légèrement mieux conservé mais toujours aussi mal daté (fig. 4). Ce sanctuaire est constitué au nord, en limite d'emprise, des ensembles E3/B4 et B5 et à 23 m environ au sud de ces derniers, du fossé 1013 , orienté est-ouest, qui délimite au sud l'aire sacrée. Onze trous de poteaux, alignés au sud de l'ensemble E3/B4, pourraient lui être liés. Enfin, on observe que le bâtiment B5 est antérieur à l'ensemble E3/B4.

\section{Le grand fossé est-ouest 1013}

Ce fossé long de $92 \mathrm{~m}$ (fig. 4 et 8), au tracé rectiligne, présente une largeur variant de 0,70 à $1,60 \mathrm{~m}$ pour une profondeur variant de $0,14 \mathrm{~m}$ à $0,60 \mathrm{~m}$ de l'ouest vers l'est (fig. 8). Il est stratifié sur l'essentiel de son tracé, sauf à l'ouest où sa profondeur et sa largeur sont moindres. C'est entre les sondages S2 et S3 qu'est relevée la densité de mobilier la plus forte : tuiles, instrumentum, coquilles d'huittres et de moules, tessons de céramique, blocs de silex et de calcaire. Ce mobilier est concentré dans la moitié supérieure et le tiers central du comblement. Ce fossé 1013 recouvert par les US de destruction du sanctuaire, colluviées, est recoupé par des fosses des II $^{e}-\mathrm{III}^{\mathrm{e}}$ s. et par le bâtiment B1 (qui relève de l'établissement sud). Son mobilier est constitué de 242 tessons de céramique, ainsi que d'une hache miniature (inv. 10131, fig. 24), deux clous de menuiserie en fer (inv. 1013-2), un anneau en alliage de cuivre (inv. 1013-3, fig. 25), une aiguille (inv. 1013-4), une cuillère-sonde (inv. 1013-7) et un clou décoratif en alliage cuivreux (inv. 1013-5), un déchet lié à la métallurgie du bronze (inv. 1013-6) et un fragment de fibule de type Feugère 14b1b (inv. 1013-8). À ces éléments s'ajoutent deux objets en alliage de cuivre issus du diagnostic (Beurion, 2013, p. 42 et 43), une tige brisée et une languette en forme d'équerre (TR12 ST9-1 et 2).

\section{La céramique du fossé 1013 (L. Féret)}

Ce fossé 1013 a livré le lot céramique le plus fourni du site, avec 242 restes (fig. 9 et 10). La sigillée, avec six individus (12\% du NMI), est fragmentée, hormis une assiette complète, des ateliers de La Graufesenque. Il s'agit d'assiettes Drag. $16\left(n^{\circ} 1\right)$, Drag. $15\left(n^{\circ} 2\right)$ et Drag. 18 ( ${ }^{\text {os }} 3$ et 4 ). Selon R. Delage, l'estampille " MEN » identifiée sur une assiette Drag. $18\left(n^{\circ} 4\right)$, ne correspond pas à une variante des marques 


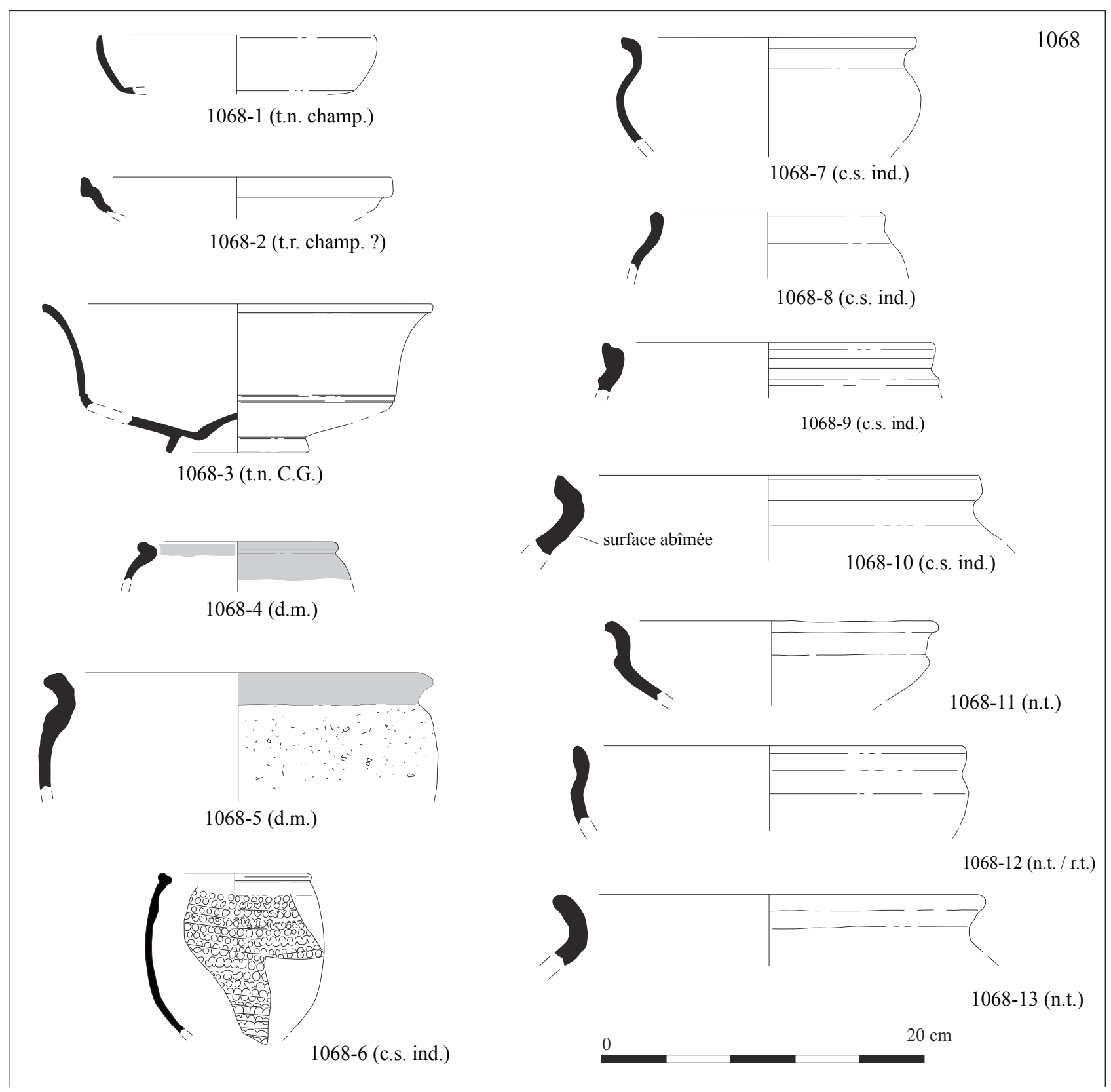

Figure 7 : Yville-sur-Seine (76), Le Sablon, le mobilier céramique du fossé 1068, premier tiers du Ir s. apr. J.-C. (L. Féret, Inrap). Figure 7: The pottery from ditch 1068 (first third of the 1st c. AD) (L. Féret, Inrap).

de MEMOR, mais au potier \{Men-\} (Hartley et Dickinson, 2008-2012, 6, p. 79). Ajoutons à ces productions rutènes du i ${ }^{\text {er }}$ s. apr. J.-C., un fragment de Drag. 29 et un Drag. 37 précoce représentant, toujours selon R. Delage, l'élément le plus récent avec un terminus post quem de 70 apr. J.-C.

Avec sept individus, la terra nigra est représentée par cinq assiettes de type Gose 289 ( $\mathrm{n}^{\text {os }} 5$ et 6 ), trois de probable provenance champenoise et deux du Centre de la Gaule. Le répertoire est complété par une coupe arverne Menez 110 et un gobelet biconique ( $\mathrm{n}^{\circ} 7$ ) du Noyonnais (Ben Redjeb,
1992, fig. 2, type 38). La céramique à engobe blanc concerne les cruches à pâte micacée brun orangé à cœur sombre provenant du Val de Loire ou du Centre de la Gaule et caractéristiques des ensembles précoces de la région (Adrian et Féret, 2014, p. 200). La céramique dorée au mica (deux individus) fait se côtoyer des productions fines, tel le haut d'un gobelet ( $\left.\mathrm{n}^{\circ} 8\right)$, avec des produits plus grossiers illustrés par des tessons résiduels. La céramique commune claire est représentée par un mortier $\left(\mathrm{n}^{\circ} 9\right)$ de type Oberaden 72 , probablement originaire du Noyonnais. Plusieurs cruches sont 


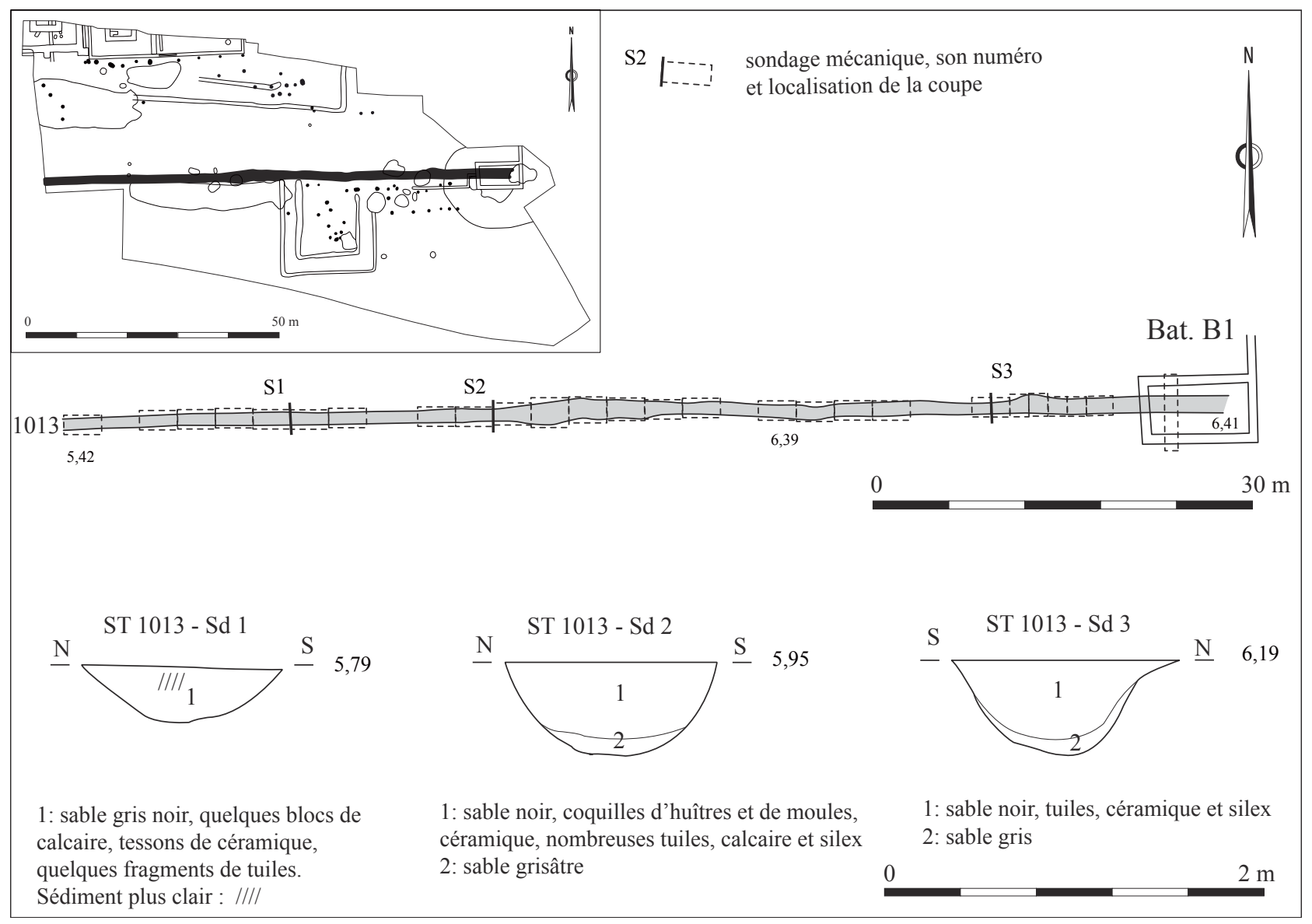

Figure 8 : Yville-sur-Seine (76), Le Sablon, le sanctuaire des $\mathrm{I}^{\mathrm{er}}-\mathrm{II}^{\mathrm{e}}$ s. apr. J.-C., le fossé 1013, localisation des sondages et choix de relevés de coupes (L. Brossard, G. Guillier, Inrap).

Figure 8: The sanctuary of the 1st-2nd c. AD, ditch 1013, locations of the trenches and selected drawings of sections (L. Brossard, G. Guillier, Inrap).

matérialisées par des fragments de panse et de fond, l'unique silhouette conservée ( $\left.\mathrm{n}^{\circ} 10\right)$ étant pré-flavienne.

La céramique commune sombre, avec 24 représentants (50\% du NMI), montre une grande diversité de fabriques et de formes : écuelle à collerette ( $\left.{ }^{\circ} 11\right)$, jatte à bord éversé $\left(n^{\circ} 12\right)$, jattes à profil en « $S$ » $\left(n^{\text {os }} 13\right.$ à 17$)$, pots trapus $\left(n^{\text {os }} 20\right.$ et 21) ou globulaires ( $n^{\text {os }} 22$ à 27). Leur origine est locale ou régionale, exception faite de l'écuelle à collerette ( $\left.n^{\circ} 11\right)$. Les fabriques proposent souvent la même forme, ainsi les deux jattes à profil en " $S$ » ( $\mathrm{n}^{\text {os }} 13$ et 14$)$ qui possèdent une pâte de teinte gris rougeâtre. Les exemplaires $n^{\text {os }} 16,17$ et 19 montrent une même pâte grise fine et les deux pots globulaires $n^{\text {os }} 24$ et 25 , au profil comparable, une pâte grise, grossière. Le pot $\mathrm{n}^{\circ} 23$ possède une pâte à vacuoles connue à Isneauville en Seine-Maritime (Adrian, 2011, p. 119). La pâte du pot $\mathrm{n}^{\circ} 22$ rappelle les productions ébrö̈ciennes de la seconde moitié du I ${ }^{\text {er }}$ s. apr. J.-C. (Adrian, 2001, fig. 20). Le pot $\mathrm{n}^{\circ} 27$ offre une pâte connue dans le Pays de Caux, à Hautot-le-Vatois en Seine-Maritime (Blancquaert et Adrian, 2006) ou dans la région d'Évreux (Adrian et Féret, 2014, p. 221). Enfin, la jatte à bord éversé $\mathrm{n}^{\circ} 12$ est proche des productions "Veauvillaise " de la fin de l'âge du Fer.

Hormis certains éléments précoces résiduels et des rejets de la première moitié du $\mathrm{III}^{\mathrm{e}}$ s. (90 tessons issus du décapage du fossé), la très large majorité des rejets s'est opérée entre le milieu et le troisième quart $\mathrm{du} \mathrm{I}^{\mathrm{er}} \mathrm{s}$., tout du moins avant l'époque flavienne.

\section{Le temple ouest : B5}

Ce temple localisé au nord-ouest de la zone fouillée, incomplet au nord et à l'ouest (fig. 4 et 11), est antérieur à l'ensemble E3/B4 (voir ci-après). Les éléments le constituant matérialisent l'angle sud-est d'une galerie et le tiers sud d'une cella (fig. 11), l'ensemble relevant d'un temple à plan centré de plan quadrangulaire ou carré, de type fanum ${ }^{3}$.

3. Le mot "fanum " a été utilisé dès le début du $\mathrm{xx}^{\mathrm{e}}$ s. pour décrire les temples de tradition indigène à galerie périphérique et plan centré, mais, "ce terme revêt en fait un sens plus générique désignant en Italie comme en Gaule différents types d'édifices cultuels » (Poux et Demierre, 2015, p. 121). Le mot « temple» lui est préféré. 


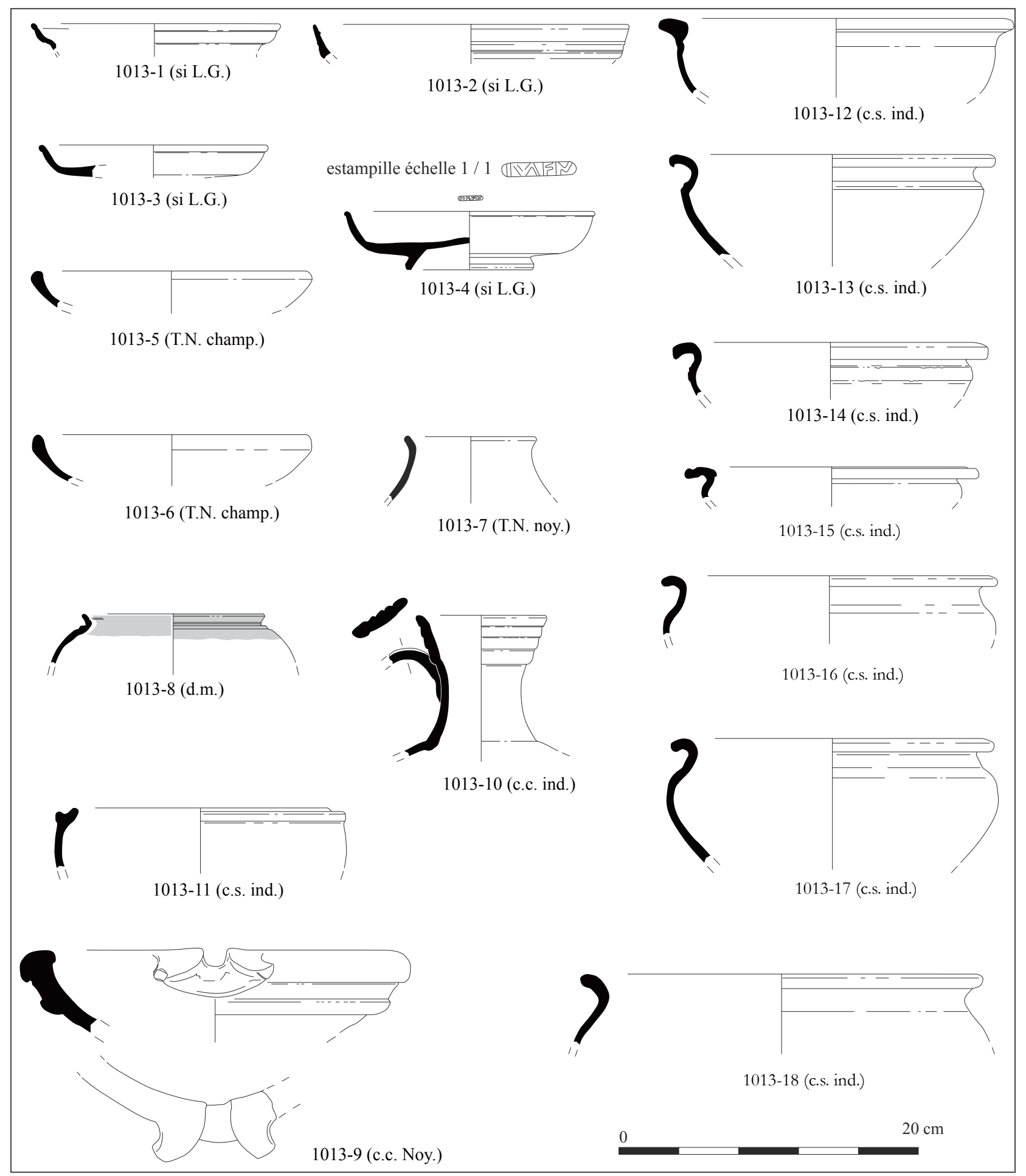

Figure 9: Yville-sur-Seine (76), Le Sablon, le mobilier céramique du fossé 1013, les vases 1 à 18, milieu du I ${ }^{\text {er }}$ s. apr. J.-C. (L. Féret, Inrap). Figure 9: The pottery from ditch 1013, vessels 1 to 18 (middle of the 1st c. AD) (L. Féret, Inrap).

Le côté sud de la cella, long de $6,35 \mathrm{~m}$, est complet; ses retours d'angle ont été dégagés sur $2 \mathrm{~m}$ de longueur environ. Cette structure 1126 est large de $1,30 \mathrm{~m}$ et profonde de $1,15 \mathrm{~m}$ (fig. 11, C1). La galerie ceinturant la cella est déterminée par les murs 1127 et 1128 qui sont chaînés à leur angle. Le premier a été mis au jour sur $12 \mathrm{~m}$ et le second sur 5,5 m (fig. 11). Deux contreforts, 1130 (fig. 12) et 1145 , soutiennent la galerie. Le mur sud de la galerie, sur 


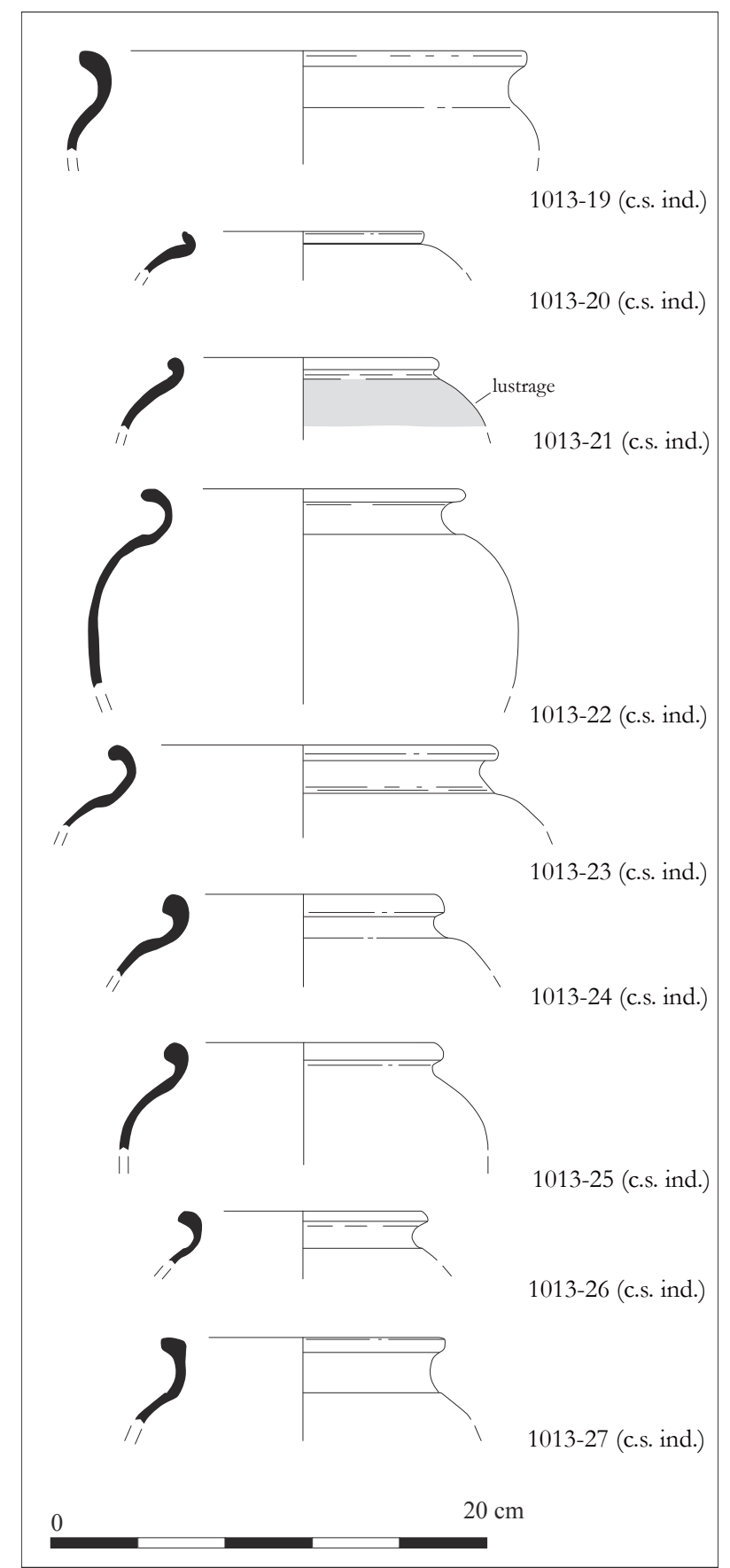

Figure 10 : Yville-sur-Seine (76), Le Sablon, le mobilier céramique du fossé 1013 , les vases 19 à 27, milieu du i ${ }^{\text {er }}$ s. apr. J.-C. (L. Féret, Inrap).

Figure 10: The pottery from ditch 1013, vessels 19 to 27 (L. Féret, Inrap).

la pente, est large de $1,40 \mathrm{~m}$, tandis que celui placé à l'est est large de 1,10 m. Leurs profondeurs sont égales : $1,10 \mathrm{~m}$ (fig. 11, coupes C2 et C3, US 2 et 3). Le mur sud 1127 est caractérisé par le contrefort 1130 (coupe C2), de plan quadrangulaire aux angles adoucis, mesurant 1,20 par 1,20 m et profond de 0,80 m. Le contrefort 1145 à l'angle sud-est de la galerie, de plan rectangulaire aux angles bien marqués, mesure en plan 1,50 par 2,10 m et sa profondeur est de $0,80 \mathrm{~m}$. Il est comblé de blocs et d'éclats de silex mêlés à des fragments de tuiles et de briques, tandis que de gros blocs de silex tapissaient le fond de la tranchée de fondation.

\section{L'ensemble cultuel E3/B4}

Il est localisé immédiatement à l'est du temple B5 et lui est postérieur (fig. 4 et 13). L'élément permettant de les associer est matérialisé par le mur 1115/1117, orienté estouest et qui délimite au sud cet ensemble. Cette structure est construite d'un seul jet, avec les maçonneries 1114 à l'ouest et 1118 à l'est. Le mur 1116, un élément commun à E3 et B4, vient buter contre 1115/1117, il mesure 3,90 m de longueur, $1 \mathrm{~m}$ de largeur et de profondeur (fig. 13 : coupe C5).

L'ensemble $\mathrm{E} 3$, très incomplet au nord, a été fouillé sur une longueur de $17,50 \mathrm{~m}$ et sur une largeur variant de 2,90 m à 4,60 m (fig. 13). Les $52 \mathrm{~m}^{2}$ de son aire interne sont vierges de tout artéfact contemporain; seule est visible la couche de destruction 1124. Les maçonneries limitant au sud et à l'est l'ensemble E3 sont chaînées à leur angle. Le mur 1118, dégagé sur une longueur de $2,90 \mathrm{~m}$, présente une largeur de $0,55 \mathrm{~m}$ et une profondeur de $0,20 \mathrm{~m}$ (fig. 13, 1118 - C7), tandis que 1117 (= 1115) qui limite au sud E3 a été mis au jour sur une longueur de $17,5 \mathrm{~m}$ et offre une largeur variant de 0,55 à $0,60 \mathrm{~m}$. Sa profondeur varie de 0,20 à 0,30 m (fig. 13, C6).

Le bâtiment B4 est très incomplet au nord (fig. 14), mais le type de vestige auquel il se rapporte se distingue assez nettement à la lecture du plan (fig. 13), il s'agit d'un temple à plan centré avec au sud, à l'est et à l'ouest les murs limitant la galerie $(1114,1115$ et 1116), tandis qu'au nord la cella partiellement dégagée est matérialisée par les maçonneries 1119,1120 et 1121 . Seuls $81 \mathrm{~m}^{2}$ de son aire interne ont été explorés (fig. 15), d'où sont issues les couches de destruction US 1125 (galerie) et US 1132 (cella). Les maçonneries 1114 et 1115 limitant la galerie de B4 sont chaînées à leur angle, 1114 , long de $6,50 \mathrm{~m}$, est large de $0,60 \mathrm{~m}$ et profond de 0,30 à $0,40 \mathrm{~m}$ (fig. $13, \mathrm{C} 1$ ), tandis que 1115 (=1117), complet sur l'emprise et limitant au sud $\mathrm{B} 4$, est long de $13 \mathrm{~m}$, et large de 0,58 à $0,60 \mathrm{~m}$. Sa profondeur conservée est de 0,40 à $0,60 \mathrm{~m}$ (fig. 13, C2).

Seul le tiers sud de la cella de B4 a été fouillé. Le mur 1119 placé au sud est complet, long de $6 \mathrm{~m}$ et large de 0,92 à $1 \mathrm{~m}$; il est chaîné à ses angles avec les côtés ouest et est de la cella. Mis au jour respectivement sur 2,50 et 2,10 m, ces derniers sont larges de 1,10 m (fig. 13, C3 et C4). Celui matérialisant le sud de cella (1119 : fig. 13) est large de $1,10 \mathrm{~m}$ au niveau des fondations et de $0,96 \mathrm{~m}$ au niveau des premières assises de l'élévation. Sa profondeur est de $1 \mathrm{~m}$. Le mur ouest de 


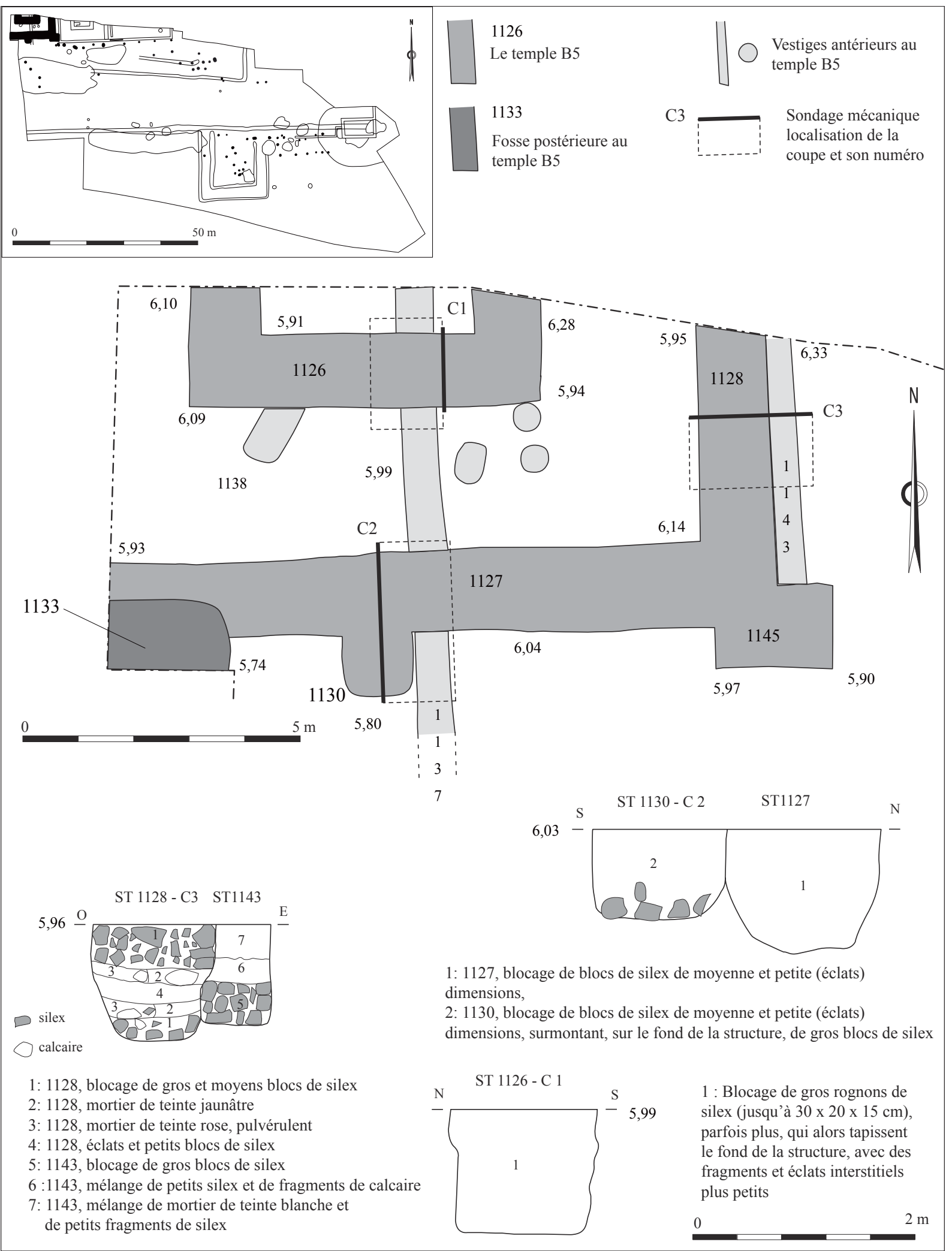

Figure 11 : Yville-sur-Seine (76), Le Sablon : le temple B5, présentation des structures, nivellement du secteur et choix de relevés coupes (L. Brossard, S. Calduch, G. Guillier, Inrap).

Figure 11: Temple B5, presentation of the structures, levelling of the sector and selected drawings of the sections (L. Brossard, S. Calduch, G. Guillier, Inrap). 


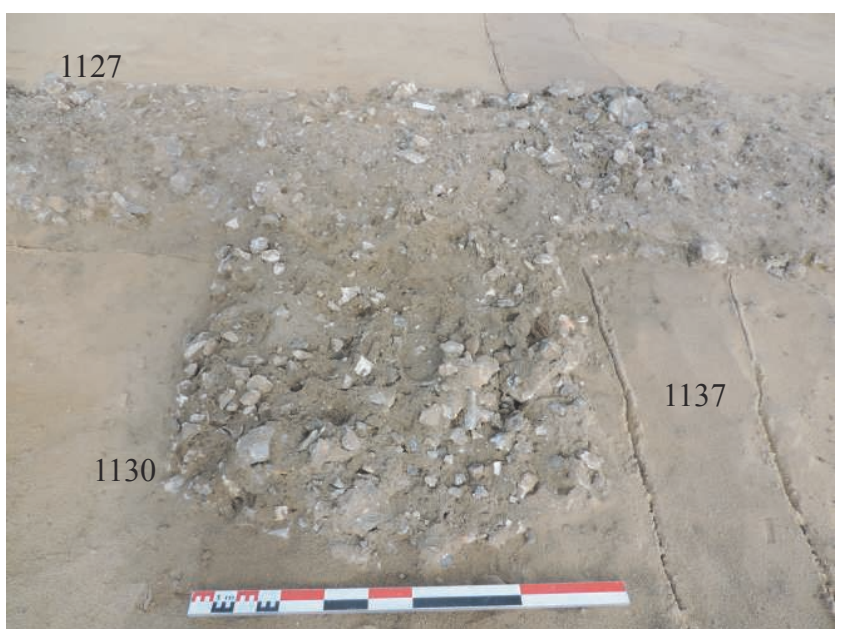

Figure 12 : Yville-sur-Seine (76), Le Sablon, le temple B5, le contrefort 1130 ainsi que le mur 1127 (et le fossé 1137), vue prise vers le nord (cliché G. Guillier, Inrap).

Figure 12: Temple B5, buttress 1130, the wall 1127 (pit 1137), view from the north (photo G. Guillier, Inrap).

la cella (1120 : fig. 13, C3) est large de $1,10 \mathrm{~m}$ au niveau des fondations tandis qu'au niveau des premières assises de l'élévation, il est large de $0,96 \mathrm{~m}$. Sa profondeur est de $1 \mathrm{~m}$ et le profil de la tranchée de fondation est légèrement piriforme. Un bloc de calcaire équarri marque l'angle externe du mur 1119/1120.

Le mur est de la cella (1121 : fig. 13, C4; fig. 16) offre un profil singulier. La fondation, large de $1 \mathrm{~m}$ et profonde de $0,75 \mathrm{~m}$, est surmontée des deux premières assises de l'élévation, qui sont décalées vers l'ouest de 0,28/0,30 m par rapport aux fondations. Ce probable repentir a été dressé au-dessus de la tranchée de fondation sans reprise du tracé de cette dernière. Ce décalage permet aux galeries est et ouest du temple B4 d'être sensiblement d'égale largeur $(2,80$ et $2,90 \mathrm{~m})$. Une autre hypothèse serait une reprise plus tardive de la maçonnerie mais sans qu'aucune trace n'ait été mise en évidence, les murs 1121 et 1119 étant chaînés à leur angle, sans différence dans le mortier les recouvrant.

Une ligne de onze trous de poteaux, légèrement sinueuse, longue de $31,50 \mathrm{~m}$, placée à une distance d'environ 0,4 à 1,20 m au sud de l'ensemble E3/B4 (fig. 13), pourrait être, selon une hypothèse non exclusive, le témoin d'un échafaudage localisé contre le côté sud de l'ensemble E3/B4.

\section{Le sanctuaire des $I^{\mathrm{er}}$ et II $\mathrm{II}^{\mathrm{e}}$., hypothèses de restitution}

Le bâtiment B5 (fig. 11) est un temple quadrangulaire à plan centré. Ce type de plan étant relativement bien connu, il est possible de proposer une hypothèse de restitution de B5. La cella devait être de plan rectangulaire ou carré et mesurer de 6 à 6,50 $\mathrm{m}$ de côté. Les largeurs de la galerie sont de 2,60 $\mathrm{m}$ au sud et de 2,80 m à l'est. La restitution géométrique des murs de la galerie évoque un ensemble mesurant de 14,25 à $14,50 \mathrm{~m}$ de côté.

Les données liées à l'ensemble E3/B4 sont également lacunaires au nord (fig. 13). En ce qui concerne le bâtiment B4, le raisonnement engagé précédemment pour le temple B5 permet d'évoquer une cella de plan quadrangulaire d'environ $6 \mathrm{~m}$ de côté. Les largeurs de la galerie sont de $2,75 \mathrm{~m}$ au sud, de 2,90 m à l'est et de 2,80 m à l'ouest. Une restitution géométrique permet d'envisager une galerie d'environ $12 \mathrm{~m}$ de côté. L'ensemble E3 est plus lacunaire encore.

Il est possible de proposer plusieurs hypothèses (fig. 17), non exclusives.

Pour venir en appui à l'hypothèse 1 , celle de deux (ou plus) cellae au sein de E3, citons les sites de Saint-PierreBellevue dans la Creuse ou de Lantenne-Vertière dans le Doubs (Fauduet, 1993, p. 69, 75), de Châteaubleau en Seine-et-Marne (Pilon, 2012, p. 105) ou de Sierentz dans le Haut-Rhin (Roth-Zehner et Le Martret, 2008), au total une quinzaine en Gaule. Régionalement, mentionnons les trois cellae disposées au sein d'une galerie allongée sur le site du Devant de la Garenne à Guichainville (Eure) (Flotté et al., 1996) (fig. 17).

Dans l'hypothèse 2, où deux temples sont accolés, mentionnons les sanctuaires de Sablé-sur-Sarthe dans la Sarthe, de Marguerides en Corrèze et de Matagne-la-Petite en Belgique (Fauduet, 1993, p. 61, 69 et 85). Ces deux hypothèses sont renforcées par la nature massive du mur 1116 , qui devait supporter conjointement les toitures de ces temples géminés.

Une troisième hypothèse est aussi plausible pour l'ensemble E3, celle d'une absence de cella. Ce serait alors une petite cour/esplanade jouxtant à l'est le bâtiment B4. Un agencement comparable a été observé à Kaiseraugst en Suisse (Riha, 1980, p. 13-15). Une cour à portique jouxtant un temple a également été fouillée près d'Orléans dans le Loiret (Verneau, 2014). Cette hypothèse semble moins recevable que les deux premières du fait de l'épaisseur du mur 1116 (fig. 13).

\section{L'établissement sud aux $\mathrm{II}^{\mathrm{e}}-\mathrm{III}^{\mathrm{e}} s$.}

Cet établissement est postérieur au fossé 1013 qui marque la limite sud du sanctuaire (fig. 4) et antérieur au semis de fosses (voir ci-après). L'établissement sud se diviserait en trois ensembles : à l'est le bâtiment rectangulaire B1, à l'ouest l'ensemble E2 matérialisé par deux fossés en forme de « $U$ » emboîtés et au milieu l'espace E7 (fig. 18). Mais leur contemporanéité n'est pas fermement assurée. Son extension n'est pas reconnue au nord-est. 


\section{Le bâtiment rectangulaire $B 1$}

Ce petit bâtiment B1 recoupe le fossé 1013 et est d'orientation comparable (fig. 18). Il est constitué d'une pièce unique de $5,3 \times 8,70 \mathrm{~m}$, d'une surface interne de $27,36 \mathrm{~m}^{2}$. Son mur est (1147) largement détruit par la fosse 1065 (voir ci-après), se prolonge vers le nord sur $3 \mathrm{~m}$ (1144) puis hors de l'emprise des travaux; ce mur 1144 est totalement récupéré (fig. 18, C4). À l'ouest, accolés à cette pièce unique, se trouvent les restes du four 1009, constitué d'un niveau rubéfié épais de 5-6 cm, surmontant un fin lit de galets et ceint des murets 1008 et 1010 (fig. 18). En mauvais état

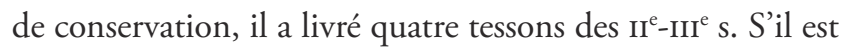

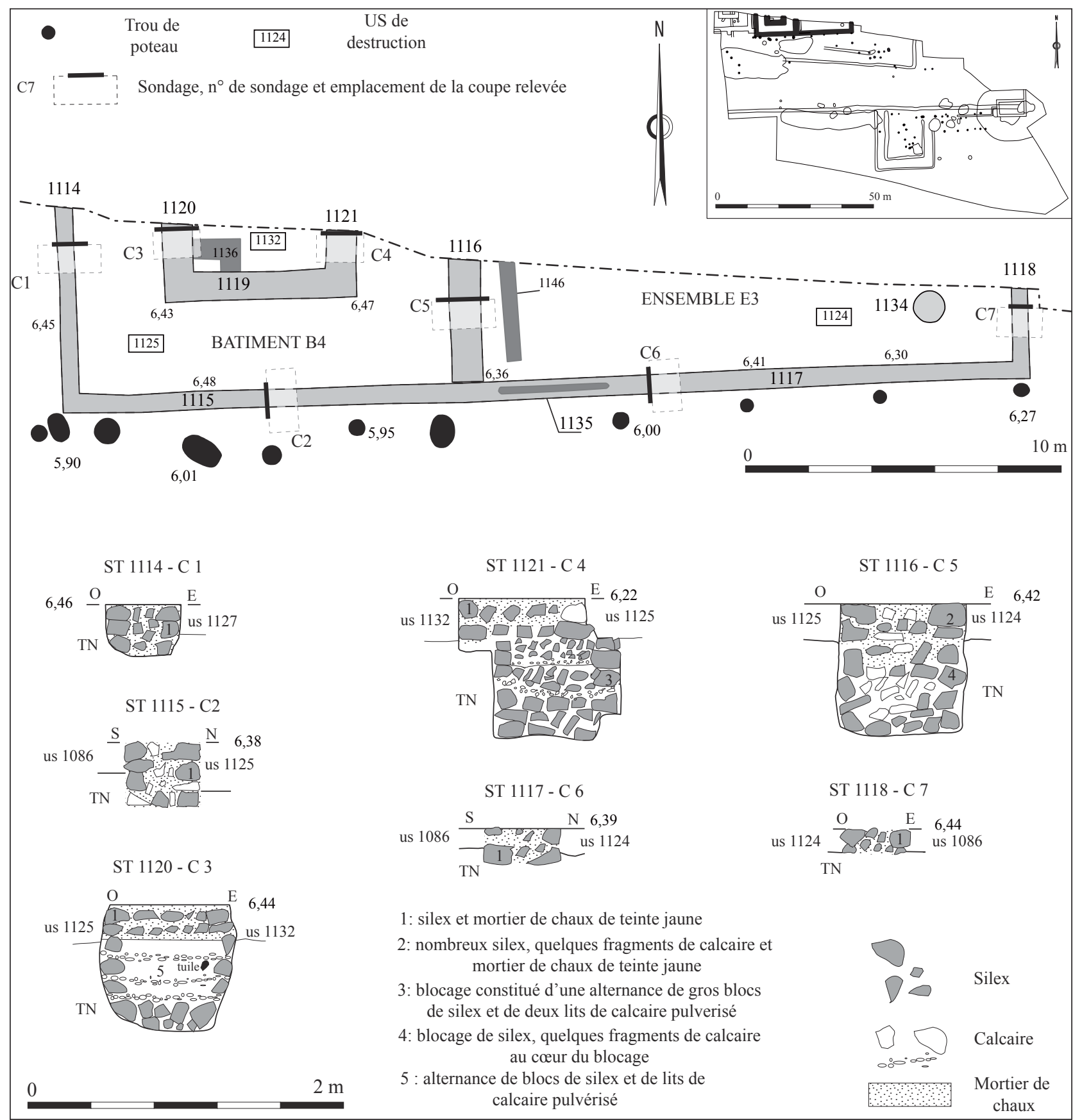

Figure 13 : Yville-sur-Seine (76), Le Sablon : l'ensemble E3/B4, plan, localisation des coupes et choix de relevés de coupes (L. Brossard, S. Calduch, G. Guillier, Inrap).

Figure 13: The E3/B4 ensemble, plan, locations of the different sections cut into the walls and selected drawings of the sections (L. Brossard, S. Calduch, G. Guillier, Inrap). 


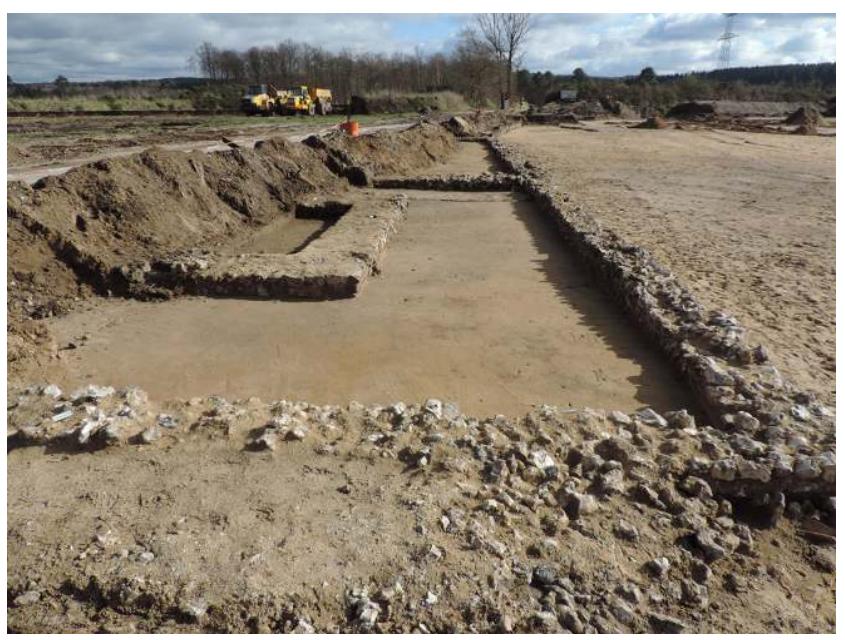

Figure 14 : Yville-sur-Seine (76), Le Sablon, le temple B4, vue prise vers l'est (cliché G. Guillier Inrap).

Figure 14: Temple B4, view from the west (photo G. Guillier Inrap).

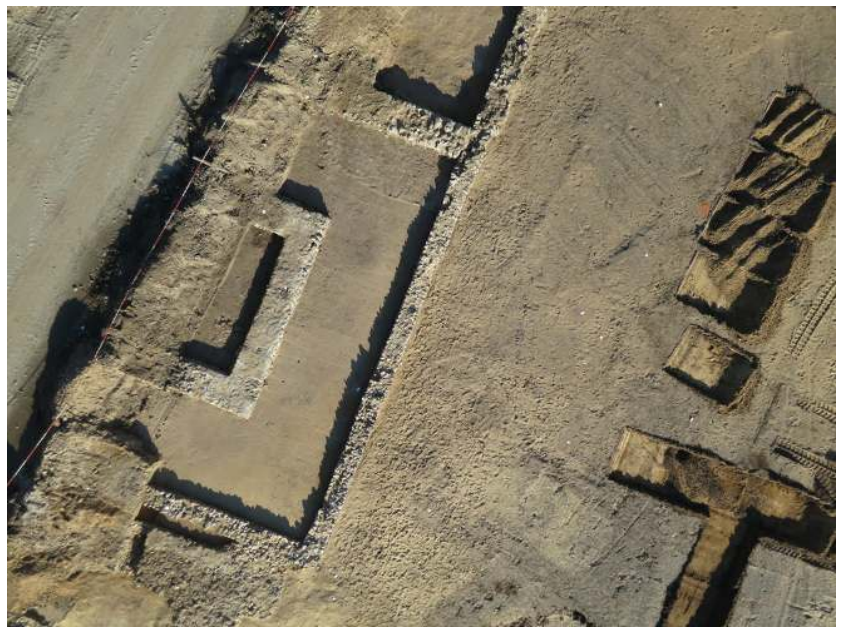

Figure 15 : Yville-sur-Seine (76), Le Sablon, le temple B4, vue verticale (cliché R. Bria / Panormandic).

Figure 15: Temple B4, vertical view (photo R. Bria / Panormandic).

possible d'y voir les restes d'un four domestique, sa surface de $3,5 \mathrm{~m}^{2}$ permettrait d'aller au-delà de cette vocation purement domestique. L'aire interne de B1 est marquée par le remblai de sol 1005, tandis que 1001 constitue une couche d'occupation sur son pourtour. La couche de destruction 1004, peu étendue au sud de B1, a livré treize tessons de la seconde moitié $\mathrm{du} \mathrm{II}^{\mathrm{e}} \mathrm{s}$. et de la première moitié du siècle suivant.

Les sondages effectués révèlent un bâtiment arasé. Au fond des tranchées de fondation, profondes de 0,60 à $0,70 \mathrm{~m}$ et larges de 0,50 à $0,60 \mathrm{~m}$, des rognons de silex de teinte grise, formant blocage de fondation, sont surmontés d'un fin lit de mortier de chaux (fig. 18, C1 et C2 : US 2 et 3), puis d'un blocage de moellons de calcaire $(\mathrm{C} 1, \mathrm{C} 2$ et $\mathrm{C} 3$ : US 4). Le remblai de sol 1005 (fig. 18), sableux, épais de

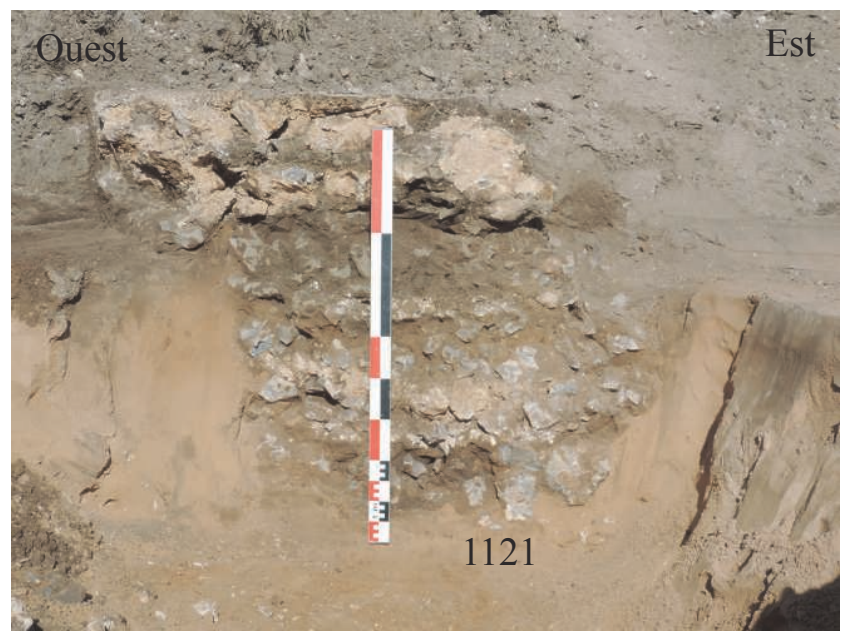

Figure 16 : Yville-sur-Seine (76), Le Sablon, la cella du temple B4, la coupe C4 effectuée dans le mur 1121, vue prise vers le nord (cliché G. Guillier, Inrap).

Figure 16: The cella of temple B4, the section of wall 1121, view from the south (photo G. Guillier, Inrap).

0,03 à $0,15 \mathrm{~m}$, recelait des fragments de tuiles et de coquilles d'huîtres, des clous de menuiserie (inv. 1005-1/3, fig. 24), une lame de couteau (inv. 1005-2, fig. 24) et trois tessons de céramique du $\mathrm{II}^{\mathrm{e}} \mathrm{s}$.

La couche 1001, d'une extension de 16 m par 22 m environ (fig. 18), est caractérisée par un sédiment sableux de teinte grise. Elle mesurait de $0,20 \mathrm{~m}$ d'épaisseur auprès de $\mathrm{B} 1 \mathrm{à} 0,02 \mathrm{~m}$ sur ses marges. Y ont été recueillis 36 tessons de céramique datés du $\mathrm{II}^{\mathrm{e}} \mathrm{s}$. à la seconde moitié du $\mathrm{IV}^{\mathrm{e}} \mathrm{s}$., une lame de couteau (inv. 1001-1, fig. 24), quelques clous de menuiserie (inv. 1001-2), un stylet en fer (inv. 1001-3) et un as d'Auguste (cat. ${ }^{\circ} 2$ ).

La chronologie du bâtiment B1, d'après la centaine de tessons recueillie, suggère une occupation datable entre la seconde moitié du $\mathrm{II}^{\mathrm{e}}$ s. et la première moitié du siècle suivant. Les quelques éléments tardifs évoquent la fin de son occupation ou sa destruction dans la seconde moitié du IV $s$.

\section{L'espace E7, un ensemble à définir}

Localisé à l'ouest du bâtiment précédent B1 et à l'est du double enclos emboîté E2, cet ensemble E7 est lié au premier par le muret-solin 1011 (fig. 18), qui ne présente pas de discontinuité avec le muret 1010 dessinant le côté ouest du four. Le côté nord de E7 matérialisé par 1011 et cinq trous de poteaux alignés, est parallèle au fossé 1013 (fig. 18). Son côté sud est composé d'un alignement de six trous de poteaux, parallèle au côté nord. Ils sont distants de 4 à $4,5 \mathrm{~m}$. Il est possible d'y restituer un espace couvert, par exemple un long porche ou un bâtiment de forme allongée ou bien encore un espace ouvert, lié à la contention ou au 


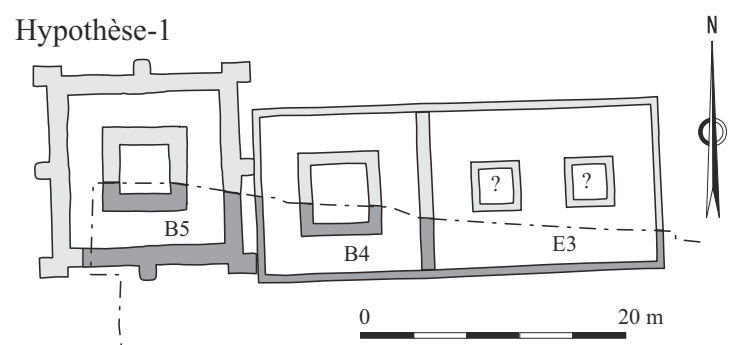

Hypothèse-2

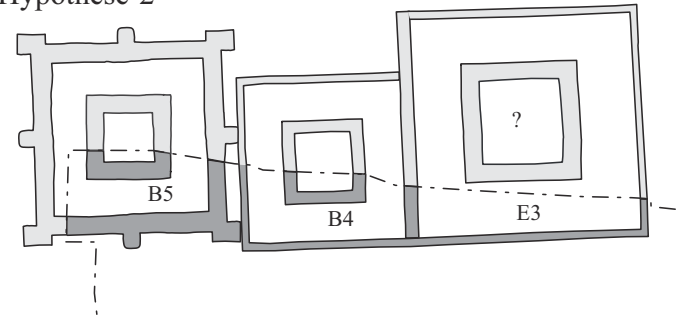

Hypothèse-3
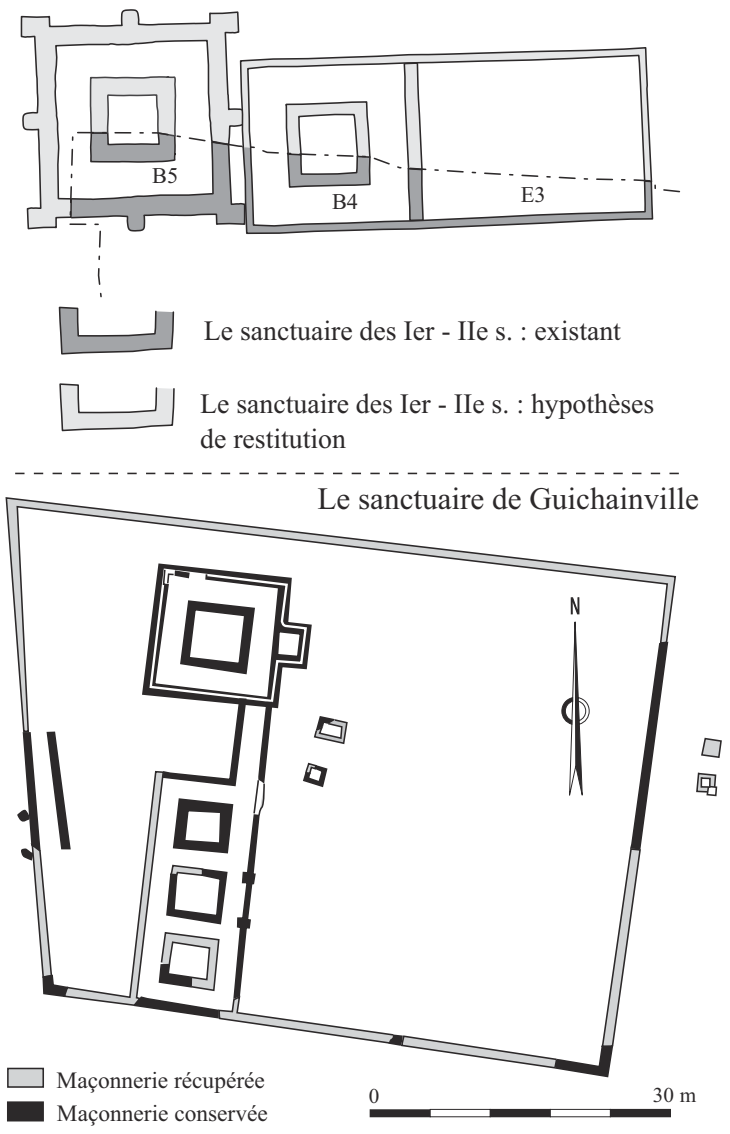

Figure 17 : Yville-sur-Seine (76), Le Sablon, le sanctuaire des $\mathrm{I}^{\mathrm{er}}-\mathrm{II}^{\mathrm{e}}$ s. : hypothèses de restitution du plan des ensembles E3/ B4 et B5 (G. Guillier, Inrap); et plan simplifié du sanctuaire de Guichainville, "Le Devant de la Garenne » dans l'Eure (Flotté et al., 1996), plan d'après Éloy-Épailly, 2008.

Figure 17: The sanctuary of the 1st-2nd c. AD: hypotheses for reconstruction of the plans of ensembles E3/B4 and B5, and simplified plan of the sanctuary of Guichainville, "Le Devant de la Garenne" in the department of the Eure (excavated by P. Flotté). maintien d'animaux... Le mobilier, limité à quelques tessons, est comparable à celui issu de B1.

\section{Les deux fossés emboîtés : l'ensemble E2}

Cet ensemble E2 est matérialisé par un double enclos emboîté en forme de U (fig. 4, 18 et 19). Ces fossés s'appuient au nord contre le fossé 1013 qui dessine le côté sud du péribole du sanctuaire. L'ensemble présente un aspect symétrique.

Le fossé externe mesure $19 \mathrm{~m}$ de côté. Le tracé du côté est (1032) ne devant pas dépasser au nord le plan de la fosse 1066, il n'y a pas de symétrie exacte entre les côtés est et ouest du fossé externe (fig. 19). À l'est et au sud, ce fossé, large de 0,50 à $0,70 \mathrm{~m}$ et profond de 0,10 à $0,20 \mathrm{~m}$, présente un sédiment d'un ton gris clair (coupes C3 à C5). À l'ouest (1058), il est un peu plus large et un plus profond $(0,46 \mathrm{~m})$; le sédiment y est gris avec des inclusions de tuiles et de silex (coupes C1 et C2). Dans la partie nord de 1058 un sédiment de teinte noire a livré des fragments de tuiles, des coquilles d'huîtres et des petits blocs de calcaire et de silex. Le mobilier se limite à un tesson de céramique issu de 1058. Aucun ossement animal n'y a été découvert.

Le fossé interne 1035/1053/1057, au plan complet (fig. 19), délimite une surface variant de 121 à $160 \mathrm{~m}^{2}$ selon qu'elle est calculée en fonction de sa plus petite ou de sa plus grande profondeur. Le tracé de son côté oriental est plus court que celui de son côté ouest, d'environ 3,50 m et il n'y a pas de symétrie entre ses côtés, à l'image de l'enclos externe.

Les sections de fossés localisés à l'est (1032 et 1035) sont les plus courtes, fait tendant à valider la possibilité d'un passage entre E7 et B2. Le fossé interne est large à l'est et au sud de 0,68 à $0,80 \mathrm{~m}$ et profond de 0,20 à $0,30 \mathrm{~m}(\mathrm{C} 8$ à $\mathrm{C} 10)$, avec un sédiment d'un ton gris qui recelait des fragments de tuiles, de calcaire et du silex. À l'ouest, le fossé 1053 est large de $1,30 \mathrm{~m}$, profond de $1,50 \mathrm{~m}$ et le sédiment y est plus foncé (C6 et C7). Dans la partie nord de 1053, des coquilles d'huîtres se distinguaient dans un sédiment de teinte noire. Le mobilier se résume à un couteau en fer (inv. 1053-2, fig. 24), à un clou long de $15 \mathrm{~cm}$ (inv. 1053-1) et à 29 tessons de céramique. Aucun ossement animal n'y a été mis en évidence.

Lespace délimité par l'enclos E2, outre un lambeau d'une couche de destruction 1034, est occupé sur une surface de $35 \mathrm{~m}^{2}$ environ par une dizaine de trous de poteaux, révélant - semble-t-il - un bâtiment de plan rectangulaire, très érodé et centré sur cet enclos (fig. 19). Les fragments de tuiles et le torchis rubéfié avec des traces de clayonnage provenant du fossé 1035 suggèrent un bâti élevé sur poteaux, aux parois de torchis et recouvert de tuiles. La localisation du mobilier, dans le secteur nord des fossés, suggère une zone de rejets préférentielle indiquant l'ouverture du bâtiment au nord. 


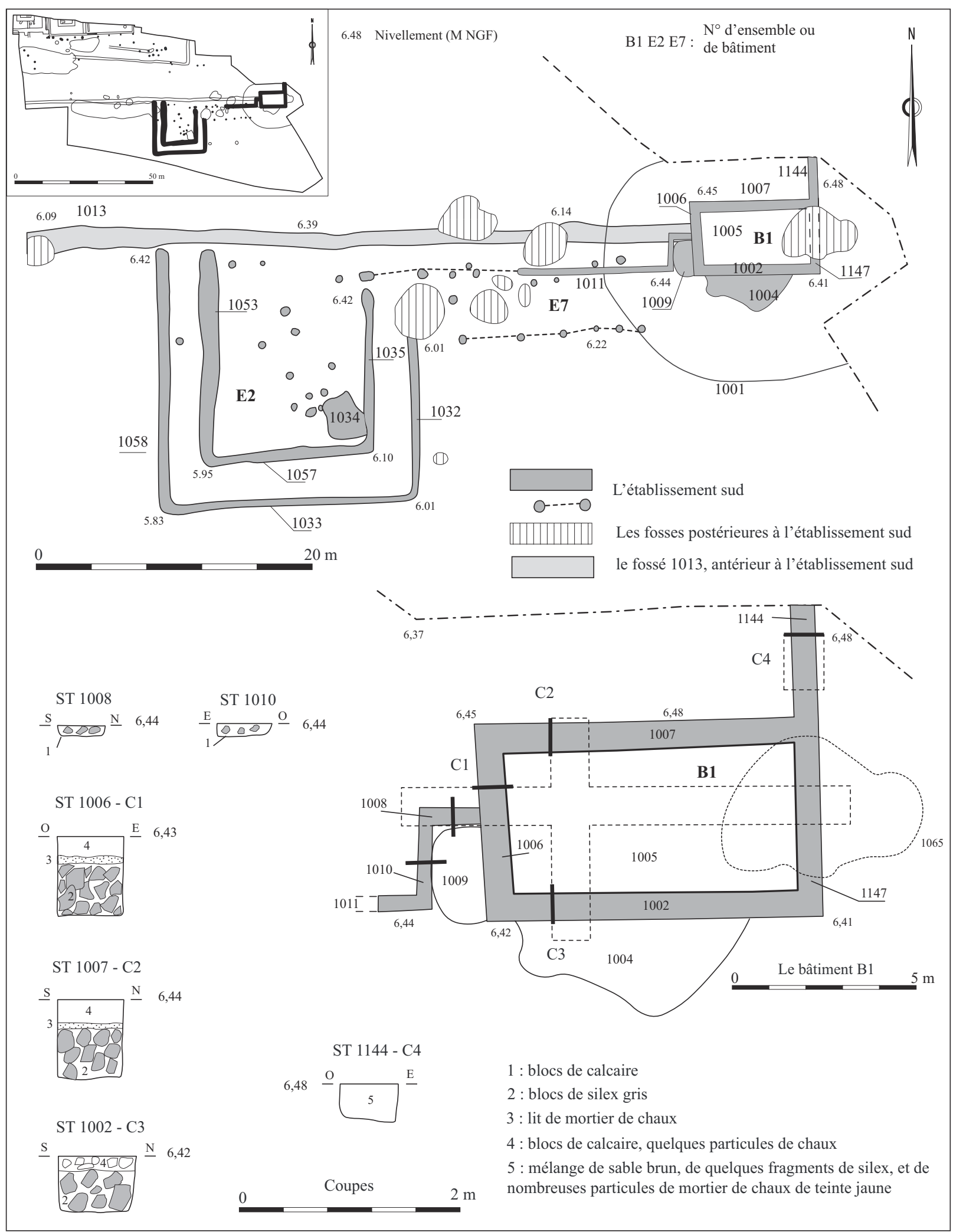

Figure 18 : Yville-sur-Seine (76), Le Sablon, plan détaillé de l'établissement sud (B1, E2 et E7), plan du bâtiment B1 et relevés de coupes (L. Brossard, S. Calduch, G. Guillier, Inrap).

Figure 18: Detailed plan of the south settlement (B1,E2 and E7), plan of building B1 and drawings of sections (L. Brossard, S. Calduch, G. Guillier, Inrap). 


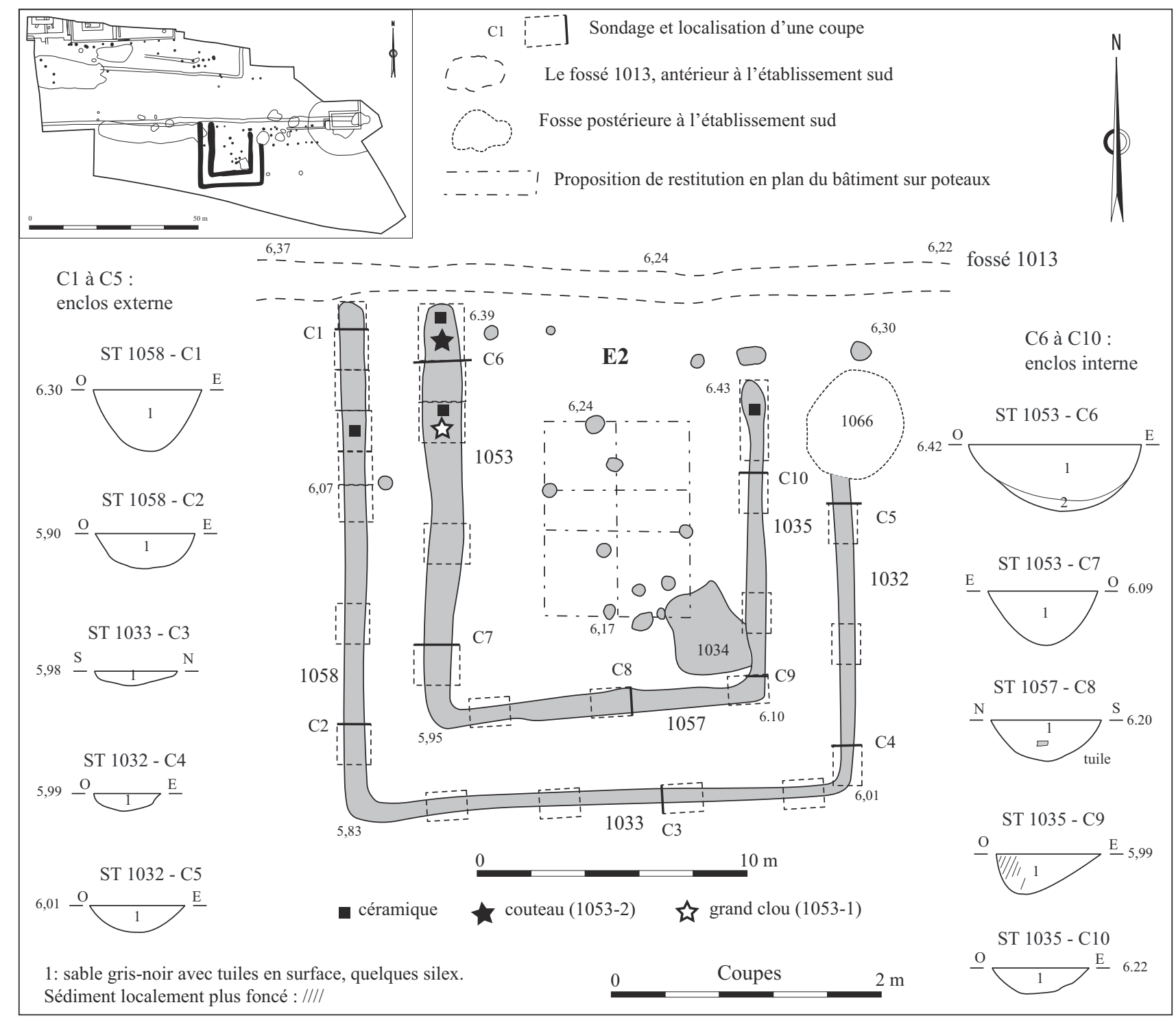

Figure 19 : Yville-sur-Seine (76), Le Sablon, l'établissement sud : l'ensemble E2, plan détaillé, localisation des sondages et des coupes et choix de relevés de coupes (L. Brossard, S. Calduch, G. Guillier, Inrap).

Figure 19: The south settlement: ensemble E2, detailed plan, location of the trenches and sections and selected drawings of sections (L. Brossard, S. Calduch, G. Guillier, Inrap).

\section{La céramique du double enclos E2 (L. Féret)}

Cet enclos a livré 30 tessons fragmentés datés de la fin du II $^{\mathrm{e}}$ à la première moitié du $\mathrm{III}^{\mathrm{e}}$ s., issus des fossés 1053 (21 restes), 1035 (8 restes) et 1058 (1 reste). On observe un bord de Drag. 37 et un fragment de bandeau de mortier de type Drag. 45/Lezoux 100, issus des ateliers arvernes. La majorité des restes (17 tessons) concerne six écuelles hémisphériques et un pot à lèvre en bourrelet tous issus de l'atelier de Montfort-sur-Risle (Eure), hormis un tesson de Lyonsla-Forêt (Eure).

\section{L'établissement sud, une annexe du sanctuaire}

Avant tout, récapitulons les éléments chronologiques à notre disposition (tabl. 1). Les 220 tessons recueillis recouvrent la seconde moitié du II et la première moitié du $\mathrm{III}^{\mathrm{e}} \mathrm{s}$. Quelques tessons du Iv ${ }^{e}$ s. précisent la durée de vie de l'établissement sud ou établissent la chronologie de sa destruction.

L'établissement sud occupe une place particulière au sein du site (fig. 4 et 18). Il recoupe le fossé 1013 (bâtiment B1) et vient s'y appuyer (double enclos E2), ce fossé fermant ainsi le côté nord du double enclos E2. Ce fossé 1013 est comblé avant l'époque flavienne et devait encore être visible environ 


\begin{tabular}{|c|c|c|c|c|}
\hline Ensemble & US /ST & Nature & Nombre de tessons & Proposition chronologique \\
\hline B1 & $1002 / 1007$ & nettoyage de surface du bâtiment & 109 & courant du II ${ }^{\mathrm{e}}-1^{\mathrm{re}}$ moitié $\mathrm{III}^{\mathrm{e}}$ s. apr. J.-C. \\
\hline B1 & 1005 & remblai de sol dans B1 & 3 & courant du II ${ }^{\mathrm{e}}$ s. apr. J.-C. \\
\hline B1 & 1009 & sole de four & 4 & $\mathrm{II}^{\mathrm{e}}$ - III' ${ }^{\mathrm{e}}$ s. apr. J.-C. \\
\hline B1 & 1001 & couche d'occupation autour de B1 & 10 & fin $\mathrm{II}^{\mathrm{e}}-1^{\mathrm{re}}$ moitié du $\mathrm{III}^{\mathrm{e}}$ s. apr. J.-C. \\
\hline B1 & 1001 & décapage mécanique de $\mathrm{B} 1$ & 26 & $\begin{array}{c}\text { mélange } \mathrm{II}^{\mathrm{e}} \text { - } \mathrm{III}^{\mathrm{e}} \text { s. apr. J.-C. et Bas-Empire (2e } \\
\text { moitié } \mathrm{IV}^{\mathrm{e}} \text { s. apr. J.-C.) }\end{array}$ \\
\hline B1 & 1004 & US de destruction de B1 & 13 & $2^{\mathrm{e}}$ moitié du II ${ }^{\mathrm{e}}-1^{\mathrm{re}}$ moitié du III ${ }^{\mathrm{e}}$ s. apr. J.-C. \\
\hline E7 & --- & trous de poteaux & 14 & $\mathrm{II}^{\mathrm{e}}$ s. apr. J.-C. au III ${ }^{\mathrm{e}}$ s. apr. J.-C. \\
\hline E2 & 1058 & enclos externe & 1 & $\mathrm{II}^{\mathrm{e}}-\mathrm{III}^{\mathrm{e}}$ s. apr. J.-C. \\
\hline E2 & 1035 & enclos interne & 8 & $2^{\mathrm{e}}$ moitié du $\mathrm{II}^{\mathrm{e}}-1^{\mathrm{re}}$ moitié du $\mathrm{III}^{\mathrm{e}}$ s. apr. J.-C. \\
\hline E2 & 1053 & enclos interne & 21 & $\mathrm{II}^{\mathrm{e}}-\mathrm{III}^{\mathrm{e}}$ s. apr. J.-C., avec résiduel précoce \\
\hline E2 & --- & bâtiment sur trous de poteaux & 11 & $\mathrm{II}^{\mathrm{e}}-\mathrm{III}{ }^{\mathrm{e}}$ s. apr. J.-C., 1 tesson du IVe s. apr. J.-C. \\
\hline
\end{tabular}

Tableau 1 : Yville sur-Seine (76), Le Sablon, les données chronologiques de l'établissement sud (G. Guillier, Inrap). Table 1: Summary of the chronological data of the south settlement (G. Guillier, Inrap).

deux siècles plus tard, et y souligner la limite sud du sanctuaire. Mais l'implantation de cet établissement sud évite d'empiéter sur le temenos, sauf au niveau du bâtiment B1. Étant donné l'absence de marqueurs chronologiques au sein du sanctuaire, il est possible de s'interroger sur la contemporanéité pouvant exister entre le sanctuaire dans son état des II $^{\mathrm{e}}-\mathrm{III}^{\mathrm{e}}$ s. apr. J.-C. (B4/E3) et l'établissement sud. Dans le cas d'une contemporanéité, il faut envisager une relation fonctionnelle entre eux. En revanche, si l'établissement sud est postérieur au sanctuaire, il est possible d'y voir un habitat peu étendu ou une dépendance d'un ensemble plus vaste.

La première hypothèse définit des éléments contemporains, ou du moins contemporains durant la durée d'occupation de l'établissement sud, celui-ci présentant alors une relation fonctionnelle avec le sanctuaire. Les vestiges mobiliers pouvant le caractériser sont peu nombreux, puisqu'ils se résument à trois couteaux en fer. Le bâtiment B1, de plan commun, s'apparente aux édifices picards à salle unique de type 1d (Bayard et Lemaire, 2014, p. 68-69), dont la surface, ici de $27 \mathrm{~m}^{2}$, correspond aux habitations gallo-romaines les plus modestes. Le four à sole irait dans ce sens ou éventuellement, par sa surface de $3,5 \mathrm{~m}^{2}$, dans celui d'un artisanat, non identifié. Comme point de comparaison privilégié, relevons au sanctuaire d'Authevernes dans l'Eure, le bâtiment 12, d'une surface d'environ $16 \mathrm{~m}^{2}$, présentant sur son côté est une "structure de combustion" (Michel, 2014, p. 198).

L'ensemble E2 est constitué de deux enclos en forme de U de $19 \mathrm{~m}$ de côté, emboîtés et asymétriques, ceignant un bâti en matériaux périssables, d'une surface de $35 \mathrm{~m}^{2}$, et n'a pas, à notre connaissance, de points de comparaison dans le cadre des sanctuaires de l'ouest de la Gaule.
L’ensemble E7, élevé sur poteaux et ponctuellement sur sablière, pourrait être un espace de circulation, d'habitat, de travail ou de stockage.

L'hypothèse 2 suppose que l'établissement sud est postérieur au sanctuaire; dans ce cas, il pourrait relever d'un établissement rural antique situé aux alentours.

\section{Un semis de fosses cultuelles au $\mathrm{III}^{\mathrm{e}}$ s. ?}

Un semis de onze fosses s'égrène le long du tracé du fossé 1013 (fig. 4 et 20). Le mobilier céramique qui en provient couvre une période allant de la première moitié au milieu du $\mathrm{III}^{\mathrm{e}} \mathrm{s}$. (tabl. 2), voire un peu plus tardivement pour la fosse 1065 qui a livré une imitation datée du milieu du Iv $v^{\mathrm{e}}$ s. (cat. $\left.\mathrm{n}^{\circ} 44\right)$.

Six d'entre elles (1003, 1024, 1065, 1078, 1079 et 1080) ont un comblement riche en matériaux organiques, coquilles d'huîtres ou de moules, souvent dense en particules de charbon de bois et recelant de nombreux fragments de tuiles, de silex et de calcaire. Elles sont peu profondément creusées dans le sable naturel et relativement étendues; une seule dépasse $0,50 \mathrm{~m}$ de profondeur (1066). Cette dernière, profonde de $2 \mathrm{~m}$, a un diamètre variant de 1,80 à $3,40 \mathrm{~m}$. Aucun mobilier ni aménagement particulier ne permettent d'envisager leur nature, hormis la fosse 1079 qui présentait sur son fond un gros bloc de silex, déposé sur sa partie plate (fig. 20). Ce fait, conjugué à sa localisation sur le tracé du fossé 1013, indiquerait la présence d'un marqueur (limite agraire, de propriété...). Ces fosses, réparties en petites concentrations le long du tracé du fossé 1013, matérialisent la dernière occupation structurée du site antique. Il peut s'agir de fosses d'extraction de sable, par la suite comblées de rejets mêlant 


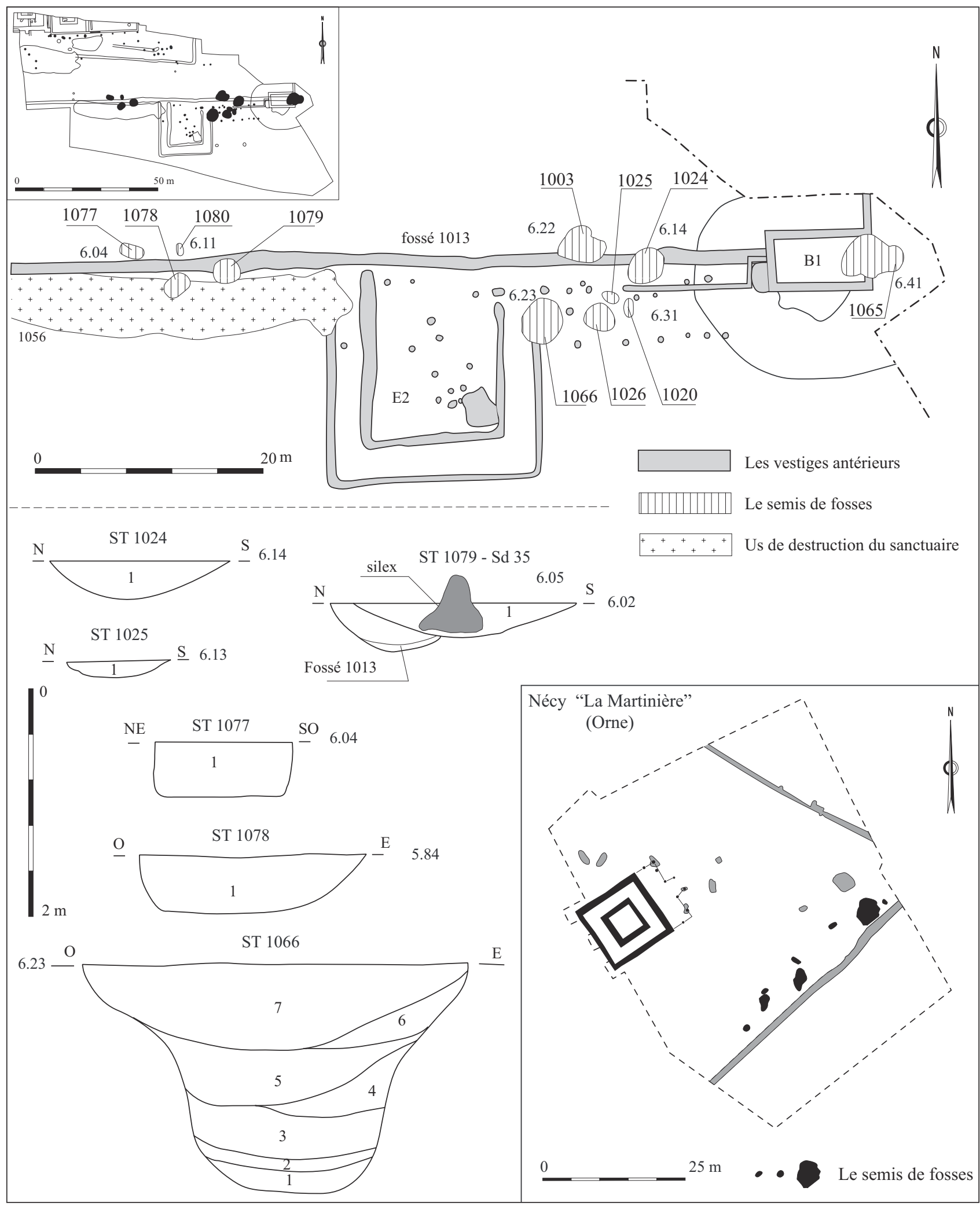

Figure 20 : Yville-sur-Seine (76), Le Sablon, le semis de fosses, plan de localisation et choix de coupes; plan du sanctuaire de Nécy dans l'Orne (M. Besnard, L. Brossard, S. Calduch, G. Guillier, Inrap).

Figure 20: The scattering of pits, plan of their locations and a selection of sections, and the general plan of the sanctuary of Nécy in the departement of Orne (M. Besnard, L. Brossard, S. Calduch, G. Guillier, Inrap). 


\begin{tabular}{|c|c|c|c|c|}
\hline $\mathbf{N}^{\circ}$ & Dim. & Profil & Remarques, mobilier & Éléments datants \\
\hline 1003 & $\begin{array}{c}\varnothing 2,25 \times \\
0,60\end{array}$ & $\begin{array}{l}\text { en U ouvert (non } \\
\text { figuré) }\end{array}$ & $\begin{array}{c}\text { comblement de sable noir, avec de nombreuses inclusions de } \\
\text { charbon de bois, de calcaire, de silex, de coquilles d'huîtres, de } \\
\text { tuiles et d'argile rubéfiée }\end{array}$ & $\begin{array}{l}9 \text { tessons de céramique } \\
\text { des } \mathrm{II}^{\mathrm{e}}-\mathrm{III}^{\mathrm{e}} \text { s.? }\end{array}$ \\
\hline 1020 & $\begin{array}{l}1,60 \times 0,80 \\
\quad \times 0,20\end{array}$ & $\begin{array}{l}\text { en U ouvert, fond } \\
\text { plat (non figuré) }\end{array}$ & $\begin{array}{l}\text { comblement de sable brun noir, avec inclusions de tuiles, } \\
\text { nodules de silex et de calcaire }\end{array}$ & $\begin{array}{l}1 \text { tesson de céramique des } \\
\qquad \mathrm{II}^{\mathrm{e}}-\mathrm{III}^{\mathrm{e}} \mathrm{s} .\end{array}$ \\
\hline 1024 & $\begin{array}{l}\varnothing \text { env. } 3 \times \\
0,70\end{array}$ & $\begin{array}{l}\text { en U ouvert } \\
\text { (figuré) }\end{array}$ & $\begin{array}{c}\text { comblement de sable noir, avec inclusions de charbon de bois, } \\
\text { tuiles, nodules de silex et de calcaire, coquilles de moules et } \\
\text { d'huîtres, localement abondantes }\end{array}$ & $\begin{array}{l}15 \text { tessons de céramique } \\
\text { première moitié / milieu } \\
\qquad \mathrm{du} \mathrm{III}^{\mathrm{e}} \mathrm{s} .\end{array}$ \\
\hline 1025 & $\begin{array}{l}1,55 \times 0,94 \\
\quad \times 0,17\end{array}$ & $\begin{array}{l}\text { en U ouvert } \\
\text { (figuré) }\end{array}$ & $\begin{array}{l}\text { comblement de sable brun noir, avec inclusions de tuiles } \\
\text { et de silex }\end{array}$ & sans mobilier céramique \\
\hline 1026 & $\begin{array}{l}\varnothing \text { env. } 2,5 \\
\times 0,10\end{array}$ & $\begin{array}{l}\text { en } U \text { très ouvert } \\
\text { (non figuré) }\end{array}$ & comblement de sable brun foncé, fragments de tuiles en surface & sans mobilier céramique \\
\hline 1065 & $\begin{array}{l}5,5 \times 3,6 \times \\
0,6\end{array}$ & $\begin{array}{l}\text { en } U \text { très ouvert } \\
\text { (non figuré) }\end{array}$ & $\begin{array}{l}\text { comblement de sable noir, avec inclusions de charbon de bois, } \\
\text { fragments de tuiles, nodules de silex et de calcaire, coquilles } \\
\text { d'huîtres, } 1 \text { couteau en fer (inv. 1065-1), } 1 \text { poignée plate en } \\
\text { fer (inv. 1065-2), } 1 \text { fragment de plaquette à fard (inv. 1065-3). } \\
\text { Recoupe le bâtiment B1 }\end{array}$ & $\begin{array}{l}65 \text { tessons de céramique } \\
\text { première moitié / milieu } \\
\text { du III }{ }^{e} \text { s. ; } 1 \text { monnaie (cat. } \\
\left.\mathrm{n}^{\circ} 44\right)\end{array}$ \\
\hline 1066 & $\begin{array}{l}\varnothing \text { env. } 3,40 \\
\quad \times 2,00\end{array}$ & $\begin{array}{l}\text { en U, ouvert en } \\
\text { surface (recreuse- } \\
\text { ment?), fond plat } \\
\text { (figuré) }\end{array}$ & $\begin{array}{l}\text { comblement stratifié : } 1,3,5,7: \text { sable brun avec rognons de } \\
\text { silex, fragments de tuiles épars; } 2,4,6: \text { graves; recoupe E2 }\end{array}$ & sans mobilier céramique \\
\hline 1077 & $\begin{array}{l}2,20 \times 1,20 \\
\quad \times 0,50\end{array}$ & $\begin{array}{l}\text { rectangulaire, fond } \\
\text { plat (figuré) }\end{array}$ & comblement de sable gris, rares tuiles antiques & sans mobilier céramique \\
\hline 1078 & $\begin{array}{l}2,40 \times 1,60 \\
\quad \times 0,50\end{array}$ & $\begin{array}{l}\text { en } U \text { ouvert, } \\
\text { asymétrique, fond } \\
\text { plat (figuré) }\end{array}$ & $\begin{array}{l}\text { comblement de sable noir, chargé de charbon de bois, de } \\
\text { coquilles d'huîtres, quelques coquilles de moules, nodules de } \\
\text { silex et de calcaire. Un clou de menuiserie }\end{array}$ & $\begin{array}{l}22 \text { tessons de céramique } \\
\text { première moitié du III }{ }^{\mathrm{e}} \mathrm{s} \text {. }\end{array}$ \\
\hline 1079 & $\begin{array}{l}2,30 \times 2,10 \\
\quad \times 0,30\end{array}$ & $\begin{array}{l}\text { en U très ouvert } \\
\text { (figuré) }\end{array}$ & $\begin{array}{l}\text { comblement de sable noir, riche en charbon de bois, coquilles } \\
\text { d'huîtres, nodules de silex, fragments de tuiles. Recelait un gros } \\
\text { bloc de silex }(0,50 \times 0,50 \times 0,50 \mathrm{~m}) \text {. Recoupe le fossé } 1013\end{array}$ & $\begin{array}{l}12 \text { tessons de céramique } \\
\text { première moitié / milieu } \\
\text { du III }{ }^{\mathrm{e}} \mathrm{s} .\end{array}$ \\
\hline 1080 & $\begin{array}{l}1,20 \times 0,60 \\
\quad \times 0,30\end{array}$ & $\begin{array}{l}\text { trapézoïdal, fond } \\
\text { plat (non figuré) }\end{array}$ & $\begin{array}{l}\text { comblement de sable noir, avec inclusions de charbon de bois, } \\
\text { petits fragments de tuiles et de calcaire, coquilles d'huîtres, } \\
\text { fragments de mortier de chaux de teinte jaune }\end{array}$ & sans mobilier céramique \\
\hline
\end{tabular}

Tableau 2 : Yville-sur-Seine (76), Le Sablon, le semis de fosses, les données relevées (dimensions, $\mathrm{L} \times 1 \times \mathrm{p}$, exprimées en mètres) (G. Guillier, Inrap).

Table 2: The scattering of pits, summary of the data recorded (dimensions, length $(L) \times$ width $(l) \times$ depth (p), expressed in metres) (G. Guillier, Inrap).

des éléments de destruction et des détritus issus d'un habitat (proche?) ou de toute autre occupation (tabl. 2).

On note un semis de fosses au sanctuaire de Pannes dans le Loiret (Dondin-Payre et Cribellier, 2011; Fauduet, 2014, p. 64), tandis que des fosses " rituelles » et plusieurs fosses de rejets tardives sont localisées sensiblement sur le tracé des segments de fossés et des bâtiments enserrant le sanctuaire d'Authevernes dans l'Eure (Michel, 2011; 2012; Provost, Archéo 27, 2019, fig. 65-66). Elles recelaient, associés à des éléments de destruction, des restes animaux et de la vaisselle où s'observeraient des gestes rituels (Michel, 2011, p. 242). Plusieurs fosses, parmi les plus tardives identifiées au sanctuaire de Nécy, La Martinière dans l'Orne (BesnardVauterin et al., 2013, p. 208 et 209) (fig. 20), offrent les mêmes caractéristiques que celles mises au jour à Yville-surSeine : des dimensions très variables, des comblements riches en matériaux organiques et en matériaux de construction. Les fosses de Nécy, au nombre de huit, sont alignées parallèlement au fossé limitant au sud-est l'aire sacrée, sur une longueur de $35 \mathrm{~m}$, matérialisant ainsi un semis de structures assez comparable à celui d'Yville-sur-Seine. Au sanctuaire de La Fontaine de l'Étuvée à Orléans (Loiret), trois fosses, liées 
à la dernière phase d'occupation du sanctuaire, manifesteraient une certaine permanence du caractère sacré du site, voire pour la fosse F2378 un rituel lié à la destruction du temple (Verneau, 2014, p. 104-108).

Deux ensembles céramiques de la première moitiél milieu du III s. : les fosses 1065 et 1079 (L. Féret)

Au sein des structures décrites ci-avant (fig. 20), le mobilier céramique de deux d'entre elles, 1065 et 1079, bien que res- treint, a été sélectionné, puisque représentatif de cette période (fig. 21). Le lot de 65 tessons issu de la fosse 1065, fragmenté, est homogène chronologiquement. Si la céramique métallescente et la paroi fine sont argonnaises, la sigillée représentée par la forme Drag. 45/Lezoux 100 est arverne (fig. 21, $\mathrm{n}^{\circ} 1$ ). La céramique métallescente est matérialisée par un fond de gobelet, tout comme la paroi fine engobée qui montre le départ d'une dépression et un décor de projection de grains de chamotte. La céramique commune sombre lustrée est illustrée

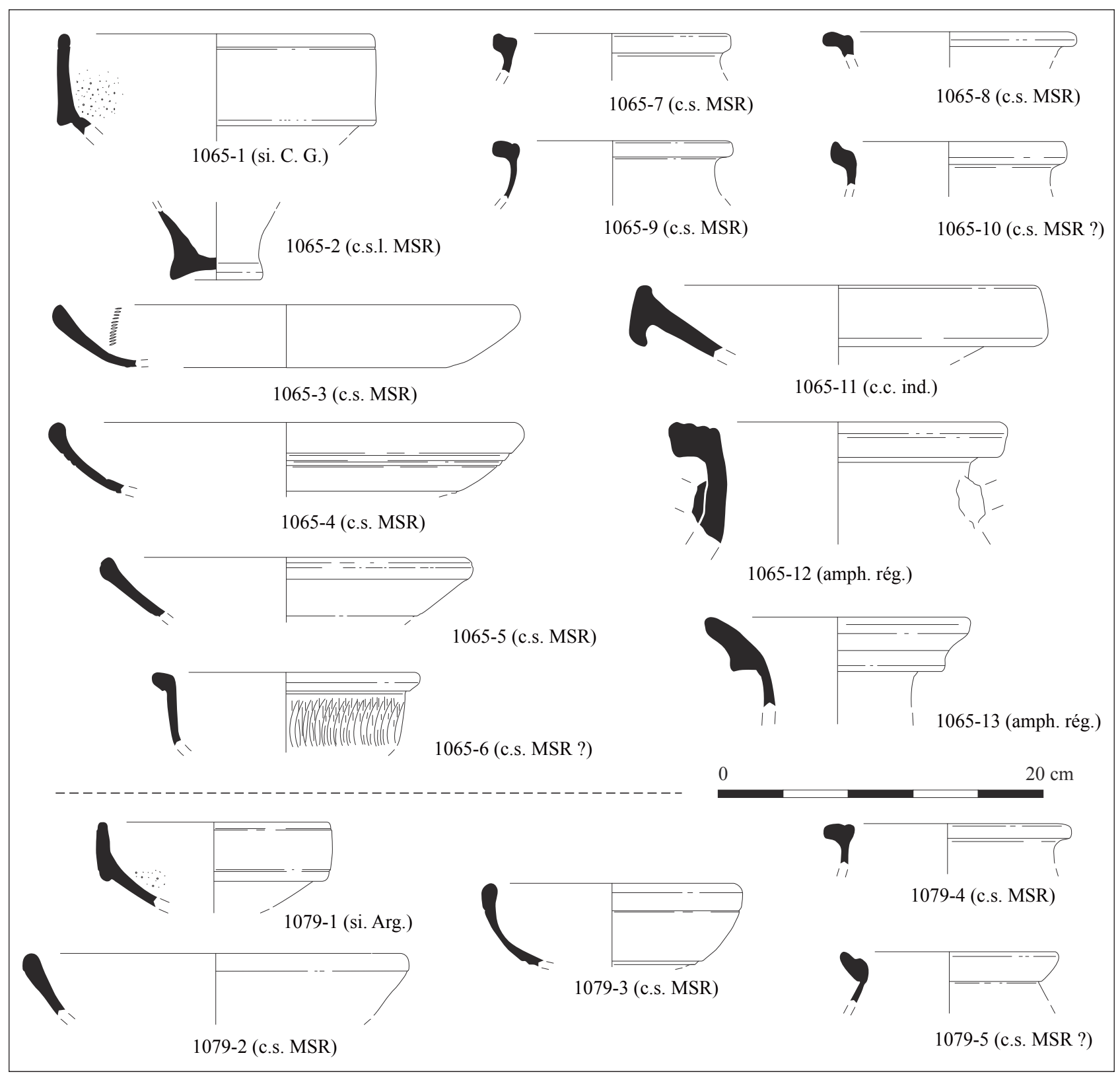

Figure 21 : Yville-sur-Seine (76), Le Sablon, le mobilier céramique de la fosse 1065, première moitié / milieu du $\mathrm{III}^{\mathrm{e}} \mathrm{s}$. et celui de la fosse 1079, première moitié du $\mathrm{III}^{\mathrm{e}}$ s. (Inrap, L. Féret).

Figure 21: The pottery from pit 1065 (1st halflmiddle 3rd c. AD) and that of pit 1079 (1st half 3rd c. AD) (Inrap, L. Féret). 
par un fond de gobelet ( $\left.\mathrm{n}^{\circ} 2\right)$, probablement issu de l'atelier de Montfort-sur-Risle (Eure). La céramique commune claire est figurée par des fragments de panses de cruches, dont une, à la pâte calcaire orange tendre, se rattache au groupe d'Argences (Calvados). Fabriqués dans d'autres pâtes locales, deux mortiers s'ajoutent à ce lot ( $\left.\mathrm{n}^{\circ} 11\right)$. La céramique commune sombre, culinaire, rassemble 14 des 27 individus recensés. L'on y distingue un plat, au moins huit écuelles tripodes hémisphériques ( ${ }^{\text {os }} 3$ à 5), une écuelle carénée décorée de guillochis $\left(n^{\circ} 6\right)$ et quatre pots à lèvre en bourrelet ( $n^{\text {os }} 7$ à 10$)$. Ces poteries semblent provenir de l'atelier " montfortais », un doute subsistant parfois sur leurs provenances ( ${ }^{\text {os }} 6$ et 10 ). Les amphores régionales sont une Gauloise 12 de grande taille $\left(n^{\circ} 12\right)$ à la pâte caractéristique des productions d'Argences, et un exemplaire à lèvre en poulie évasée $\left(\mathrm{n}^{\circ} 13\right)$.

La fosse 1079 a livré un lot chronologiquement homogène de six individus (12 fragments). S'y distingue un mortier argonnais de type Drag. 45 (fig. 21, $\mathrm{n}^{\circ} 1$ ), accompagné de plusieurs poteries en pâte sombre, issues presque exclusivement de l'atelier de Montfort-sur-Risle, correspondant à des plats $\left(\mathrm{n}^{\circ} 2\right)$, écuelles tripodes hémisphériques $\left(\mathrm{n}^{\circ} 3\right)$ et pots ( $\mathrm{n}^{\text {os }} 4$ et 5$)$.

\section{Les couches de destruction du sanctuaire}

Plusieurs couches de destruction liées au sanctuaire sont localisées à l'intérieur des temples et au sud de ces derniers (fig. 22).

\section{Les couches localisées sur l'aire interne de E3/B4}

L'US 1124, épaisse de 0,25 m et située dans l'espace E3 (fig. 22), présentait dans un sédiment sableux de teinte noire à brune chargé en fines particules de charbon de bois, une forte densité de fragments de tuiles, de nodules de mortier de teinte jaune, de blocs de calcaire et de silex, de petits et rares fragments d'enduits peints et 51 tessons de céramique, dont 19 résiduels et 32 attribuables aux II $^{\mathrm{e}}$ et $\mathrm{III}^{\mathrm{e}} \mathrm{s}$. Y sont relevés une possible clavette (inv. 1124-1, fig. 24), un déchet lié à la paléométallurgie du cuivre et un antoninien, une imitation de la seconde moitié du $\mathrm{III}^{\mathrm{e}} \mathrm{s}$. (cat. no 19).

L'US 1125, circonscrite à la galerie du temple B4 (fig. 22), est constituée d'un sédiment comparable à celui de l'US 1124. Son épaisseur est de 0,25 à $0,30 \mathrm{~m}$. Un fragment d'aiguille en os (inv. 1125-1, fig. 25) et 18 tessons (voir ciaprès) en proviennent. L'US 1132, située dans la cella du bâtiment B4, identique à l'US 1124 et épaisse de 0,25 à 0,30 m, a livré une clochette en fer (inv. 1132-1, fig. 25).

Le mobilier issu de ces couches de destruction suggère une datation couvrant les $\mathrm{II}^{\mathrm{e}}$ et $\mathrm{III}^{\mathrm{e}}$ s. La monnaie provenant de l'US 1124 semble un peu plus tardive (cat. $\mathrm{n}^{\circ} 19$ : ca 270-310). Ces trois couches surmontaient directement le terrain naturel, sans niveau de sol ou d'occupation intermédiaire. Il est possible d'envisager que les niveaux de sols antiques aient été totalement récupérés, en effet, des fragments de dallage proviennent des différentes couches de destructions identifiées.

\section{Les couches localisées au sud des temples}

Une vaste couche de destruction, recouvrant une aire mesurant environ de 40 à $50 \mathrm{~m}$ de côté (fig. 22), s'étend au sud des temples, recouvre le fossé 1013 puis s'étire au-delà de ce fossé, sur 12 à $18 \mathrm{~m}$. Les US 1056 et 1086 isolent des secteurs particulièrement denses en mobilier archéologique et en éléments de destruction. Sa stratigraphie a été enregistrée de part et d'autre du fossé 1013 (fig. 22, coupe M2). Cette couche constituée d'un sédiment de teinte brune à noire, épaisse de 0,10 à $0,20 \mathrm{~m}$, voire ponctuellement $0,25 \mathrm{~m}$, recelait de très nombreux fragments de tuiles et de briques, de nombreuses coquilles d'huîtres et de moules, du charbon de bois ainsi que des blocs de calcaire et de silex.

De l'US 1056 proviennent 86 tessons de céramique regroupant des éléments des $\mathrm{I}^{\mathrm{er}}, \mathrm{II}^{\mathrm{e}}, \mathrm{III}^{\mathrm{e}}$ et $\mathrm{IV}^{\mathrm{e}}$ s. S'y distingue un fragment de panse de Black-Burnished Ware. Le mobilier métallique est matérialisé par 20 monnaies et un instrumentum varié (fig. 24 et 25). Dans l'US 1086, ce sont 28 monnaies qui ont été mises au jour, accompagnées par un instrumentum où l'on note un pendant d'oreille en or (inv. 1086-1, fig. 25). Cette couche déborde nettement au sud du fossé 1013, il est possible qu'elle ait pu être mobilisée (colluviée?). Le mobilier céramique, hétérogène, est datable du $\mathrm{I}^{\mathrm{er}}$ au $\mathrm{IV}^{\mathrm{e}} \mathrm{s}$.

Les monnaies issues des couches de destruction au nombre de 48 (soit $89 \%$ de l'ensemble des monnaies du site), couvrent une large période allant d'Octave (ca 36 av. J.-C., cat. $\mathrm{n}^{\circ} 1$ ) à Valentinien II ( ca 388-392, cat. $\mathrm{n}^{\circ} 54$ ), le lot étant à hauteur de $85 \%$ contemporain ou postérieur au milieu du $\mathrm{III}^{\mathrm{e}}$ s. et à environ $50 \%$ dans le $\mathrm{IV}^{\mathrm{e}} \mathrm{s}$.

Un ensemble céramique de la première moitié / milieu du III s. : l'US 1125 du temple B4 (L. Féret)

Y ont été mis au jour 18 tessons appartenant à 12 poteries. Hormis trois tessons résiduels, ce lot apparaît homogène. La sigillée se distingue avec un mortier Drag. 45/Lezoux 100 caractérisé par son mufle de lion (fig. $23, \mathrm{n}^{\circ} 1$ ). Sont identifiées deux écuelles tripodes de l'atelier de Montfort-surRisle dans l'Eure $\left(\mathrm{n}^{\circ} 2\right)$ et deux amphores. La première, une Gauloise $12\left(n^{\circ} 3\right)$ à la pâte calcaire orange, est caractéristique des productions de Normandie occidentale. La seconde $\left(\mathrm{n}^{\circ} 4\right)$, d'origine inconnue, montre une large lèvre percée avant cuisson de petites perforations, et rappelle un exemplaire de Val-de-Reuil dans l'Eure (Adrian et Lukas, 2015). Ces productions orientent la datation de ce contexte vers la première moitié et le milieu du $\mathrm{III}^{\mathrm{e}} \mathrm{s}$. 


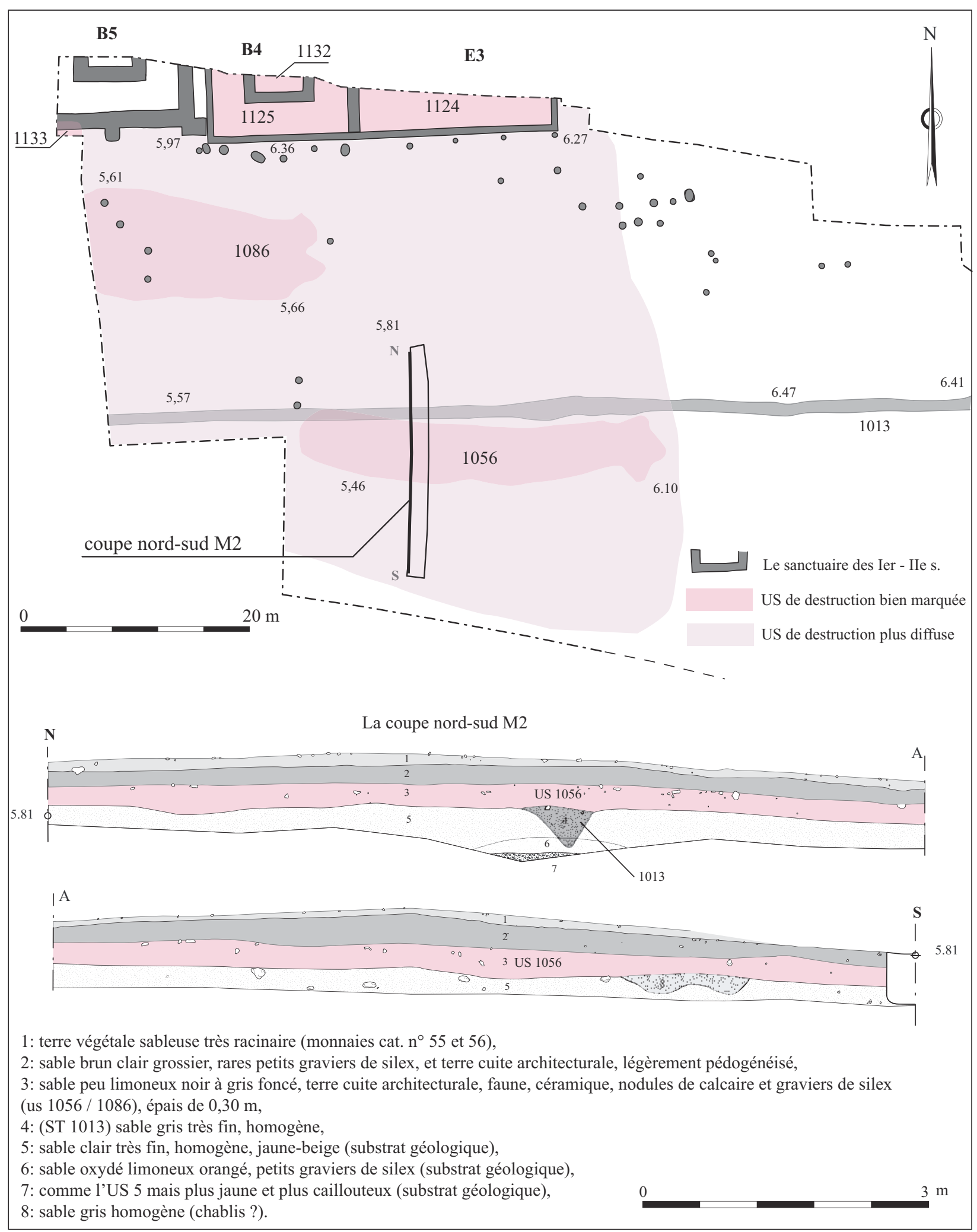

Figure 22 : Yville-sur-Seine (76), Le Sablon, le sanctuaire des $\mathrm{I}^{\mathrm{er}}-\mathrm{II}^{\mathrm{e}}$ s. : plan d'ensemble des structures, localisation des couches de destruction et de la coupe nord-sud M2 et relevé de cette dernière (L. Brossard, S. Calduch, G. Guillier, Inrap).

Figure 22: The sanctuary of the 1st-2nd c. AD: plan of the ensemble of structures, location of destruction layers and that of the north-south section M2 and drawing of the latter (L. Brossard, S. Calduch, G. Guillier, Inrap). 


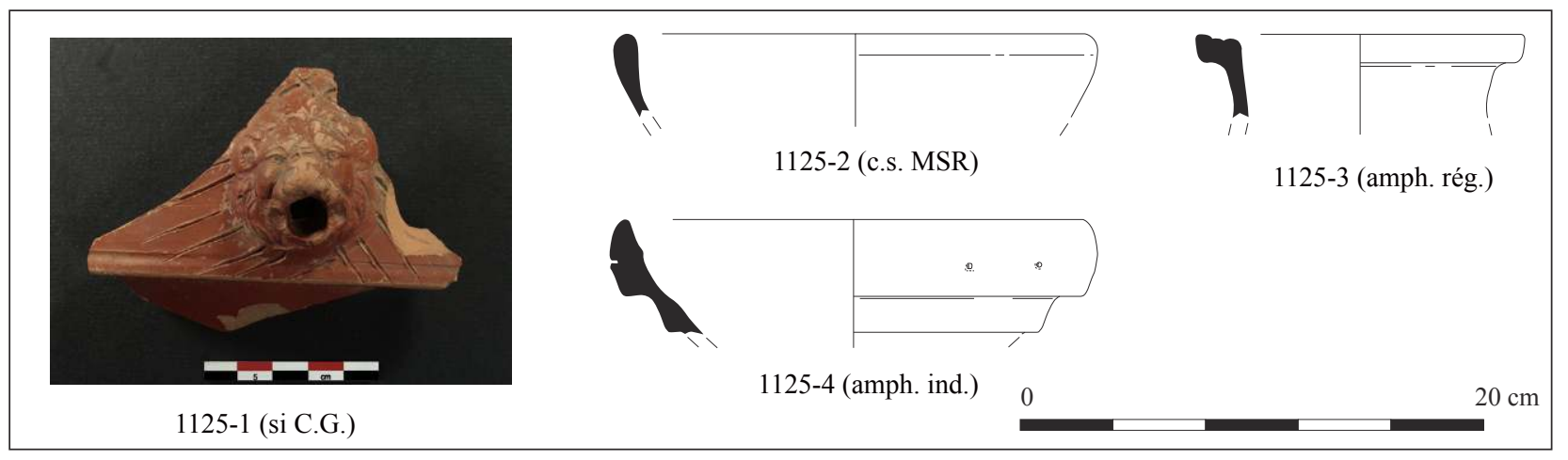

Figure 23 : Yville-sur-Seine (76), Le Sablon, le mobilier céramique de l'US 1125, première moitié du III ${ }^{\mathrm{e}}$ s. (L. Féret, Inrap). Figure 23: The pottery of US 1125 (1st half 3rd c. AD) (L. Féret, Inrap).

Les niveaux de destruction du sanctuaire du Sablon: des ensembles peu fiables

Les couches localisées à l'intérieur des temples ont livré (fig. 22), au mieux, un ensemble céramique homogène daté de première moitié et du milieu du III $^{\mathrm{e}} \mathrm{s}$. (US 1125) ou d'un mélange de tessons allant de La Tène D2/époque augustéenne aux $\mathrm{II}^{\mathrm{e}}$ et $\mathrm{III}^{\mathrm{e}}$ s. ainsi qu'un antoninien émis vers 270-310 (US 1124, cat. $n^{\circ} 19$ ), voire aucun élément datant (US 1132). Celles identifiées au sud des temples, mobilisées postérieurement à leur constitution initiale, regroupent des tessons de céramique des $\mathrm{I}^{\mathrm{er}}$, $\mathrm{II}^{\mathrm{e}}$, III ${ }^{\mathrm{e}}$ et $\mathrm{IV}^{\mathrm{e}}$ s. et un lot monétaire allant d'Octave à Valentinien II. L'essentiel, contemporain ou postérieur au milieu du $\mathrm{III}^{\mathrm{e}}$ s., indique une présence liée à une occupation tardive de la zone du sanctuaire ou à une ou plusieurs phases de destruction possiblement situées vers la fin du IV $\mathrm{IV}^{\mathrm{e}}$. Soulignons comme de nombreux auteurs que la chronologie et les modalités d'abandon des lieux de culte sont parfois difficiles à appréhender (Bossard, 2019, p. 80).

\section{Une monnaie carolingienne}

Au sein des couches de surface (fig. 3, US 1 et 2) a été recueillie une obole carolingienne en argent de Louis I $^{\text {er }}$ dit le Pieux, frappée à Melle dans les Deux-Sèvres (cat. no 55), le Mellois étant connu pour ses mines d'argent à l'époque médiévale. Les découvertes d'oboles à la légende LVDOVVIC sont courantes dans tout l'Empire carolingien. La monnaie du Sablon n'est pas isolée en Normandie, citons les exemplaires d'Alizay et de Bacquepuis dans l'Eure. S. Coupland ${ }^{4}$ propose l'hypothèse que ce type d'obole ait été émis avec les deniers correspondants, sa date d'émission se situant entre 816 et 822 ou 823 .

4. Remercions ici le Rev. Dr. S. Coupland (MDIAR, Cambridge) pour ces informations.

\section{ÉTUDES SPÉCIALISÉES}

\section{Étude numismatique (F. Pilon)}

Le lot comprend 56 monnaies en excellent état de conservation (tabl. 3). Une provient du diagnostic et 55 ont été découvertes lors de la fouille. 54 sont romaines, une est carolingienne et la dernière est moderne (un denier tournois de Louis XIII frappé à Tours).

Les monnaies romaines couvrent un intervalle chronologique très large allant d'un dupondius d'Octave, frappé à Vienne vers 36 av. J.-C., à un aes 4 à l'effigie de Valentinien II, frappé à Arles entre 388 et 392, lequel constitue le terminus post quem de l'ensemble.

Sur la seule base des dates estimatives de perte (DEP) (Pilon, 2011), les découvertes monétaires témoignent de deux périodes d'occupation plus ou moins importantes : $c a$ milieu du $\mathrm{I}^{\text {er }}$ s. apr. J.-C. (cat. $\mathrm{n}^{\mathrm{o}} 1-3$ ); seconde moitié du $\mathrm{II}^{\mathrm{e}}$ s.-fin $\mathrm{IV}^{\mathrm{e}}$ s. ( $\mathrm{n}^{\mathrm{o}}$ 4-54), avec une belle continuité chronologique de tous les spécimens exhumés (tabl. 3). On notera l'absence de monnaies rognées, courantes à l'extrême fin du $\mathrm{IV}^{\mathrm{e}} \mathrm{s}$. et dans la première moitié $\mathrm{du} \mathrm{V}^{\mathrm{e}} \mathrm{s}$.

On relève la présence dans ce lot d'un antoninien de bon aloi de Gordien III (cat. n ${ }^{\circ}$ 8), d'un antoninien de Claude II peu commun (cat. $\mathrm{n}^{\circ} 11$ ) et d'un autre de Divus Victorinus (cat. $\mathrm{n}^{\circ} 14$ ), et enfin d'un aurelianus de Carin encore couvert de son argenture (cat. $\mathrm{n}^{\circ}$ 15). Le tabl. 4 présente les Datations Numismatiques (DNum) des différentes couches recelant des monnaies et correspondant pour sa part à la période pendant laquelle on considère, à partir des seules données numismatiques, qu'une unité stratigraphique s'est constituée. Ces DNum sont comparées avec les datations obtenues par l'étude du mobilier céramique présent dans ces couches. 


\begin{tabular}{|c|c|c|c|c|}
\hline Octave & 1 & 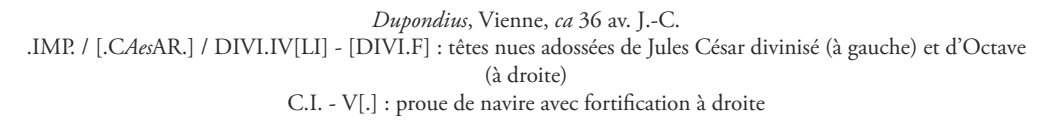 & $\begin{array}{l}\text { Burnett, Amandry et Ripollès, } \\
1995,517 \\
19,12 \mathrm{~g} ; 1 \mathrm{~h} \\
\text { Inv. } 1056-13\end{array}$ & $\begin{array}{l}\text { DEP } \\
0-80\end{array}$ \\
\hline \multirow[t]{2}{*}{$\begin{array}{l}\text { Auguste } \\
\text { pour Tibère, } \\
\text { César }\end{array}$} & 2 & $\begin{array}{l}\text { As, Lyon, ca 12-14 } \\
\text { TI CA[ESAR AVGVST F IM]PERAT VII : buste nu, lauré à droite } \\
\text { Exergue ROM ET [AVG] : autel de Lyon composé d'une plate-forme flanquée de deux Victoires qui se tiennent } \\
\text { chacune sur une colonne; sur le devant de la plate-forme, la couronne civique entre deux branches de laurier et } \\
\text { deux lares; au-dessus, des objets indéfinissables }\end{array}$ & $\begin{array}{l}\text { Sutherland, } 1984,245 \\
7,97 \mathrm{~g} ; 8 \mathrm{~h} ; \text { frappe décentrée au } \\
\text { revers } \\
\text { Inv. } 1001-1\end{array}$ & $\begin{array}{l}\text { DEP } \\
30-60 \\
(275)\end{array}$ \\
\hline & 3 & $\begin{array}{l}\text { Semis, Lyon, ca 12-14 } \\
\text { [TI CAESAR AVGVST F IMPERAT VII] : buste nu, lauré à droite } \\
\text { Exergue [ROM ET AVG] : cf monnaie ci-dessus }\end{array}$ & $\begin{array}{l}\text { Sutherland, } 1984,246 \\
\quad 4,27 \mathrm{~g} ; \text { ? h } \\
\text { Inv. } 1056-2\end{array}$ & $\begin{array}{l}\text { DEP } \\
50-180 \\
(275)\end{array}$ \\
\hline \multirow[t]{3}{*}{ Hadrien } & 4 & $\begin{array}{c}\text { Dupondius, Rome, 123-128 } \\
\text { [HADRIANVS - AVGVSTVS] : buste nu, radié à droite, avec traces de paludamentum sur les épaules } \\
\text { [COS III S C] : Fides debout à droite ou debout de face, regardant à droite, tenant des épis de blé de la main droite } \\
\text { et un plateau de fruits de la main gauche levée }\end{array}$ & $\begin{array}{l}\text { Mattingly et Sydenham, 1926, } \\
\text { 656; Garonne : Étienne et Rachet, } \\
\text { 1984, } 2857-2862 \\
12,26 \text { g; } 5 \text { h } \\
\text { Inv. } 1056-17\end{array}$ & $\begin{array}{c}\text { DEP } \\
160-175\end{array}$ \\
\hline & 5 & $\begin{array}{c}\text { As, Rome, 130-138 } \\
\text { HADRIANVS - AVG COS III [P P] : buste nu, lauré à droite } \\
{[\text { AEQVI]-TAS AVG S C : Aequitas debout à gauche ou debout de face, regardant à gauche, tenant une balance de }} \\
\text { la main droite et une corne d'abondance de la main gauche }\end{array}$ & $\begin{array}{l}\text { Mattingly et Sydenham, 1926, } \\
\text { 795d; Garonne : Étienne et } \\
\text { Rachet, } 1984,3371 \\
11,30 \mathrm{~g} ; 12 \mathrm{~h} \\
\text { Inv. } 1056-16\end{array}$ & $\begin{array}{l}\text { DEP } \\
150-180 \\
(275)\end{array}$ \\
\hline & 6 & $\begin{array}{l}\text { As, Rome, 130-138 } \\
\text { [HADRIANVS - AVG COS III P] : buste nu, lauré à droite, avec traces de paludamentum sur les épaules } \\
{[\ldots] \text { : personnification indéterminée allongée à gauche }}\end{array}$ & $\begin{array}{l}\text { Mattingly et Sydenham, 1926,? } \\
\quad 12,03 \mathrm{~g} ; 1 \mathrm{~h} \\
\text { Inv. } 1056-18\end{array}$ & $\begin{array}{c}\text { DEP } \\
170-175\end{array}$ \\
\hline $\begin{array}{l}\text { Marc Aurèle } \\
\text { pour Lucius } \\
\text { Verus }\end{array}$ & 7 & $\begin{array}{l}\text { As, Rome, 167-168 } \\
\text { [L VERVS AVG] - ARM PARTH MAX : buste lauré à droite, avec cuirasse et paludamentum, vu de trois quarts en } \\
\text { avant } \\
\text { [TR P VIII IMP IIII COS] III S C : Mars en habit militaire, la chlamyde flottant derrière lui, allant à droite, } \\
\text { tenant une haste pointée en avant de la main droite et un trophée sur l'épaule gauche de la main gauche }\end{array}$ & $\begin{array}{l}\text { Mattingly et Sydenham, 1930, } \\
\text { 1469; Rouen : Hollard et Pilon, } \\
2007 \\
\text { 8,91 g; } 11 \mathrm{~h} \\
\text { Inv. } 1056-19\end{array}$ & $\begin{array}{l}\text { DEP } \\
167-190 \\
(275)\end{array}$ \\
\hline Gordien III & 8 & $\begin{array}{l}\text { Antoninien, Rome, } 241-243 \text { (Émission 4) } \\
\text { IMP GORDIANVS PIVS FEL AVG : buste radié à droite, avec cuirasse et paludamentum, vu de trois quarts } \\
\text { en arrière } \\
\begin{array}{c}\text { AETER-N-ITATI AVG : Sol nu, la chlamyde passée sur le bras gauche, debout à gauche, levant la main droite } \\
\text { et tenant un globe dans la main gauche, tournée vers l'extérieur }\end{array}\end{array}$ & $\begin{array}{l}\text { Mattingly et Sydenham, } 1930 \text {, } \\
\text { 83; Cravent : Foucray et Hollard, } \\
\text { 1995, } 152 \\
5,01 \mathrm{~g} ; 1 \mathrm{~h} \\
\text { Inv. } 1056-1\end{array}$ & $\begin{array}{c}\text { DEP } \\
241-320\end{array}$ \\
\hline $\begin{array}{l}\text { Gallien } \\
\text { pour } \\
\text { Salonine }\end{array}$ & 9 & $\begin{array}{l}\text { Antoninien, Trèves, 260-261 (Émissions 1-2) } \\
\text { SALONINA AVG : buste drapé diadémé à droite, sur un croissant } \\
\text { VESTA; - I-I/Q : Vesta voilée, assise à gauche sur un trône, tenant une patère de la main droite et un sceptre } \\
\text { transversal de la main gauche }\end{array}$ & $\begin{array}{c}\text { Webb, 1927, 252/253; Cunetio: } \\
\text { Besly et Bland, 1983, 1181/1187; } \\
\text { Normanby : Bland et Burnett, } \\
1988,199 / 202 \\
1,34 \mathrm{~g} ; 7 \mathrm{~h} \\
\text { Inv. } 1056-10\end{array}$ & $\begin{array}{c}\text { DEP } \\
260-320\end{array}$ \\
\hline $\begin{array}{c}\text { Gallien } \\
\text { (règne seul) }\end{array}$ & 10 & $\begin{array}{c}\text { Antoninien, Rome, 265-266 (Émission 5) } \\
{[(? \mathrm{IMP}) \text { GALLIE]NVS AVG : buste nu, radié à droite }} \\
\text { PAX AE-T-ERNA [AVG]; } \triangle / / / / \text { - : Pax debout à gauche ou debout de face, regardant à gauche, tenant un rameau } \\
\text { de la main droite levée et un sceptre transversal de la main gauche }\end{array}$ & $\begin{array}{c}\text { Webb, 1927, 26; V-1 }{ }^{2}, 135 ; \\
\text { Cunetio : Besly et Bland, 1983, } \\
\text {-; Normanby : Bland et Burnett, } \\
\text { 1988, 593var. } \\
\text { 1,34 g; } 11 \mathrm{~h} \\
\text { Inv. } 1065-10\end{array}$ & $\begin{array}{c}\text { DEP } \\
265-320\end{array}$ \\
\hline \multirow[t]{3}{*}{ Claude II } & 11 & $\begin{array}{l}\text { Antoninien, Rome, fin 268-début } 269 \text { (Émission 1) } \\
\text { IMP C CLAVDIVS AVG : buste radié à droite, avec cuirasse et paludamentum, vu de trois quarts en arrière } \\
\text { [CO]NCOR EXERCI; - /-I/- : Fides debout à gauche, regardant à droite, tenant une enseigne verticale de la main } \\
\text { droite et une enseigne transversale de la main gauche }\end{array}$ & $\begin{array}{l}\text { Webb, 1927, 26; V-1a, 135; } \\
\text { Cunetio: Besly et Bland, 1983, } \\
\text {-; Normanby: Bland et Burnett, } \\
\text { 1988, 593var. } \\
\text { 3,10 g; 11 h } \\
\text { Inv. 1086-6 }\end{array}$ & $\begin{array}{c}\text { DEP } \\
268-320\end{array}$ \\
\hline & 12 & $\begin{array}{c}\text { Antoninien, Rome, septembre } 268 \text {-mi } 270 \text { (Émissions 1-2) } \\
\text { [IMP (?C)] CLAVDIVS AVG : buste nu, radié à droite } \\
\text { [GENIVS E]XERCI; - -I//-: Génie, coiffé du modius, debout à gauche, nu, la chlamyde passée sur le bras gauche, } \\
\text { tenant une patère de la main droite et une corne d'abondance de la main gauche }\end{array}$ & $\begin{array}{c}\text { Webb, } 1927,48 / 49 ; \mathrm{V}-1 \mathrm{a} \text {, } \\
\text { 232/364; Cunetio : Besly et Bland, } \\
\text { 1983, 1982/-; Normanby: Bland } \\
\text { et Burnett, } 1988,658 / 861 \\
1,41 \mathrm{~g} ; 5 \mathrm{~h} \\
\text { Inv. } 1086-28\end{array}$ & $\begin{array}{c}\text { DEP } \\
268-320\end{array}$ \\
\hline & 13 & $\begin{array}{l}\text { Antoninien, Rome, mi-août } 270 \text { (Émission 3) } \\
\text { IMP C[LAVDI]VS AVG : buste nu, radié à droite } \\
\text { SECV-R-IT AVG; -/XI//-: Securitas debout de face, regardant à gauche, les jambes croisées, le coude gauche } \\
\text { appuyé sur une colonne, tenant un sceptre de la main droite }\end{array}$ & $\begin{array}{l}\text { Webb, 1927, 100var.; V-1a, 536; } \\
\text { Cunetio 2228: Besly et Bland, } \\
\text { 1983,; Normanby: Bland et } \\
\text { Burnett, 1988, } 987 \\
2,50 \mathrm{~g} ; 1 \mathrm{~h} \\
\text { Inv. 1056-3 }\end{array}$ & $\begin{array}{c}\text { DEP } \\
268-320\end{array}$ \\
\hline $\begin{array}{c}\text { Divus } \\
\text { Victorinus }\end{array}$ & 14 & $\begin{array}{c}\text { Antoninien, Trèves ou Cologne, } 271 \\
\text { DIVO VICT[ORINO P]IO : buste nu, radié à droite } \\
\text { CO[NSACRATI]O : aigle éployé sur un globe, debout à droite, regardant à gauche }\end{array}$ & $\begin{array}{l}\text { Webb, } 1927,785 \text {; Cunetio : Besly } \\
\text { et Bland, } 1983,2633 ; \text { Normanby: } \\
\text { Bland et Burnett, } 1988,1453 \\
\quad 2,31 \mathrm{~g} ; 1 \mathrm{~h} \\
\text { Inv. 1086-2 }\end{array}$ & $\begin{array}{c}\text { DEP } \\
271-320\end{array}$ \\
\hline
\end{tabular}




\begin{tabular}{|c|c|c|c|c|}
\hline Carin & 15 & $\begin{array}{l}\text { Aurelianus, Lyon, décembre } 282 \text { (Émission } 4 \text { de Bastien) } \\
\text { CARINVS NOBIL CAES : buste radié à droite, avec cuirasse et paludamentum, vu de trois quarts en avant } \\
\text { SAECVLI FELICITAS; -/D//- : l'empereur en habit militaire debout à droite, tenant une haste transversale pointée } \\
\text { en avant de la main droite et un globe dans la main gauche }\end{array}$ & $\begin{array}{l}\text { Webb, 1933, 152; Bastien, 1976, } \\
\text { 522; La Venera: Gricourt, 2000, } \\
31-38 \\
3,57 \mathrm{~g} ; 7 \mathrm{~h} \\
\text { Inv. } 1056-4\end{array}$ & $\begin{array}{c}\text { DEP } \\
282-320\end{array}$ \\
\hline \multirow[t]{7}{*}{$\begin{array}{l}\text { Imitations } 2^{\mathrm{e}} \\
\text { moitié III s. } \\
\text { Divo Claudio }\end{array}$} & 16 & $\begin{array}{c}\text { Antoninien, } c a \text { 270-310 } \\
\text { JO CLAVDI : buste nu, radié à droite } \\
\text { ]O : autel allumé dont la face antérieure est ornée d'une ou de plusieurs guirlandes }\end{array}$ & $\begin{array}{l}\text { cf. Webb, } 1927,261 \\
1,70 \mathrm{~g} ; \varnothing 16 \mathrm{~mm} ; 5 \mathrm{~h} \\
\text { Inv. } 1086-9\end{array}$ & $\begin{array}{c}\text { DEP } \\
270-320 \\
(366)\end{array}$ \\
\hline & 17 & $\begin{array}{c}\text { Antoninien, ca } 270-310 \\
\text { ]VDIO : buste nu, radié à droite } \\
\text { CONSE : : autel allumé dont la face antérieure est ornée d'une ou de plusieurs guirlandes }\end{array}$ & $\begin{array}{l}\text { cf. Webb, } 1927,1933,261 \\
1,43 \mathrm{~g} ; \varnothing 13-15 \mathrm{~mm} ; 11 \mathrm{~h} \\
\text { Inv. } 1086-3\end{array}$ & $\begin{array}{c}\text { DEP } \\
270-320 \\
(366)\end{array}$ \\
\hline & 18 & $\begin{array}{c}\text { Antoninien, ca } 270-310 \\
\text { ]LAVD [ : buste nu, radié à droite } \\
\text { CO[ : autel allumé dont la face antérieure est ornée d'une ou de plusieurs guirlandes }\end{array}$ & $\begin{array}{l}\text { cf. Webb, } 1927,261 \\
0,75 \mathrm{~g} ; \varnothing 13-16 \mathrm{~mm} ; 5 \mathrm{~h} \\
\text { Inv. } 1086-14\end{array}$ & $\begin{array}{c}\text { DEP } \\
270-320 \\
(366)\end{array}$ \\
\hline & 19 & $\begin{array}{c}\text { Antoninien, } \text { ca } 270-310 \\
\text { ]AVDI[ : buste nu, radié à droite } \\
\text { CONSE [ : aigle debout à gauche ou debout de face, regardant à droite }\end{array}$ & $\begin{array}{l}\text { cf. Webb, } 1927,266 \\
2,23 \mathrm{~g} ; \varnothing 16-17 \mathrm{~mm} ; 1 \mathrm{~h} \\
\text { Inv. } 1124-1\end{array}$ & $\begin{array}{c}\text { DEP } \\
270-320 \\
(366)\end{array}$ \\
\hline & 20 & $\begin{array}{c}\text { Antoninien, } c \text { ca } 270-310 \\
\text { ]IV[ : buste nu, radié à droite } \\
\text { CO[ ]ATIO : aigle debout à gauche ou debout de face, regardant à droite }\end{array}$ & $\begin{array}{l}\text { cf. Webb, } 1927,266 \\
1,46 \mathrm{~g} ; \varnothing 12-13 \mathrm{~mm} ; 10 \mathrm{~h} \\
\text { Inv. } 1086-10\end{array}$ & $\begin{array}{c}\text { DEP } \\
270-320 \\
(366)\end{array}$ \\
\hline & 21 & $\begin{array}{c}\text { Antoninien, } \text { ca } 270-310 \\
\text { ]VO CLA[ : effigie radiée à droite } \\
\text { ]NSECRAT[ : aigle debout à gauche ou debout de face, regardant à droite }\end{array}$ & $\begin{array}{l}\text { cf. Webb, } 1927,266 \\
1,08 \mathrm{~g} ; \varnothing 11,5-13 \mathrm{~mm} ; 10 \mathrm{~h} \\
\text { Inv. } 1086-12\end{array}$ & $\begin{array}{c}\text { DEP } \\
270-320 \\
(366)\end{array}$ \\
\hline & 22 & $\begin{array}{c}\text { Antoninien, ca } 270-310 \\
{[\ldots]: \text { buste nu, radié à droite }} \\
{[\ldots]: \text { aigle debout à gauche ou debout de face, regardant à droite }}\end{array}$ & $\begin{array}{l}\text { cf. Webb, } 1927,266 \\
1,05 \mathrm{~g} ; \varnothing 12 \mathrm{~mm} ; 11 \mathrm{~h} \\
\text { Inv. } 1086-13\end{array}$ & $\begin{array}{c}\text { DEP } \\
270-320 \\
(366)\end{array}$ \\
\hline $\begin{array}{l}\text { Imitation } 2^{\mathrm{e}} \\
\text { moitié III' } s \text {. } \\
\quad \text { Victorin }\end{array}$ & 23 & $\begin{array}{l}\text { Antoninien, } c \text { a 270-310 } \\
\text { ]TORI : effigie radiée à droite } \\
\text { ]-ET : personnification indéterminée debout à gauche, tenant une corne d'abondance de la main gauche }\end{array}$ & $\begin{array}{l}\text { cf. Elmer, } 1941 ? \\
1,00 \mathrm{~g} ; \varnothing 11,5-14 \mathrm{~mm} ; 9 \mathrm{~h} \\
\text { Inv. } 1056-11\end{array}$ & $\begin{array}{c}\text { DEP } \\
270-320 \\
(366)\end{array}$ \\
\hline \multirow[t]{3}{*}{$\begin{array}{l}\text { Imitations } 2^{\mathrm{e}} \\
\text { moitié III }{ }^{\mathrm{e}} \text { s. } \\
\text { Tétricus I }\end{array}$} & 24 & $\begin{array}{l}\text { Antoninien, } c \text { a 275-310 } \\
\text { IMP TETR [ : buste radié à droite, avec cuirasse et paludamentum, vu de trois quarts en avant } \\
\text { ]- AVG : Pax debout à gauche ou debout de face, regardant à gauche, tenant un rameau de la main droite levée } \\
\text { et un sceptre transversal de la main gauche }\end{array}$ & $\begin{array}{l}\text { cf. Elmer, } 1941,682 \text { (Victorin, } \\
\text { type Pax aug) } \\
1,52 \mathrm{~g} ; \varnothing 16 \mathrm{~mm} ; 7 \mathrm{~h} \\
\text { Inv. } 1086-22\end{array}$ & $\begin{array}{c}\text { DEP } \\
275-320 \\
(366)\end{array}$ \\
\hline & 25 & $\begin{array}{l}\text { Antoninien, } c a 275-310 \\
\text { CVS P [ : effigie radiée à droite } \\
{[\ldots] \text { : Pax debout à gauche, tenant un rameau de la main droite et un sceptre vertical de la main gauche }}\end{array}$ & $\begin{array}{l}\text { cf. Elmer, } 1941,771 / 775 \text { (type } \\
\text { Pax aug) } \\
0,21 \mathrm{~g} \text { Ø } 10-11 \mathrm{~mm} ; 6 \mathrm{~h} \\
\text { Inv. } 1086-21\end{array}$ & $\begin{array}{c}\text { DEP } \\
275-320 \\
(366)\end{array}$ \\
\hline & 26 & $\begin{array}{l}\text { Antoninien, } c \text { a } 275-310 \\
\text { IMP C TETRICVS P F : buste radié à droite, avec cuirasse ou cuirasse et petit pan de paludamentum } \\
\text { ] AGG : soldat debout à gauche, tenant une haste de la main gauche et s'appuyant sur un bouclier de la main droite }\end{array}$ & $\begin{array}{l}\text { cf. Elmer, } 1941,780 \text { (type Virtus } \\
\text { augg) } \\
1,78 \mathrm{~g} ; \varnothing 13,5-15 \mathrm{~mm} ; 5 \mathrm{~h} \\
\text { Inv. } 1056-7\end{array}$ & $\begin{array}{l}\text { DEP } \\
275-320 \\
(366)\end{array}$ \\
\hline $\begin{array}{l}\text { Imitation } 2^{\mathrm{e}} \\
\text { moitié III }{ }^{\mathrm{e}} \mathrm{s} \\
\text { Tétricus } \\
\quad \text { César }\end{array}$ & 27 & $\begin{array}{l}\text { Antoninien, } \text { ca } 275-310 \\
\text { C PIV ESV TETRICVS CAES : buste radié à droite, avec cuirasse et paludamentum, vu de trois quarts en arrière } \\
\text { ]-S - [ ]GG : Hilaritas debout à gauche ou debout de face, regardant à gauche, tenant une palme de la main droite } \\
\text { et une corne d'abondance de la main gauche }\end{array}$ & $\begin{array}{l}\text { cf. Elmer, } 1941,789 \text { (type Hila- } \\
\text { ritas augg) } \\
2,06 \mathrm{~g} \text { Ø } 15,5-19 \mathrm{~mm} ; 8 \mathrm{~h} \\
\text { Inv. } 1086-1\end{array}$ & $\begin{array}{c}\text { DEP } \\
275-320 \\
(366)\end{array}$ \\
\hline \multirow[t]{4}{*}{$\begin{array}{l}\text { Imitations } 2^{\mathrm{e}} \\
\text { moitié } \mathrm{III}^{\mathrm{e}} \mathbf{s} \\
\text { Empereur } \\
\text { indéterminé }\end{array}$} & 28 & $\begin{array}{c}\text { Antoninien, ca } 275-310 \\
\text { ]VS [ : effigie radiée à droite } \\
\text { ]V[; */-//-: Sol nu, la chlamyde flottant derrière lui, allant à gauche, levant la main droite et tenant un fouet } \\
\text { de la main gauche }\end{array}$ & $\begin{array}{l}\text { cf. Elmer, } 1941,683 \text { (Victorin, } \\
\text { type Invictus) } \\
1,08 \mathrm{~g} ; \varnothing 13-15,5 \mathrm{~mm} ; 1 \mathrm{~h} \\
\text { Inv. } 1056-6\end{array}$ & $\begin{array}{l}\text { DEP } \\
275-320 \\
(366)\end{array}$ \\
\hline & 29 & $\begin{array}{l}\text { Antoninien, } c \text { ca } 275-310 \\
\text { IM[ : effigie radiée à droite } \\
\text { ]V[ : personnage indéterminé debout à gauche }\end{array}$ & $\begin{array}{l}\text { cf. Elmer, } 1941 ? \\
1,00 \mathrm{~g} ; \varnothing 13-14 \mathrm{~mm} ; 1 \mathrm{~h} \\
\text { Inv. } 1086-11\end{array}$ & $\begin{array}{c}\text { DEP } \\
275-320 \\
(366)\end{array}$ \\
\hline & 30 & $\begin{array}{l}\text { Antoninien, } c a \text { } 275-310 \\
{[\ldots] \text { : effigie radiée à droite }} \\
{[\ldots] \text { : façade d'un temple }}\end{array}$ & $\begin{array}{l}\text { cf. Elmer, } 1941 ? \\
0,85 \mathrm{~g} ; \varnothing 12-13,5 \mathrm{~mm} ; 4 \mathrm{~h} \\
\text { Inv. } 1056-12\end{array}$ & $\begin{array}{l}\text { DEP } \\
275-320 \\
(366)\end{array}$ \\
\hline & 31 & $\begin{array}{c}\text { Antoninien, } \text { ca } 275-310 \\
{[\ldots] \text { : effigie radiée à droite }} \\
{[\ldots] \text { : personnage indéterminé debout à gauche }}\end{array}$ & $\begin{array}{c}\text { cf. Elmer, } 1941 \text { ? } \\
0,81^{*} \text { g; } \varnothing 11-12 \mathrm{~mm} ; 10 \mathrm{~h} \\
\text { Inv. } 1086-24\end{array}$ & $\begin{array}{c}\text { DEP } \\
275-320 \\
(366)\end{array}$ \\
\hline Licinius I & 32 & $\begin{array}{l}\text { Nummus (1/96 de livre), Trèves, 316-317 } \\
\text { IMP LICINIVS P F AVG : buste lauré à droite, avec cuirasse et paludamentum, vu de trois quarts en avant } \\
\text { GENIO - POP ROM; T/F//ATR : Génie, coiffé du modius, debout à gauche, nu, la chlamyde passée sur le bras } \\
\text { gauche, tenant une patère de la main droite et une corne d'abondance de la main gauche }\end{array}$ & $\begin{array}{l}\text { Bruun, } 1966,120 \text {; Luxeuil : } \\
\text { Gricourt, } 1999,- \\
3,23 \mathrm{~g} ; 6 \mathrm{~h} \\
\text { Inv. } 1086-7\end{array}$ & $\begin{array}{c}\text { DEP } \\
316-348 \\
(366)\end{array}$ \\
\hline Constantin I & 33 & $\begin{array}{c}\text { Nummus (1/48 de livre), Londres, } 307-310 \\
\text { IMP CONSTANTINVS P F AVG : buste lauré à droite, avec cuirasse, vu de trois quarts en avant } \\
\text { PRINCIPI IV-VENTVTIS; - -///PLN : l'empereur, en habit militaire, debout à gauche, } \\
\text { tenant deux enseignes militaires }\end{array}$ & $\begin{array}{l}\text { Sutherland, } 1967,111 \text {; Luxeuil : } \\
\text { Gricourt, } 1999,- \\
6,19 \mathrm{~g} ; 5 \mathrm{~h} \\
\text { Inv. } 1056-14\end{array}$ & $\begin{array}{c}\text { DEP } \\
307-313\end{array}$ \\
\hline
\end{tabular}




\begin{tabular}{|c|c|c|c|c|}
\hline & 34 & $\begin{array}{l}\text { Nummus (1/288 de livre), Trèves, } 310-311 \\
\text { CONSTANTINVS AVG : buste lauré à droite, avec cuirasse, vu de trois quarts en avant } \\
\text { VOT/[X]/MVL/XX; - -///- : couronne de laurier dans laquelle est inscrite une légende votive }\end{array}$ & $\begin{array}{l}\text { Sutherland, 1967, 913; Luxeuil : } \\
\text { Gricourt, 1999, - } \\
0,94 \mathrm{~g} ; 11 \mathrm{~h} \\
\text { Inv. } 1056-15\end{array}$ & $\begin{array}{c}\text { DEP } \\
310-313\end{array}$ \\
\hline & 35 & $\begin{array}{l}\text { Nummus (1/96 de livre), Trèves, 316-317 } \\
\text { CONSTANTINVS P F AVG : buste lauré à droite, avec cuirasse, vu de trois quarts en avant } \\
\text { SOLI INVIC-TO COMITI; T/F//ATR : Sol nu, la chlamyde passée sur le bras gauche, debout à droite, regardant } \\
\text { à gauche, levant la main droite et tenant un globe dans la main gauche, tournée vers l'extérieur }\end{array}$ & $\begin{array}{l}\text { Bruun, 1966, 94; Luxeuil : Gri- } \\
\text { court, } 1999,259 \\
\text { 4,08 g; } 12 \mathrm{~h} \\
\text { Inv. } 1075-2\end{array}$ & $\begin{array}{l}\text { DEP } \\
316-348 \\
(366)\end{array}$ \\
\hline & 36 & $\begin{array}{l}\text { Nummus (1/96 de livre), Trèves, 316-317 } \\
\text { CONSTANTINVS P F AVG : buste lauré à droite, avec cuirasse, vu de trois quarts en avant } \\
\text { SOLI INVIC-TO COMITI; T/F//ATR : Sol nu, la chlamyde passée sur le bras gauche, debout à droite, regardant } \\
\text { à gauche, levant la main droite et tenant un globe dans la main gauche, tournée vers l'extérieur }\end{array}$ & $\begin{array}{l}\text { Bruun, 1966, 94; Luxeuil : Gri- } \\
\text { court, } 1999,259 \\
2,91 \mathrm{~g} ; 12 \mathrm{~h} \\
\text { Inv. ST8-1 }\end{array}$ & $\begin{array}{c}\text { DEP } \\
316-348 \\
(366)\end{array}$ \\
\hline & 37 & $\begin{array}{l}\text { Nummus (1/96 de livre), Trèves, 316-317 } \\
\text { CO[NSTAN]TINVS P F AVG : buste lauré à droite, avec cuirasse, vu de trois quarts en avant } \\
\text { SOLI INVIC-TO COM[ITI]; T/F//ATR : Sol nu, la chlamyde passée sur le bras gauche, debout à droite, } \\
\text { regardant à gauche, levant la main droite et tenant un globe dans la main gauche, tournée vers l'extérieur }\end{array}$ & $\begin{array}{l}\text { Bruun, 1966, 94; Luxeuil : Gri- } \\
\text { court, } 1999,259 \\
\text { 2,21 g; } 1 \mathrm{~h} \\
\text { Inv. } 1056-9\end{array}$ & $\begin{array}{l}\text { DEP } \\
316-348 \\
(366)\end{array}$ \\
\hline & 38 & $\begin{array}{c}\text { Nummus (1/96 de livre), Trèves, } 325-326 \\
\text { CONSTAN-TINVS AVG : buste nu, lauré à droite } \\
\text { PROVIDEN-TIAE AVGG; - -/-//PTR (croissant) : porte de camp surmontée de deux tourelles. Au-dessus, l'astre } \\
\text { solaire. Pas de vantaux visibles }\end{array}$ & $\begin{array}{l}\text { Bruun, 1966, } 461 \text {; Luxeuil : } \\
\text { Gricourt, } 1999,412 \\
2,41 \mathrm{~g} ; 7 \mathrm{~h} \\
\text { Inv. } 1086-18\end{array}$ & $\begin{array}{l}\text { DEP } \\
325-348 \\
(366)\end{array}$ \\
\hline $\begin{array}{l}\text { Constantin I } \\
\text { pour Constan- } \\
\text { tin II, César }\end{array}$ & 39 & $\begin{array}{l}\text { Nummus (1/96 de livre), Siscia, } 320 \\
\text { CONSTANTINVS IVN NOB C : buste à gauche, avec cuirasse et paludamentum, tenant un pugio dans la main } \\
\text { gauche et un globe nicéphore dans la droite } \\
\text { VIRTVS - EXERCIT; VOT/X; S/FsurH//\&SIS* : étendard doté d'une inscription et au pied duquel se trouvent } \\
\text { deux captifs assis, les mains libres ou liées derrière le dos }\end{array}$ & $\begin{array}{l}\text { Bruun, 1966, 126; Luxeuil : } \\
\text { Gricourt, } 1999,1134 \\
3,20 \mathrm{~g} ; 7 \mathrm{~h} \\
\text { Inv. } 1086-17\end{array}$ & $\begin{array}{l}\text { DEP } \\
320-348 \\
(366)\end{array}$ \\
\hline $\begin{array}{l}\text { Constantin I } \\
\text { pour Crispus, } \\
\quad \text { César }\end{array}$ & 40 & $\begin{array}{l}\text { Nummus (1/96 de livre), Londres, 322-323 } \\
\text { CRISPVS - NOBIL C -C }{ }_{1}^{*} \text { : buste à gauche, avec cuirasse et casque non lauré, sans aigrette } \\
\text { BEAT TRA-NQLITAS; VOT/IS/XX; F/B//PLON : autel doté d'une inscription en trois lignes sur la face } \\
\text { antérieure. Sur l'autel, un globe divisé en quatre parties. Au-dessus, trois étoiles }\end{array}$ & $\begin{array}{l}\text { Bruun, 1966, 275; Luxeuil : } \\
\text { Gricourt, } 1999,- \\
3,55 \mathrm{~g} ; 7 \mathrm{~h} \\
\text { Inv. } 1086-20\end{array}$ & $\begin{array}{l}\text { DEP } \\
322-348 \\
(366)\end{array}$ \\
\hline $\begin{array}{l}\text { Constance II } \\
\text { ou Constant }\end{array}$ & 41 & $\begin{array}{c}\text { Nummus (1/192 de livre), Rome, } 337-340 \\
{[\ldots] \text { : buste diadémé à droite, avec cuirasse et paludamentum, vu de trois quarts en avant }} \\
\text { [SECVR]ITA[S REI P(?VB)]; - -I/I? : Securitas debout de face, regardant à droite, les jambes croisées, le coude } \\
\text { gauche appuyé sur une colonne, tenant un sceptre de la main droite }\end{array}$ & $\begin{array}{l}\text { Kent, } 1981, ? \\
1,54 \mathrm{~g} ; 6 \mathrm{~h} \\
\text { Inv. } 1056-20\end{array}$ & $\begin{array}{l}\text { DEP } \\
337-400 \\
(420)\end{array}$ \\
\hline Constant & 42 & $\begin{array}{c}\text { Nummus (1/192 de livre), Trèves, } 348 \\
\text { [CONSTAN]-S P F AVG : buste diadémé à droite, avec cuirasse et paludamentum, vu de trois quarts en avant } \\
\text { [VICTORIAE DD AVGGQ NN]; (palme)//TR? : deux Victoires se faisant face, tenant chacune une couronne } \\
\text { et une palme }\end{array}$ & $\begin{array}{l}\text { Kent, 1981, 205-206/209-210; cf. } \\
\text { Gricourt, } 1998, \text { p. 127-139 } \\
\text { 1,07 g; } 11 \mathrm{~h} \\
\text { Inv. } 1086-23\end{array}$ & $\begin{array}{l}\text { DEP } \\
348-400 \\
(420)\end{array}$ \\
\hline $\begin{array}{l}\text { Imitation } \\
\text { milieu IV }{ }^{\text {e }} \text {. } \\
\text { Type Fel temp } \\
\text { reparatio } \\
\text { (cavalier) }\end{array}$ & 43 & $\begin{array}{c}\text { Aes } 4 \text {, ca 348-366 } \\
{[\ldots . .] \text { : buste diadémé à droite, avec cuirasse et paludamentum, vu de trois quarts en avant }} \\
\text { ]AEDPAVG[; - -I//? : soldat casqué tenant un bouclier de la main gauche et perçant de sa haste un guerrier tom- } \\
\text { bant de cheval; la plupart du temps, bouclier sur le sol, à droite. Le cavalier, qui fait face au soldat, porte un bonnet } \\
\text { pointu et tend le bras gauche }\end{array}$ & $\begin{array}{l}\text { 1,08 g; Ø } 14-16 \mathrm{~mm} ; 12 \mathrm{~h} \\
\text { Inv. } 1086-26\end{array}$ & $\begin{array}{l}\text { DEP } \\
348-400 \\
(420)\end{array}$ \\
\hline $\begin{array}{l}\text { Imitation } \\
\text { milieu IV }{ }^{\text {e }} \text {. } \\
\text { Type Fel temp } \\
\text { reparatio } \\
\text { (galère) }\end{array}$ & 44 & $\begin{array}{c}\text { Maiorina, ca 348-350 } \\
\text { D N CONSTA-NS P F AVG : buste à droite, avec cuirasse et paludamentum, vu de trois quarts en avant, } \\
\text { diadème perlé }\end{array}$ & $\begin{array}{l}\text { cf. Kent, } 1981,114 \text { (Rome) } \\
4,10 \mathrm{~g} ; \varnothing 20 \mathrm{~mm} ; 6 \mathrm{~h} \\
\text { Inv. } 1065-1\end{array}$ & $\begin{array}{c}\text { DEP } \\
348-400\end{array}$ \\
\hline $\begin{array}{l}\text { Imitation } \\
\text { milieu IV }{ }^{\mathrm{e}} \text {. } \\
\text { Type Gloria } \\
\text { exercitus (2 } \\
\text { enseignes) }\end{array}$ & 45 & $\begin{array}{c}\text { Aes } 4, \text { ca } 330-366 \\
{[\ldots]: \text { effigie à droite }} \\
{[\ldots \ldots] ; \text { ? ??/?? : deux soldats debout, se faisant face, tenant chacun une haste renversée et un bouclier posé verticale- }} \\
\text { ment sur le sol. Entre eux, deux enseignes }\end{array}$ & $\begin{array}{l}0,99 \mathrm{~g} ; \varnothing 13-14,5 \mathrm{~mm} ; 8 \mathrm{~h} \\
\text { Inv. } 1086-25\end{array}$ & $\begin{array}{l}\text { DEP } \\
330-400 \\
(420)\end{array}$ \\
\hline \multirow[t]{2}{*}{$\begin{array}{l}\text { Imitations } \\
\text { milieu IV }{ }^{\mathrm{e}} \text {. } \\
\text { Type Urbs } \\
\text { Roma }\end{array}$} & 46 & $\begin{array}{c}\text { Aes } 4 \text {, ca } 330-366 \\
\text { VRBS - ROMA : buste à gauche, avec cuirasse et casque non lauré, sans aigrette } \\
\text { Anépigraphique; -/-//TR・P : la Louve debout à droite, allaitant Rémus et Romulus; au-dessus, } \\
\text { deux étoiles }\end{array}$ & $\begin{array}{l}\text { cf. Bruun, } 1966,542 \text { (Trèves) } \\
\text { 1,66 g; Ø } 14 \mathrm{~mm} ; 6 \mathrm{~h} \\
\text { Inv. } 1056-5\end{array}$ & $\begin{array}{l}\text { DEP } \\
330-400 \\
(420)\end{array}$ \\
\hline & 47 & $\begin{array}{c}\text { Aes 4, ca 330-366 } \\
\text { VRBS - [ : buste à gauche, avec cuirasse et casque non lauré, sans aigrette } \\
\text { Anépigraphique; -I-I/? -Louve } 2: \text { la Louve debout à droite, allaitant Rémus et Romulus; au-dessus, deux étoiles }\end{array}$ & $\begin{array}{l}\text { 1,12 g; Ø } 12-14 \mathrm{~mm} ; 1 \mathrm{~h} \\
\text { Inv. 1086-19 }\end{array}$ & $\begin{array}{l}\text { DEP } \\
330-400 \\
(420)\end{array}$ \\
\hline $\begin{array}{l}\text { Imitation } \\
\text { milieu IV } \text { s. }^{\text {s. }} \\
\text { Hybride types } \\
\text { Urbs Roma / } \\
\text { Constantino- } \\
\quad \text { polis }\end{array}$ & 48 & 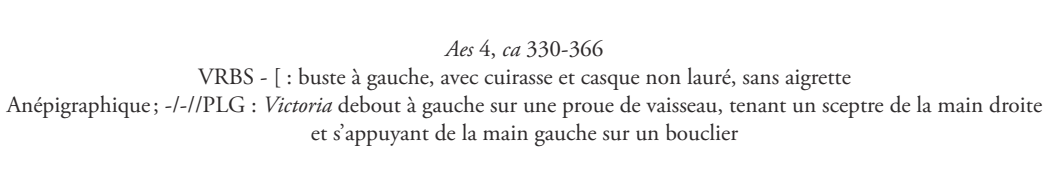 & $\begin{array}{l}0,91 \mathrm{~g} ; \varnothing 12 \mathrm{~mm} ; 5 \mathrm{~h} \\
\text { Inv. 1086-4 }\end{array}$ & $\begin{array}{l}\text { DEP } \\
330-400 \\
(420)\end{array}$ \\
\hline $\begin{array}{l}\text { Imitation } \\
\text { milieu IV }{ }^{\mathrm{e}} \text {. } \\
\text { Type Victoriae } \\
\text { dd nn aug et } \\
\quad \text { cae(s) }\end{array}$ & 49 & $\begin{array}{c}\text { Demi-maiorina, ca 350-366 } \\
{[\ldots] \text { : effigie diadémée à droite }} \\
{[\ldots] ; \text { IOV/AN; }-/-/ / \text { : deux Victoires se faisant face, tenant une couronne dotée d'une inscription }}\end{array}$ & $\begin{array}{l}0,61 \mathrm{~g} ; \varnothing 10-12 \mathrm{~mm} ; 11 \mathrm{~h} \\
\text { Inv. } 1086-16\end{array}$ & $\begin{array}{c}\text { DEP } \\
350-400\end{array}$ \\
\hline
\end{tabular}




\begin{tabular}{|c|c|c|c|c|}
\hline Valens & 50 & $\begin{array}{c}\text { Aes } 3 \text { (1/132 de livre), Rome, 367-375 } \\
\text { [D N V]ALEN-S [P F] AVG : buste à droite, avec cuirasse et paludamentum, vu de trois quarts en avant, } \\
\text { diadème perlé } \\
\text { SECVR[ITAS - REIPVBLICAE] ; -/-//[R•]TERTIA : deux Victoires se faisant face, tenant chacune une couronne } \\
\text { et une palme }\end{array}$ & $\begin{array}{l}\text { Pearce, } 1933,17 \mathrm{~b} / 24 \mathrm{~b} \text { xib } \\
2,02 \mathrm{~g} ; 6 \mathrm{~h} \\
\text { Inv. } 1086-8\end{array}$ & $\begin{array}{c}\text { DEP } \\
367-420\end{array}$ \\
\hline & 51 & $\begin{array}{l}\text { Aes } 3 \text { (1/132 de livre), Rome, } 367-375 \\
\text { D N VALEN-S P F AVG : buste à droite, avec cuirasse et paludamentum, vu de trois quarts en avant, diadème perlé } \\
\text { [SECVRITAS] - REIPVBLICAE; -////[R•]TERTIA : Victoria marchant à gauche, tenant une couronne de la main } \\
\text { droite et une palme reposant sur le bras ou l'épaule gauche de la main gauche }\end{array}$ & $\begin{array}{l}\text { Pearce, } 1933,17 \mathrm{~b} / 24 \mathrm{~b} \text { xib } \\
1,81 \mathrm{~g} ; 7 \mathrm{~h} \\
\text { Inv. } 1086-5\end{array}$ & $\begin{array}{c}\text { DEP } \\
367-420\end{array}$ \\
\hline & 52 & $\begin{array}{l}\text { Aes } 3 \text { (1/132 de livre), atelier indéterminé, 364-378 } \\
\text { D N VALEN-S P F AVG : buste à droite, avec cuirasse et paludamentum, vu de trois quarts en avant, } \\
\text { diadème perlé }\end{array}$ & $\begin{array}{l}\text { Pearce, } 1933, ? \\
2,25 \mathrm{~g} ; 7 \mathrm{~h} \\
\text { Inv. } 1056-8\end{array}$ & $\begin{array}{c}\text { DEP } \\
364-420\end{array}$ \\
\hline Gratien & 53 & $\begin{array}{l}\text { Aes } 3 \text { (1/132 de livre), Arles, 367-375 } \\
\text { D N GRATIA[NVS] AVGG AVG : buste à droite, avec cuirasse et paludamentum, vu de trois quarts en avant, } \\
\text { diadème perlé } \\
\begin{array}{c}\text { GLORIA NO-VI SAEC[VLI] ; -/-//TCON : l'empereur en habit militaire, debout de face, regardant à gauche, } \\
\text { tenant le labarum de la main droite et s'appuyant sur un bouclier de la main gauche }\end{array}\end{array}$ & $\begin{array}{l}\text { Pearce, } 1933,15 \text { xivc } \\
2,51 \mathrm{~g} ; 5 \mathrm{~h} \\
\text { Inv. } 1075-1\end{array}$ & $\begin{array}{c}\text { DEP } \\
367-420\end{array}$ \\
\hline Valentinien II & 54 & $\begin{array}{c}\text { Aes } 4 \text { (1/252 de livre), Arles, 388-392 } \\
\text { [D N VALEN]TINI-ANVS [P F AVG] : buste à droite, avec cuirasse et paludamentum, vu de trois quarts en avant, } \\
\text { diadème perlé } \\
\text { [VICTOR]-IA AVGGG ; -/-//SCON : Victoria marchant à gauche, tenant une couronne de la main droite et une } \\
\text { palme reposant sur le bras ou l'épaule gauche de la main gauche }\end{array}$ & $\begin{array}{l}\text { Pearce, 1933, 30avar. } \\
1,18 \mathrm{~g} ; 6 \mathrm{~h} \\
\text { Inv. } 1086-15\end{array}$ & $\begin{array}{c}\text { DEP } \\
388-450\end{array}$ \\
\hline $\begin{array}{l}\text { Empire } \\
\text { carolingien } \\
\text { Louis } \text { Ir dit }^{\text {le Pieux (le }} \\
\text { Débonnaire) }\end{array}$ & 55 & $\begin{array}{l}\text { Obole de type 2, Melle, } c a \text { 816-823 } \\
\text { LVDO/VVIC; grènetis au pourtour } \\
\quad+\text { METALLVM : Croix }\end{array}$ & $\begin{array}{c}\text { Poey d'Avant, } 1858-1862,2345 ; \\
\text { Prou, 1892, 709; Sarah, 2009, } \\
\text { p. } 70-71,82 \\
0,79 \mathrm{~g} ; 4 \mathrm{~h} \\
\text { Inv. HS-1 }\end{array}$ & $\begin{array}{c}\text { DEP } \\
818-900\end{array}$ \\
\hline Louis XIII & 56 & $\begin{array}{l}\text { Double tournois, } 7^{\mathrm{e}} \text { type, Tours, } 1635 \\
\text {.L[OYS.XIII.R.DE.FRAN.]ET.NAV.; exergue différent d'atelier E }: \text { grand buste du Roi à droite, lauré, drapé et } \\
\text { cuirassé, avec grand col plat } \\
+ \text { DOVBL[E.TOVRNOIS.]1635: trois lis posés } 2 \text { et } 1\end{array}$ & $\begin{array}{l}\text { Duplessy, } 1989,1369 \\
\text { 2,69 g; } 6 \mathrm{~h} \\
\text { Inv. HS-2 }\end{array}$ & $\begin{array}{c}\text { DEP } \\
\text { XVIIB }\end{array}$ \\
\hline
\end{tabular}

Tableau 3 : Yville-sur-Seine, Le Sablon, catalogue des monnaies (F. Pilon).

Table 3: Le Sablon, catalogue of coins (F. Pilon).

\section{La céramique (L. Féret)}

Rappelons le faible effectif des lots mis au jour (fig. 6, 7, $9,10,21$ et 23), avec un total de 940 restes, dont 242 (soit $26 \%$ de l'ensemble) pour le seul fossé 1013.

De l'extrême fin de la période gauloise et l'époque augustéenne, puis pour la première partie du $\mathrm{I}^{\mathrm{er}}$ s. apr. J.-C., les assemblages, malgré leur faiblesse, sont comparables à ce qui est déjà connu régionalement - absence de sigillée précoce, bonne représentation de la terra nigra champenoise et arverne et présence non négligeable de céramique de tradition indigène non tournée ou reprise au tour pour les contextes les plus anciens.

Les contextes $\mathrm{du} \mathrm{I}^{\mathrm{er}} \mathrm{s}$., antérieurs à l'époque flavienne (fossé 1013), se caractérisent par des importations de sigillée de La Graufesenque, par les productions du Noyonnais et la diversité des provenances des poteries en pâte sombre.

La première moitié du $\mathrm{III}^{\mathrm{e}} \mathrm{s}$. est marquée par des ensembles restreints (fig. 21 et 23). Tout au plus, y voit-on la présence fréquente des mortiers sigillés de type Drag. 45 et quelques éléments issus du Centre de la Gaule ou de l'Argonne. Les céramiques sombres lustrées et les céramiques culinaires à pâte sombre proviennent majoritairement de l'atelier de la forêt de Montfort-sur-Risle (commune d'Appeville-Annebault, Eure), pour une raison de proximité. À Yville-surSeine, les représentants de l'atelier de la forêt de Lyons (Eure) sont rares tandis que l'on note une forte représentation des écuelles hémisphériques tripodes de l'atelier de la forêt de Montfort. Une dernière caractéristique de ces ensembles est la présence d'amphores régionales de type Gauloise 12, dont l'origine serait à situer dans le Pays d'Auge (?).

En dernier lieu, aucun élément particulier en rapport avec le caractère cultuel du site n'est à recenser (mutilation, vaisselle miniature...). Mais la faiblesse numérique du lot et son mauvais état de conservation expliquent peut-être en partie cet état de fait.

\section{L'instrumentum}

Le corpus est constitué de 90 éléments (fig. 24 et 25; tabl. 5) dont deux, en alliage de cuivre, sont issus du diagnostic archéologique (Beurion, 2013). Dans chaque catégorie, les objets seront décrits en fonction de leur origine, le sanctuaire, l'établissement sud et les éléments divers. Le 


\begin{tabular}{|c|c|c|}
\hline St. & DNum & $\begin{array}{l}\text { Remarques et données } \\
\text { céramiques }\end{array}$ \\
\hline 1001 & $30<$ & $\begin{array}{l}\text { US d'occupation autour du bâtiment } \\
\text { B1, } \\
\text { Céramique : mélange } \mathrm{II}^{\mathrm{e}} / \mathrm{III}^{\mathrm{e}} \mathrm{s} \text {, et } \\
\text { Bas-Empire ( } 2^{\mathrm{e}} \text { moitié } \mathrm{IV}^{\mathrm{e}} \mathrm{s} \text {.) }\end{array}$ \\
\hline 1056 & $0-420$ & $\begin{array}{l}\text { US de destruction sud, vraisemblable- } \\
\text { ment remanié/colluvionnée; céra- } \\
\text { mique : grande majorité } \mathrm{II}^{\mathrm{e}} / \mathrm{III}^{\mathrm{e}}+\mathrm{qq} \\
\text { éléments } \mathrm{IV}^{\mathrm{e}} \text { s. et résiduel } \mathrm{I}^{\mathrm{er}} \mathrm{s} \text {. }\end{array}$ \\
\hline 1065 & $348<$ & $\begin{array}{l}\text { Fosse qui vient recouper le bâtiment } \\
\qquad \text { B1; } \\
\text { Céramique : } \mathrm{II}^{\mathrm{e}} / \mathrm{III}^{\mathrm{e}} \mathrm{s} \text {. }\end{array}$ \\
\hline 1075 & $316-420$ & $\begin{array}{c}\text { Fosse La Tène D2 / augustéen + } \mathrm{II}^{\mathrm{e}} / \\
\mathrm{III}^{\mathrm{e}} \text { s., monnaies intrusives }\end{array}$ \\
\hline 1086 & $\begin{array}{c}260-450 \\
\text { DNum affinée } \\
260-400 \\
\text { (pas de mon- } \\
\text { naies rognées) }\end{array}$ & $\begin{array}{l}\text { US de destruction nord, US vraisem- } \\
\text { blablement remaniée/colluvionnée; } \\
\text { pas de céramique }\end{array}$ \\
\hline 1124 & $270<$ & $\begin{array}{l}\text { Couche de destruction de E3; céra- } \\
\text { mique; mélange La Tène D2 / } \\
\text { augustéen et II }{ }^{\mathrm{e}} / \mathrm{III}^{\mathrm{e}} \text { s. }\end{array}$ \\
\hline ST8 & $316<$ & Équivalent de 1086 \\
\hline HS & $\mathrm{IX}^{\mathrm{e}}, \mathrm{XVII}^{\mathrm{e}} \mathrm{s}$. & Décapage et HS surface \\
\hline
\end{tabular}

Tableau 4 : Yville-sur-Seine, Le Sablon, Datations numismatiques (DNum) des monnaies et des contextes (F. Pilon).

Table 4: Numismatic dates (DNum) for coins and contexts (F. Pilon).

corpus détaille les vestiges les plus intéressants tandis que les points de comparaison privilégient les sanctuaires, notamment ceux de l'ouest de la Gaule.

\section{Les objets en fer du sanctuaire}

- Le fossé 1013 (comblement du fossé sud du péribole)

Cultuel : hache miniature en fer, longue de $36 \mathrm{~mm}$, large de $12 \mathrm{~mm}$ et épaisse de $13 \mathrm{~mm}$ (inv. 1013-1, fig. 24), elle est munie d'un œil ovale à circulaire (étampé?), sa lame est triangulaire, le dos et la face inférieure sont droits tandis que la nuque est dans le prolongement du dos. Elle reproduit en miniature des haches à œil utilisées pour le travail du bois (Mouquin et Rossier, 2001, p. 113) telles celles de type Duvauchelle 1 (2005, p. 36-37).

Les hachettes votives antiques sont habituellement en bronze, elles peuvent être en argent telle celle de Fesques en Seine-Maritime (Mantel, 1997, p. 266-267). Parfois chez les Helvètes, elles sont aussi en fer (Mouquin et Rossier, 2001). Des haches en fer proviennent du sanctuaire de Châteauneuf en Savoie (Mermet, 1993, p. 103-104), de Marsens-Riaz en Suisse (Mouquin et Rossier, 2001, cat. $n^{\circ} 13$ : fig. 24), du sanctuaire d'Antigny dans la Vienne (Éneau, 2002, cat. 172, fig. 24) et de Faye-l'Abbesse dans les Deux-Sèvres (Lejars, 1989, p. 30). Mentionnons la découverte, au sanctuaire de Flaviers à Mouzon dans les Ardennes, de cinq hachettes en fer (Tisserand, 1980, fig. 16; fig. 24 types $\mathrm{n}^{\circ \mathrm{as}}$ a, b et c), dont deux (fig. 24, $\mathrm{n}^{\text {os }}$ a et b) sont comparables à celle du Sablon.

- US 1056 (US de destruction des temples)

Huisserie : aile mâle d'une fiche à brisure (inv. 1056-4, fig. 24). Un élément comparable provient du sanctuaire de la forêt d'Eawy en Seine-Maritime (Halbout et al., 1987, p. 80).

Quincaillerie : patte fiche repliée, enserrant un anneau (inv. 1056-1, fig. 24). C'est un objet fréquent dans les sanctuaires de Normandie (Halbout et al., 1987, p. 118).

- US 1124 (US de destruction localisée dans l'ensemble E3)

Outillage : clavette (?) à tête ronde, de section carrée (inv. 1124-1, fig. 24).

- US 1132 (US de destruction localisée dans la cella du temple B4)

Cultuel/domestique : clochette en fer à anneau de suspension, haute de $49 \mathrm{~mm}$, la base est de plan rectangulaire aux angles arrondis $(33 \times 48 \mathrm{~mm})$, le battant est absent (inv. 1132-1, fig. 24). Elle est constituée d'une tôle reliée et d'une bélière rapportée, laitonnés à chaud.

Les sonnailles signalées en contexte cultuel sont souvent en alliage de cuivre comme aux Bolards à Nuits-Saint-Georges en Côte-d'Or (Pommeret, 2001, p. 366-369). Un exemplaire en fer proche de celui du Sablon provient de Rouen en Seine-Maritime (Halbout et al., 1987, p. 86). D'autres ont été découverts au sanctuaire de Val-de-Reuil dans l'Eure (Lukas, 2014, p. 258) et sur celui de Bennecourt dans les Yvelines (Bourgeois, 1999, p. 115-116).

\section{Les objets en fer de l'établissement sud}

- US 1001 (US d'occupation autour du bâtiment B1)

Domestique : lame de couteau longue et effilée, avec départ de la soie (inv. 1001-1, fig. 24). La lame est longue de $125 \mathrm{~mm}$, au profil triangulaire et dos rectiligne. Des couteaux comparables sont mentionnés au sanctuaire d'Antigny dans la Vienne (Éneau, 2002, no 219) et de Bennecourt (Bourgeois, 1999, p. 113-114). L'élargissement observé près du manche caractériserait un couteau à désosser (Leconte, 2013, p. 237-239).

Écriture : stylet de section circulaire (inv. 1001-3, fig. 24). Un objet du même type, commun en contexte d'habitat ou de sanctuaire, est signalé au Vieil-Évreux dans l'Eure (Halbout et al., 1987, p. 86). 


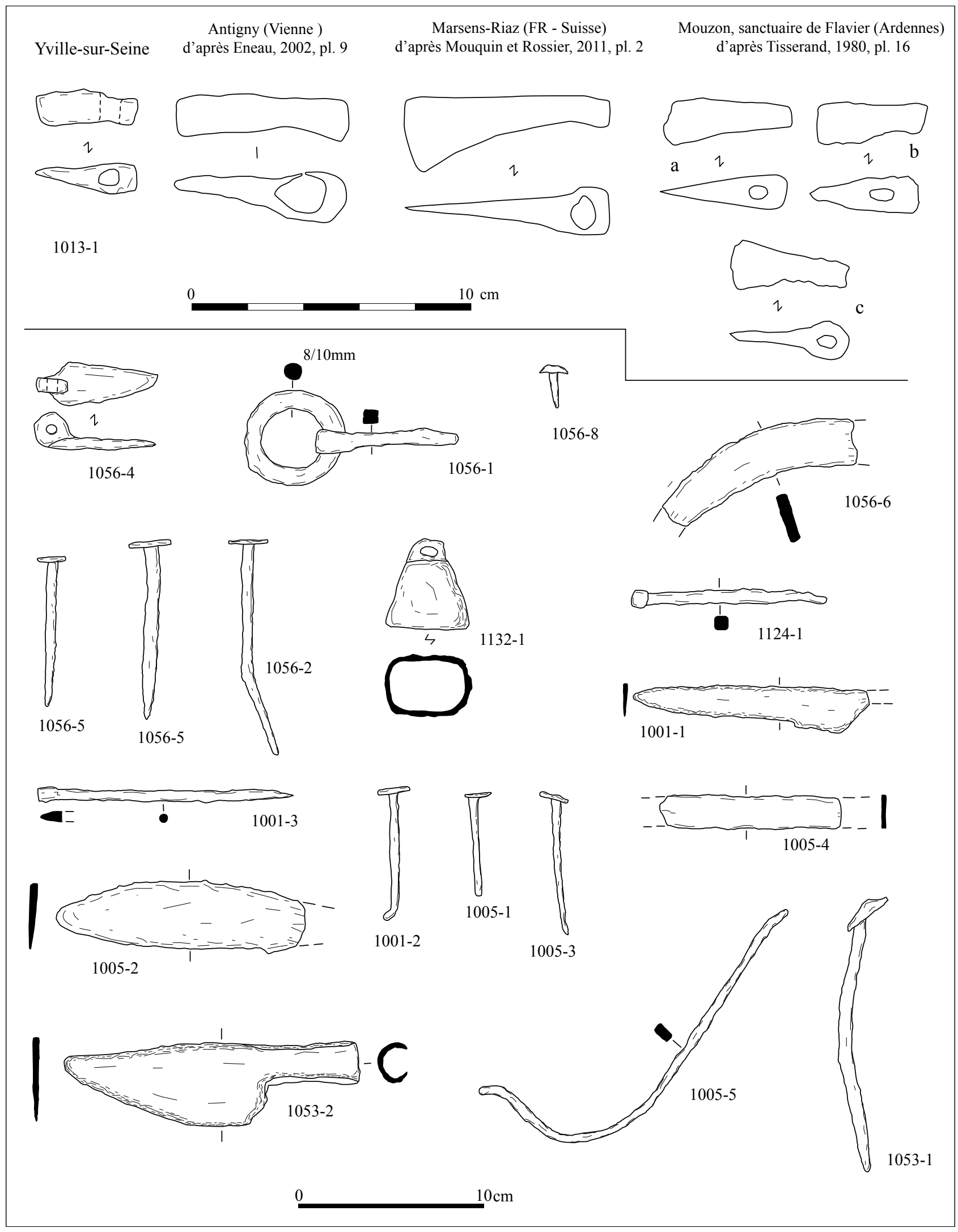

Figure 24 : Yville-sur-Seine (76) : les objets en fer (G. Guillier, Inrap).

Figure 24 : Presentation of the instrumentum, the objects in iron (G. Guillier, Inrap). 


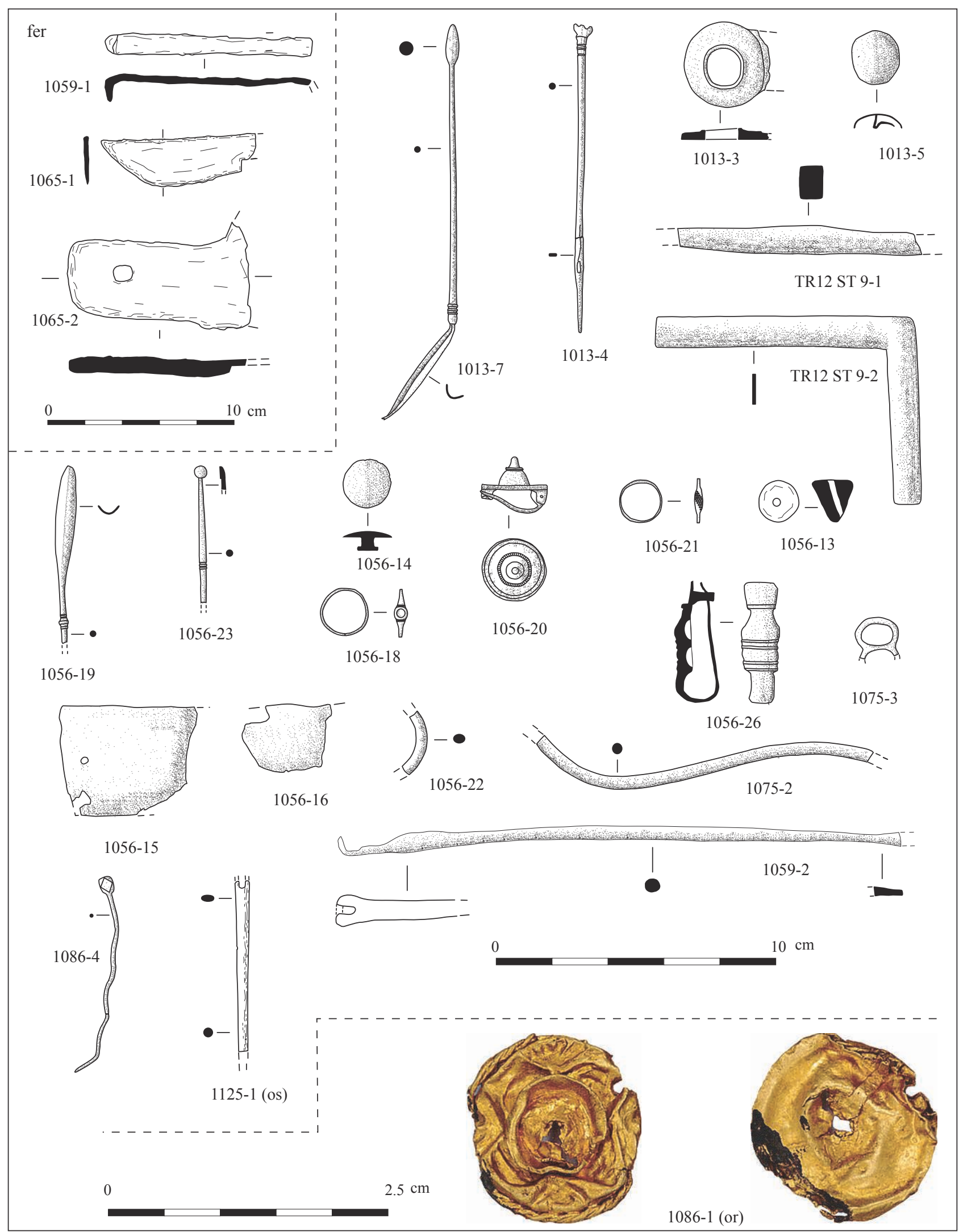

Figure 25 : Yville-sur-Seine (76) : les objets en fer, en alliage de cuivre, en os, boucle d'oreille en or (G. Guillier, Inrap). Figure 25: The objects made from iron, copper alloy, bone and a gold earring (G. Guillier, Inrap). 


\begin{tabular}{|c|c|c|}
\hline Matériau & Nb d'éléments & $\mathbf{\%}$ \\
\hline os & 1 & 1.1 \\
\hline or & 1 & 1.1 \\
\hline lithique & 2 & 2.2 \\
\hline plomb & 14 & 15,9 \\
\hline alliages de cuivre & 31 & 33 \\
\hline fer & $41(26)$ & $46,7(30,7)$ \\
\hline Total & 90 & 100 \\
\hline
\end{tabular}

Tableau 5 : Yville-sur-Seine (76), Le Sablon, répartition de l'instrumentum, avec entre parenthèses, pour les clous, leur nombre ainsi que leur pourcentage (G. Guillier, Inrap).

Table 5: Distribution of the instrumentum, the number of elements and the percentage; indicated in parentheses, for the nails, is the number as well as the percentage (G. Guillier, Inrap).

- US 1005 (remblai de sol dans le bâtiment B1)

Domestique : lame de couteau longue de $134 \mathrm{~mm}$, de forme lancéolée et pointe arrondie, au dos courbe, à lame large, épaisse (inv. 1005-2, fig. 24), emmanchement à soie manquant. Un élément comparable provient de Frénouville dans le Calvados (Halbout et al., 1987, p. 89). Ce type de lame est compatible avec la découpe des aliments (Leconte, 2013, p. 239).

- Le fossé 1053 (établissement sud, fossé intérieur de l'ensemble E2)

Domestique : couteau complet à douille, long de 160 mm (inv. 1053-2, fig. 24), le tranchant forme un net décrochement par rapport à la douille où un clou de fixation est en place, le talon de la lame est découpé. Ces éléments suggèrent une utilisation pour la découpe des carcasses (Leconte, 2013, p. 237-239).

\section{Les autres objets en fer}

- Découverte mobilière isolée 1059 (localisation : fig. 4)

Ameublement : agrafe ou crampon de menuiserie? (inv. 1059-1, fig. 25).

- La fosse 1065 (recoupe le bâtiment B1)

Domestique : lame de canif, longue de $82 \mathrm{~mm}$, elle conserve son axe et une lamelle en alliage cuivreux destinée à faciliter la rotation dans le manche (inv. 1065-1, fig. 25).

Vaisselle : poignée plate, épaisse, percée d'un trou de suspension (inv. 1065-2, fig. 25).

\section{Les objets en bronze, plomb et autres du sanctuaire}

- Le fossé 1013 (il délimite le côté sud du péribole)

Instrument de toilette : cuillère-sonde, à la tige de section circulaire, la pliure est ancienne, moulures à la base de la cuillère, surface étamée, longue de $143 \mathrm{~mm}$ (inv. 1013-7, fig. 25). De type Riha 461-495 var. E (1986, pl. 43-45), ces instruments peuvent provenir de sanctuaires à l'image de celui du Vieil-Évreux (Fauduet, 1992, p. 125-132).

Parure : tête d'une fibule de type Feugère 14b1b (1985, p. 262-267) (inv. 1013-8), ce type est signalé à CracouvilleLe Vieil-Évreux (Fauduet, 1992, p. 72-73), à Fesques (Mantel, 1997, p. 193 et 195) et au sanctuaire d'Eu en Seine-Maritime (Mangard, 2008, $\mathrm{n}^{\circ}$ 58-65). Datation : d'Auguste à Tibère / Claude.

Domestique : aiguille à chas (antique ou médiévale?), en alliage de cuivre, à la tête ornée, longue de $111 \mathrm{~mm}$, de section circulaire et pointe aplatie (inv. 1013-4, fig. 25).

Varia : tige brisée de section rectangulaire et languette en forme d'équerre, de section plate, en alliage de cuivre (Beurion, 2013, p. 42-43; fig. 25, TR12 ST9-1 et 9-2).

- US 1056 (US de destruction des temples localisée au sud du fossé 1013)

Instruments de toilette : spatule creuse d'une cuillèresonde, longue de 62 mm (inv. 1056-19, fig. 25). Fragment de cure-oreilles étamé à palette circulaire, long de $50 \mathrm{~mm}$, à section circulaire, et petit décor mouluré sur la tige (inv. 1056-23, fig. 25). Il se rapporte au type Riha 254-263 var. D (1986, pl. 27) et est signalé au Vieil-Évreux (Fauduet, 1992, p. 130-131).

Parure : bouton plat avec rivet de fixation (inv. 105614, fig. 25). Des parallèles sont mentionnés à Val-de-Reuil (Lukas, 2014, p. 251-253).

Petite bague de $18 \mathrm{~mm}$ de diamètre, de section rectangulaire $(1 \times 1,5 \mathrm{~mm})$ à chaton circulaire et décor manquant (inv. 1056-18, fig. 25). Elle présente des parallèles au sanctuaire des Bolards à Nuits-Saint-Georges en Côte-d'Or (Pommeret, 2001, p. 357-359).

Autre petite bague de $15 \mathrm{~mm}$ de diamètre, de section rectangulaire $(1 \times 1 \mathrm{~mm})$, l'anneau épaissi montre de fines bossettes en relief (inv. 1056-21, fig. 25). Cette bague de type Guiraud 2g (Guiraud, 1989, p. 181) est présente aux Bolards (Pommeret, 2001, p. 357-359, cat 8-10) et à Fesques (Mantel, 1997, fig. 16 p. 237).

Fibule conique de type Feugère 25a, à charnière de type i en fer, diam. $23 \mathrm{~mm}$, h. $20 \mathrm{~mm}$, l'avers garde des traces de dorure (inv. 1056-20, fig. 25). Ce type, attesté dès la fin du $\mathrm{I}^{\text {er }}$ s. apr. J.-C., persistant durant la première moitié du $\mathrm{II}^{\mathrm{e}}$ s., est surtout présent dans le quart nord-est de la Gaule et sur le limes de Germanie supérieure (Feugère, 1985, p. 352). 
Construction : scellement en plomb de forme tronconique (inv. 1056-13, fig. 25).

Harnachement : extrémité de courroie à décor mouluré et rivet de fixation (inv. 1056-26, fig. 25). Cet élément traditionnellement lié à l'équipement militaire est mentionné à Mauves-sur-Loire en Loire-Atlantique (Monteil et al., 2009, p. 180-181).

- Le fossé 1068 (segment de fossé, un premier état du sanctuaire?)

Construction : fragment de lingot (?) en plomb, avec traces de découpe (poids 319,5 g).

- US 1086 (US de destruction des temples)

Parure : pendant d'oreille en forme de fleur, en or, écrasé, orné de fins décors en reliefs et ceint d'un fin filigrane constitué de deux fils torsadés soudés au paillon, le chaton central et une partie du cordon tressé sont manquants (inv. 1086-1, fig. 25). Un exemplaire proche a été découvert à Lyon dans le Rhône (Besson, 2015, p. 563 et 573) et deux autres à Augst en Suisse (Riha, 1990, pl. 30, nos 694 et 695). L'exemplaire d'Augst Riha 695 est daté de la première moitié au milieu du III $^{\mathrm{e}}$ s. (ibid., p. 148).

Épingle à tête polyédrique, aux déformations anciennes (long. $71 \mathrm{~mm}$, inv. 1086-4, fig. 25), de type Riha 21 var. 2 (ibid., $\mathrm{n}^{\mathrm{o}}$ 2461-2467), traditionnellement datée des $\mathrm{III}^{\mathrm{e}}$ et $\mathrm{IV}^{\mathrm{e}} \mathrm{s}$. Une épingle identique a été identifiée dans un contexte tardif au sanctuaire du Gué-de-Sciaux dans la Vienne (Bertrand, 2018, V. I, p. 64).

- US 1125 (US de destruction localisée dans la galerie du temple B4)

Domestique : fragment d'aiguille à chas en os (inv. 11251, fig. 25).

\section{Quelques autres objets}

- Découverte mobilière 1059 (localisation : fig. 4).

Instrument de mesure : fléau de balance (?) en alliage de cuivre (inv. 1059-2, fig. 25).

Domestique : moitié de catillus en poudingue, de forme tronconique, avec perforation latérale destinée à l'emmanchement, H : 160 mm; diam. : 316 mm (inv. 1059-3). De telles meules ont été produites à Avrilly dans l'Eure (Guillier et al., 2005).

- La fosse 1065 (vaste structure recoupant le bâtiment B1)

Instrument de toilette : fragment de palette à fard en schiste noir à fines passées grises, aux bords biseautés et angles arrondis (larg. $70 \mathrm{~mm}$, long. $50 \mathrm{~mm}$, ép. max.
$9 \mathrm{~mm}$ ). De fortes traces d'usage marquent le centre de la palette : son épaisseur est réduite à moins de $2 \mathrm{~mm}$ (inv. 1065-3). On note, en termes de comparaison, deux palettes à fard en schiste, fragmentées, à Val-de-Reuil dans l'Eure (Lukas, 2014, p. 244), dans des contextes des III $^{\mathrm{e}-}$ $\mathrm{IV}^{\mathrm{e}}$ s., hors du sanctuaire.

\section{Premiers regards sur l'instrumentum d'Yville-sur-Seine}

Avec 90 objets, le corpus est relativement réduit (fig. 24 et 25 ; tabl. 6), dont 65 (soit $72,2 \%$ ) sont issus des couches en relation avec le sanctuaire et 15 (soit 16,6\%) avec celles liées à l'établissement sud. Régionalement, il a été relevé le site de Val-de-Reuil avec 267 éléments (et 1073 clous) ou le sanctuaire des Mureaux à Authevernes dans l'Eure (Michel, 2011) avec 277 objets, dont 74 en alliages cuivreux.

Certains sanctuaires régionaux sont également pauvres en mobilier, parmi lesquels on peut mentionner celui de Saint-Martin-des-Entrées dans le Calvados (Paez-Rezende et Adrian, 2014, p. 263), ou de Nécy dans l'Orne (BesnardVauterin et al., 2013, p. 214 et 215).

Du sanctuaire du Sablon proviennent nombre d'éléments en fer ( $25 \%$ du corpus), essentiellement des clous, tous les éléments liés à la construction, scellements, chutes et autres éléments en plomb, l'essentiel des instruments de toilette avec trois éléments sur quatre, deux objets domestiques sur six, toute la parure et tous les éléments liés à la paléomanufacture du bronze. L'établissement sud, aux $\mathrm{II}^{\mathrm{e}}-\mathrm{III}^{\mathrm{e}} \mathrm{s}$., ne présente que des objets en fer, quincaillerie et couteaux, éléments absents de la sphère cultuelle, alors que sur certains sanctuaires, nombre de couteaux ont été découverts autour des temples (Éneau, 2002; Guillier, 2013 et 2020).

Le monde des croyances est représenté par un tintinnabulum (inv. 1132-1, fig. 24) et une hachette (inv. 10131, fig. 24). La sonnaille est un objet commun, aux vertus prophylactiques, qui devait par son tintement éloigner les mauvaises fortunes (Le Cloirec, 2001, p. 54) ou, dans les sanctuaires, attirer l'attention des dieux sur les personnes l'utilisant, être suspendue ou encore liée à un accessoire d'un temple. La hache miniature, avec peu de points de comparaison, pourrait être un ex-voto (Tisserand, 1980; Lejars, 1989) ou une miniature votive (Éneau, 2002, p. 58 et p. 62-63), bien qu'Isabelle Bertrand mette cette hypothèse en doute pour la plus petite des hachettes du Gué-de-Sciaux à Antigny dans la Vienne (Bertrand, 2018, II, p. 525, 574 et 575).

Les militaria, parfois mis en évidence sur les sanctuaires, sont faiblement illustrés régionalement (Lukas, 2014, p. 248-250; Mantel, 1997). À Yville-sur-Seine, on note une extrémité de courroie (inv. 1056-26, fig. 25), traditionnellement liée à l'équipement militaire (Deschler-Erb, 1999, pl. 35-36). 
Tableau 6 : Yville-sur-Seine (76), Le Sablon, répartition de l'instrumentum en fonction des différentes catégories fonctionnelles, puis ventilation en fonction de la provenance sur le site (le nombre d'éléments en fer est indiqué entre parenthèses; NR : nombre de restes) (G. Guillier, Inrap).

Table 6: Distribution of the instrumentum according to categories of function revealed, and according to provenance on the site (the number of elements in iron is indicated in parentheses; NR: number of elements remaining) (G. Guillier, Inrap).

\begin{tabular}{|c|c|c|c|c|c|}
\hline Catégories fonctionnelles & NR & Sanctuaire & Établissement sud & Autre & HS \\
\hline Outillage & 1 & $1(1)$ & & & \\
\hline Huisserie & 1 & $1(1)$ & & & \\
\hline Harnachement & 1 & 1 & & & \\
\hline Cultuel & 2 & $2(2)$ & & & \\
\hline Paléomanufacture & 5 & 5 & & & \\
\hline Parure & 7 & 7 & & & \\
\hline Construction & 14 & 14 & & & \\
\hline Varia & 7 & 7 & & & \\
\hline Écriture & 1 & & $1(1)$ & & \\
\hline Instruments de toilette & 4 & 3 & & 1 & \\
\hline Vaisselle & 1 & & & $1(1)$ & \\
\hline Instruments de mesure & 1 & & & 1 & \\
\hline Ameublement & 4 & 1 & & $1(1)$ & 2 \\
\hline Indéterminé & 6 & $3(1)$ & $2(2)$ & 1 & \\
\hline Domestique & 7 & 2 & $3(3)$ & $2(1)$ & \\
\hline Quincaillerie & 28 & $18(17)$ & $9(9)$ & $1(1)$ & \\
\hline Totaux & 90 & $65(22)$ & $15(15)$ & $8(4)$ & 2 \\
\hline
\end{tabular}

Le domaine personnel est, à Yville-sur-Seine, représenté par deux cuillères-sondes et un fragment de cure-oreilles (fig. 25). Ces instruments sont recueillis en faible nombre sur les sanctuaires où leur statut d'offrande est sujet à caution (Gruel et Brouquier-Reddé, 2003, p. 146). Au sein des accessoires vestimentaires, signalons une épingle à tête polyédrique, attribuable aux $\mathrm{III}^{\mathrm{e}}$ et $\mathrm{IV}^{\mathrm{e}} \mathrm{s}$. et deux fibules de types Feugère $14 \mathrm{~b} 1 \mathrm{~b}$ et $25 \mathrm{a}$. Les éléments de parure sont figurés par un pendant d'oreille en or (mutilé?) et deux bagues en alliage de cuivre. Celle ornée de fines bossettes est d'un type courant sur les sanctuaires en Gaule. Proche du domaine personnel, la toilette est représentée par un fragment de palette à fard en schiste, mais cet objet n'est pas directement lié au sanctuaire. Deux aiguilles se rattachent aussi à cette catégorie.

Les activités économiques et sociales sont illustrées par un stylet en fer (inv. 1001-3, fig. 24), témoignant peut-être dans le cadre de la rédaction de messages aux divinités de l'usage de l'écriture, par un vraisemblable fléau de balance et par une meule en poudingue de production locale ou régionale. Des meules sont présentes autour du sanctuaire des Mureaux à Authevernes (Michel, 2011). Au sein des éléments liés à la construction, ceux en plomb issus des couches de destruction, sauf pour les petits scellements, seraient liés à la présence de blocs de grand appareil. Cinq éléments associés à la paléomanufacture du bronze relèveraient de la fonte ou la refonte sur place de statuaire ou d'éléments décoratifs des temples. L'outillage est figuré par une possible clavette. Le site du Sablon est dans cette catégorie, pauvre par rapport à d'autres sites régionaux (Lukas, 2014; Michel, 2011).

La vie domestique à Yville-sur-Seine est essentiellement matérialisée par les couteaux issus de l'établissement sud (fig. 24), qui seraient à relier à des activités de boucherie ou de découpe (Leconte, 2013). Mais leur découverte n’est pas exceptionnelle. Ils sont connus par exemple à Neuville-surSarthe (Guillier, 2013, 2, p. 144; Guillier, 2020). D'autres sites en ont livrés en grand nombre, au Gué-de-Sciaux dans la Vienne (Éneau, 2002, p. 30-33). Un canif et une poignée plate en fer provenant du comblement d'une fosse complètent cette évocation.

La quincaillerie rassemble de nombreux objets qui peuvent être employés pour de multiples usages, ameublement, charpente, construction, huisserie, menuiserie.... Le clou de menuiserie est l'élément le plus commun sur le site du Sablon, mais un clou long de 150 mm (inv. 1053-1, fig. 24) a pu être mis en œuvre dans la charpente ou sur de gros assemblages. Dans cette catégorie, une patte-fiche, une fiche à brisure et une agrafe peuvent servir à assembler des pièces de bois, en menuiserie par exemple. 


\section{Le SANCtUAire D'Yville-SUR-Seine, DISCUSSION}

Tentons succinctement de replacer ce sanctuaire au sein des données acquises pour ce type de monument dans les départements de la Seine-Maritime et de l'Eure. En effet, le sanctuaire d'Yville-sur-Seine est localisé sensiblement au centre de l'ensemble constitué par ces deux départements ${ }^{5}$, recouvrant l'ancienne Haute-Normandie (fig. 26). En Seine-Maritime, il a été recensé près de 40 sanctuaires et indices de sanctuaires, tandis que dans l'Eure, il en a été inventorié environ 70, ceci grâce à des prospections aériennes particulièrement développées (Provost, Archéo 27, 2019, p. 56-61). Enfin, mentionnons, dans l'Eure, la fouille récente des sanctuaires des Mureaux à Authevernes (Michel, 2011; 2012; 2014; Provost, Archéo 27, 2019, p. 124-127) et du Chemin des Errants à Val-de-Reuil (Lukas, 2014; Aubin et al., 2014, p. 245-246).

Les sanctuaires des départements de la Seine-Maritime et de l'Eure peuvent se situer à proximité d'une rivière ou d'un fleuve, par exemple dans les boucles de la Seine ou sur ses hauteurs (Éloy-Épailly, 2008). Leur implantation peut aussi être liée à la proximité d'agglomérations voire d'une villa (Provost, Archéo 27, 2019, p. 61; Bossard, 2019, p. 81). Enfin, plusieurs sanctuaires marqueraient des limites de territoire comme celui de Berthouville dans l'Eure. Ce serait le cas pour le Sablon, situé possiblement sur la limite de cité entre les Calètes et les Véliocasses (Guyard et al., 2015, p. 192), quoi que cette notion de sanctuaire-limite soit discutée. Le sanctuaire d'Yville-sur-Seine offre ainsi une configuration spécifique : il est localisé au cœur du méandre de la Seine d'Anneville-Ambourville; il domine le fleuve d'où il devait être visible par des bateaux remontant le fleuve; il surplombe une vaste zone marécageuse à l'ouest et il est localisé à $3 \mathrm{~km}$ au sud de la possible agglomération antique d'Anneville-sur-Seine. Mais son environnement immédiat reste largement inconnu.

\section{L'espace sacré}

Dans la région étudiée, le péribole est matérialisé par un fossé ou moins fréquemment, par un mur maçonné. Sur une vingtaine de cas documentés, dix sont définis par des fossés, huit par des murs parfois flanqués d'un portique et un par un aménagement mixte alliant trous de poteaux et fossés. À Fesques (Seine-Maritime), le mur de péribole succède à une palissade en bois dont il ne reste que des trous de poteaux. Mais ce sont les sanctuaires de dimensions petite ou moyenne qui semblent essentiellement limités par des

5. Ces deux départements circonscrivent sensiblement notre zone d'étude, qui rassemble les territoires des Calètes, des Véliocasses, des Aulerques Éburovices ainsi que la moitié orientale du territoire lexovien. fossés. Les grands sanctuaires civiques, publics ou collectifs tels Le Vieil-Évreux, Guichainville, Eu et éventuellement Val-de-Reuil, sont délimités par des murs. À Yville-surSeine, le seul élément nettement attribuable à un péribole est matérialisé par le fossé 1013. La chronologie du sanctuaire recouvrant les $\mathrm{I}^{\mathrm{er}}$, $\mathrm{II}^{\mathrm{e}}$ et $\mathrm{III}^{\mathrm{e}} s$. et le fossé recélant un mobilier pré-flavien, il est possible que cette limite ait continué à marquer le paysage, d'autant que l'établissement sud, occupé de la première moitié du $\mathrm{II}^{\mathrm{e}} \mathrm{s}$. au milieu du $\mathrm{III}^{\mathrm{e}} \mathrm{s}$. (voire légèrement plus tardivement) et situé à l'extérieur du fossé de péribole, vient ponctuellement s'y accoler, voire le fossiliser. Est-il encore possible pour les phases les plus anciennes de rattacher le segment de fossé 1068 (ainsi que 1073 ?) à un premier état de péribole, le fossé 1013 marquant ainsi un second état du péribole? Quoi qu'il en soit, l'évolution parfois admise pour les sanctuaires de quelque importance du péribole fossoyé vers le péribole maçonné, n'est pas vérifiée à Yville-sur-Seine. La longueur du segment de fossé 1013, visible sur plus de $90 \mathrm{~m}$, mais certainement plus long, notamment à l'ouest, suggère une vaste surface enclose et indique la présence d'un sanctuaire collectif. Les dimensions reconnues du péribole d'Yville-sur-Seine classent celui-ci dans la catégorie des grands périboles, la moyenne relevée en Gaule étant d'environ $50 \mathrm{~m}$ de côté (Fauduet, 2010, p. 75). Régionalement, mentionnons les périboles fossoyés 1 et 2, aux plans complets, de SaintMartin-des-Entrées (Calvados), mesurant respectivement 57,5 par $77 \mathrm{~m}$ et 72,5 par $77 \mathrm{~m}$ (Paez-Rezende, Adrian, 2014). Dans le département de l'Eure, lorsqu'elle est mesurable, la surface des aires sacrées avoisine 2500 à $3000 \mathrm{~m}^{2}$ (Provost, Archéo 27, 2019, p. 61; Bossard, 2019, p. 79).

\section{Les temples}

À Yville-sur-Seine, le temple B4 succède au bâtiment B5. L'ensemble E3 est mal défini faute de données suffisantes, mais il est structurellement lié à B4 (fig. 27). S'agit-il d'un édifice à une voire deux cellae ou bien d'une petite esplanade localisée à l'est de $\mathrm{B} 4$ ? La présence d'un mur assez puissant entre les espaces $\mathrm{E} 3$ et $\mathrm{B} 4$ suggère la présence de deux temples accolés. Enfin, malgré des données fragmentaires, les hypothèses de restitution en plan permettent de les comparer aux autres vestiges de l'Eure et de la Seine-Maritime (fig. 28). Ces derniers se rapportent généralement à des sanctuaires à plan centré. Ils se définissent par une cella ceinte d'une galerie de circulation dont les plans sont carrés ou proches du carré, comme sur la majorité des sanctuaires ruraux de la Gaule. Dans de rares occurrences, plusieurs cellae sont ceintes d'une galerie à l'image du site de Guichainville dans l'Eure. Les dimensions des galeries varient majoritairement de 13 à $15 \mathrm{~m}$ de 


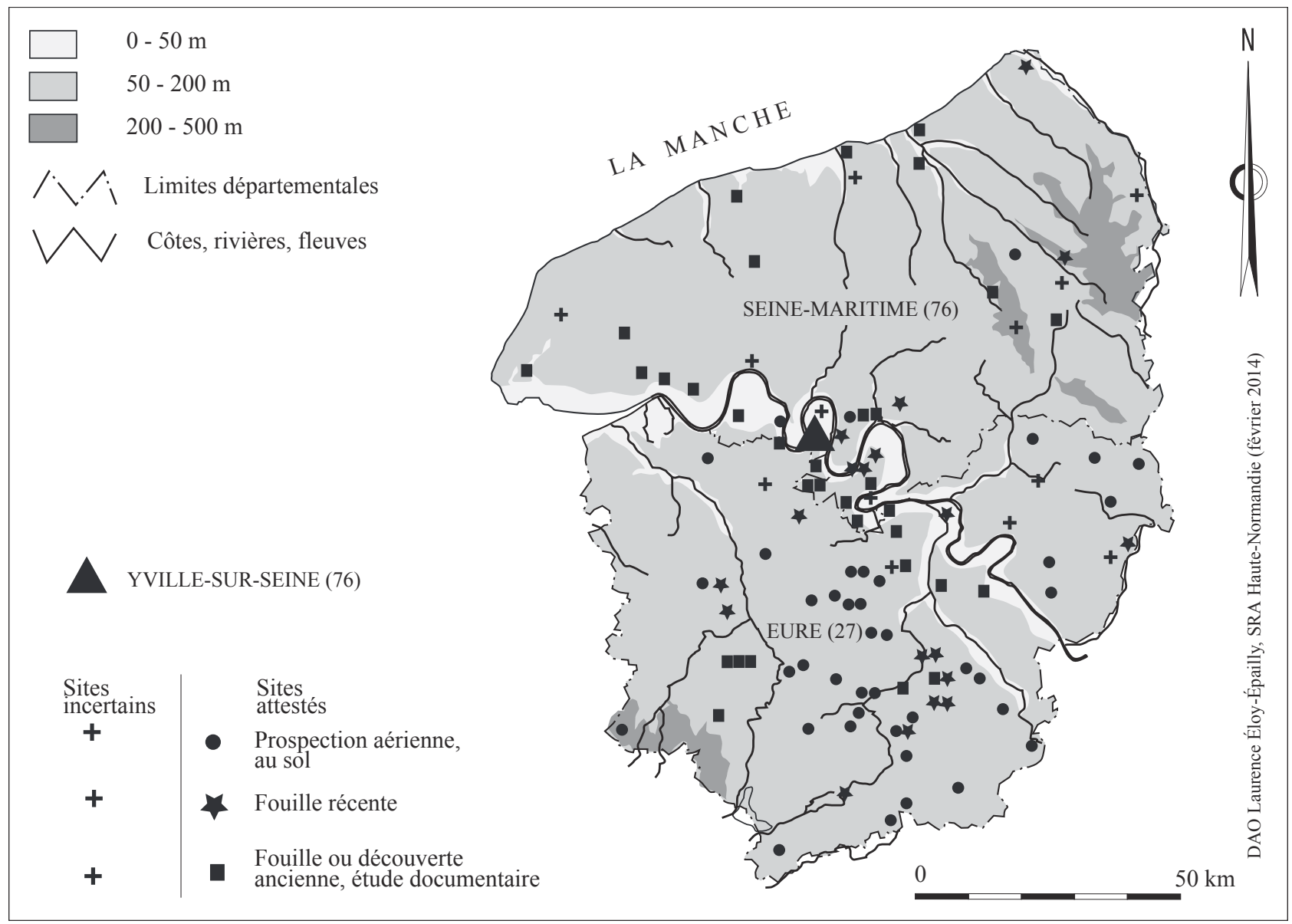

Figure 26 : Les lieux de culte recensés dans l'Eure et en Seine-Maritime (DAO L. Éloy-Épailly, SRA Haute-Normandie). Figure 26: Ancient places of worship registered in the Eure and Seine-Maritime (CAD L. Éloy-Épailly, SRA Haute-Normandie).

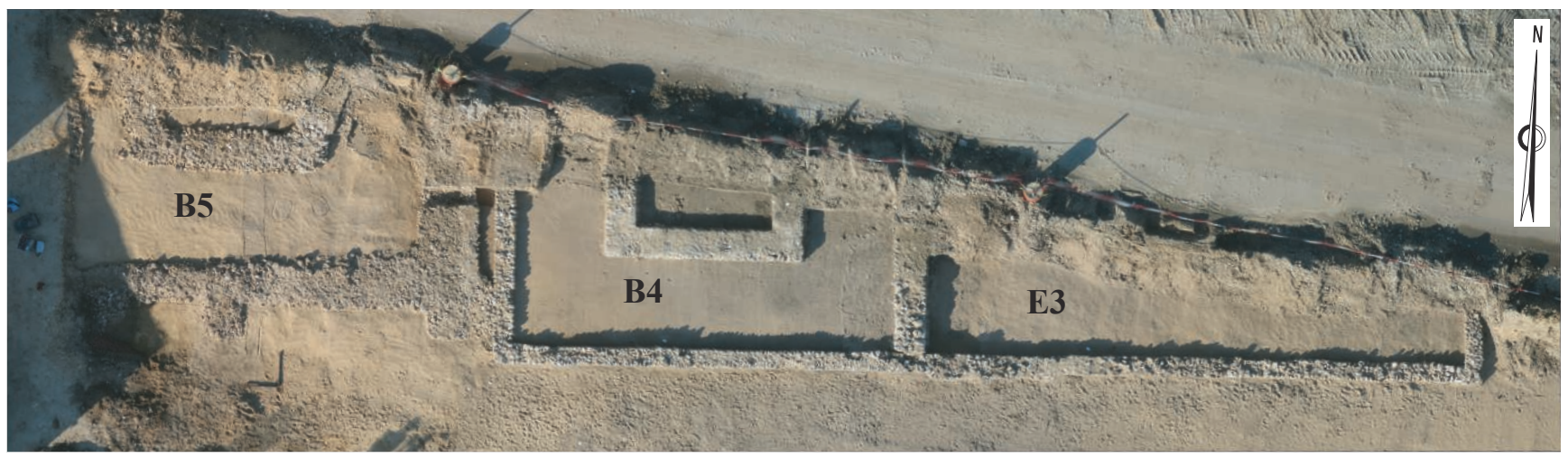

Figure 27 : Yville-sur-Seine (76), Le Sablon, de gauche à droite les bâtiments B5, B4 et E3, vue verticale (cliché R. Bria / Panormandic). Figure 27: From left to right, buildings B5, B4 and E3, vertical view (photo R. Bria / Panormandic).

côté, avec un minimum de 7,70 m à Hecmanville (Eure), quelques exemples étant plus imposants avec 16 à $17 \mathrm{~m}$ de côté à Criquebeuf-sur-Seine (Eure), à comparer avec celles d'Yville-sur-Seine, de 13 par 13,2 m (bâtiment B4) et de 14,2 par 14,2 m (bâtiment B5).
Les cellae mesurent en moyenne $6,50 \mathrm{~m}$ de côté et varient de 5 à $7 \mathrm{~m}$ de côté, avec quelques disparités, allant d'une cella de 4,40 m de côté à Hecmanville (Eure) à des exemples pouvant mesurer de 7,5 à $8 \mathrm{~m}$ de côté à Bracquemont (Seine-Maritime). Les deux cellae d'Yville-sur-Seine, mesu- 


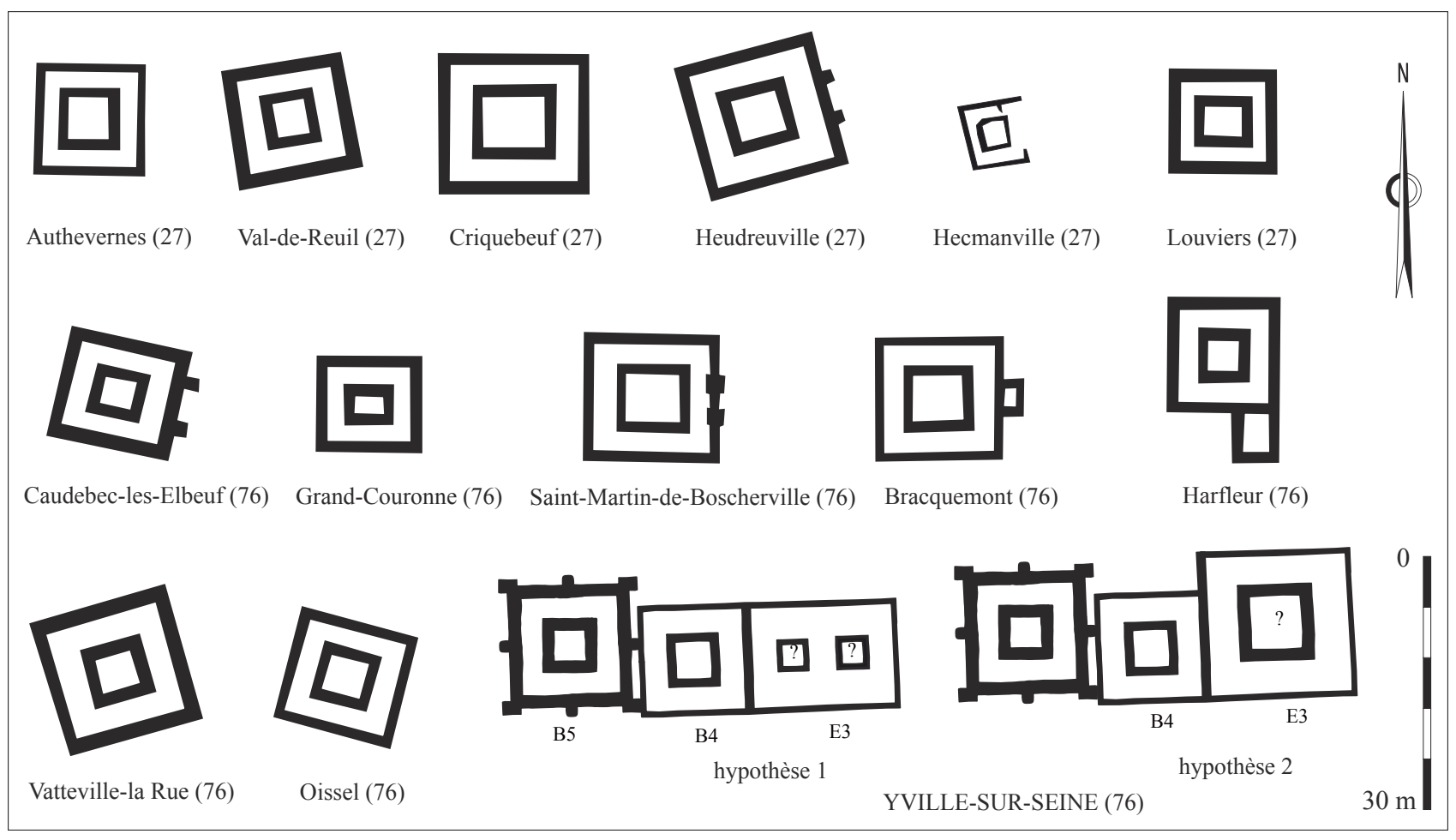

Figure 28 : Présentation d'un choix de temples à plan centré provenant des départements de l'Eure et de la Seine-Maritime (G. Guillier, Inrap). Figure 28: Presentation of a selection of temples with central plan in the Eure and Seine-Maritime (G. Guillier, Inrap).

rant 6 par 6,2 m et 6,3 par 6,3 m, offrent des dimensions entrant dans la moyenne régionale.

Le plan du temple B5 est assez inhabituel. Malgré des fondations puissantes, ce bâtiment présente d'importants contreforts placés aux angles, ainsi qu'au milieu et à l'extérieur de chaque galerie. Leur présence serait due au substrat sableux, jugé peu stable ou bien à celle d'un temple aux élévations imposantes. Ces contreforts sont parfois notés, plus discrètement, ainsi pour l'état 1 d'un temple à JouarsPontchartrain dans les Yvelines (Blin, 2000). Ceux du bâtiment B5, particulièrement bien marqués, offrent peu de points de comparaison. Leur restitution étant purement géométrique, une modulation de ce plan doit être envisagée, notamment en ce qui concerne l'emplacement des contreforts par rapport à l'accès au temple. Un contrefort est localisé au sud de B5, il est donc peu probable que son accès s'effectue par ce côté; est-il possible d'estimer que, comme dans $90 \%$ des cas (Fauduet, 2010, p. 122), l'entrée se faisait à l'est? Pour l'ensemble E3/B4, cette orientation est contradictoire avec les hypothèses de deux temples accolés. Dans ce cas, les accès seraient orientés au nord ou au sud, impliquant un changement d'orientation des temples successifs.

L'épaisseur des murs de la cella est souvent plus importante que l'épaisseur de ceux de la galerie (Fauduet, 2010, p. 126).
Cette remarque se vérifie pour le temple B4, mais pas pour B5 où ils sont de largeur équivalente. Le mur séparant B4 de l'ensemble E3 est, lui, épais et plus fondé que ceux placés à l'est et sud de la galerie de E3, légitimant l'hypothèse qu'il devait supporter conjointement les galeries de B4 et de E3, et invalider l'hypothèse 3, d'une cour ou d'une esplanade pour E3.

Les matériaux employés dans la construction des fondations, le calcaire et le silex, sont d'origine locale. Les affleurements sont nombreux dans les falaises et sur les pentes qui marquent les rives de la Seine à quelques kilomètres au sud du site.

La couverture des temples se faisait, comme majoritairement en Gaule, en imbrices et tegulae. Si la majorité des tuiles sur le site sont de couleur orangée à rouge, d'autres sont de teinte beige clair, blanc-beige ou beige-rosé clair. Les toitures pouvaient ne pas présenter toutes la même monochromie orangée à rouge, caractéristique de la période antique, mais parfois offrir un ton plus beige, presque crème.

Aucun sol ou remblai de sol en place n'a été mis en évidence dans les temples. En revanche, huit restes de dallage de sol en calcaire, épais de 20 à $35 \mathrm{~mm}$, sont issus essentiellement des couches de destruction (1056, 1124, 1125, 1132 et 1135). Il a ainsi été identifié un calcaire local à cérithes (Lutétien). Le décor du sanctuaire est seulement connu par de rares petits 
fragments d'enduits peints, de teinte rouge ou blanche, issus des couches de destruction de l'ensemble E3/B4.

\section{La chronologie du sanctuaire}

La chronologie est loin d'être précisément établie. Les premières occupations regroupent les éléments antérieurs au sanctuaire en activité aux $\mathrm{I}^{\mathrm{er}}, \mathrm{II}^{\mathrm{e}}$ et $\mathrm{III}^{\mathrm{e}}$ s. et il est possible qu'elles ne soient pas synchrones et ne relèvent pas d'un lieu de culte, à l'image de la fosse 1075. Les vestiges sont incomplets et morcelés, déconnectés entre eux, et ont livré peu ou pas de mobilier archéologique. En revanche, les fossés 1068 et 1073 renvoient possiblement aux limites sud d'une ou plusieurs aires sacrées d'un premier sanctuaire. Dans le département de l'Eure, les premiers temples maçonnés apparaîtraient à la période augustéenne (Bossard, 2019, p. 80). Les premières occupations de ce type au Sablon pourraient relever de cette époque.

$\mathrm{Si}$, régionalement, des occupations antérieures aux sanctuaires antiques sont constatées à Berthouville (Eure), Bracquemont ou Eu (Seine-Maritime), leur nature religieuse n'est pas toujours avérée (Éloy-Épailly, 2008). Relevons un site cultuel gaulois préexistant au sanctuaire antique aux Mureaux à Authevernes dans l'Eure (Michel, 2011; 2012, p. 93-95). Parfois, un sanctuaire succède à une ferme indigène, ainsi le site de la Martinière à Nécy dans l'Orne (Besnard-Vauterin et al., 2013). À Saint-Martin-des-Entrées (Calvados), le site cultuel est implanté, après un hiatus d'environ un siècle, sur un enclos d'habitat et un parcellaire de La Tène moyenne/finale (Paez-Rezende et Adrian, 2014, p. 263-264). Ces quelques exemples, qui demandent à être complétés, n'indiqueraient pas de schéma préétabli d'implantation des sanctuaires.

Aux éléments précédents succède, à partir du milieu du $\mathrm{I}^{\mathrm{er}}$ s., au $\mathrm{II}^{\mathrm{e}}$ s. et jusqu'au $\mathrm{III}^{\mathrm{e}}$ s., un ensemble un peu plus complet, légèrement mieux conservé et suffisamment structuré pour envisager précisément sa nature cultuelle, mais il est toujours aussi mal daté. Le premier point d'accroche chronologique est le fossé 1013, localisé au sud des temples B5 et E3/B4, et comblé vers le milieu du i ${ }^{\text {er }}$ s. apr. J.-C.

Le second point est constitué des couches de destruction du sanctuaire. Au temple B5 succède l'ensemble E3/B4, sans plus de précision autre que relative. La chronologie de l'abandon et de la destruction du sanctuaire est liée à la présence de plusieurs couches de destruction. Au mieux, celles localisées dans les temples sont datées de la première moitié et du milieu du $\mathrm{III}^{\mathrm{e}} \mathrm{s}$., tandis que celles identifiées au sud (US 1056 et 1086), regroupent de la céramique des $\mathrm{I}^{\mathrm{er}}$, $\mathrm{II}^{\mathrm{e}}, \mathrm{III}^{\mathrm{e}}$ et $\mathrm{IV}^{\mathrm{e}}$ s. ainsi qu'un lot monétaire allant d'Octave à Valentinien II. Les modalités d'abandon et de récupération des matériaux du sanctuaire sont inconnues.

\section{L'établissement sud est-il contemporain du sanctuaire?}

L'approche chronologique du sanctuaire se fait également par celle de l'établissement sud, occupé de la première moitié $\mathrm{du} \mathrm{II}^{\mathrm{e}}$ s. au milieu du $\mathrm{III}^{\mathrm{e}}$ s., voire légèrement plus tardivement. Un semis de fosses se superpose par la suite à cet établissement. Ces deux occupations marquent l'importance spatiale du fossé 1013. Aux II et III s., ce fossé sert d'appui à l'implantation de l'établissement sud et dessine une limite où s'égrène le semis de fosses. À la vue des hypothèses émises sur la chronologie du sanctuaire, on peut émettre celle de la contemporanéité du sanctuaire et de l'ensemble sud. Des échoppes d'artisans ou de commerçants, des établissements liés au repos des pèlerins, à la préparation de banquets ou de nourriture pour les pèlerins, l'habitat d'un gardien, sont parfois mentionnés autour des sanctuaires (Fauduet, 2010, p. 91) : Baron-sur-Odon et Vieux dans le Calvados, Saint-Marcel dans l'Indre, Isle-etBardais dans l'Allier (Laüt, 2012) ou encore Pannes dans le Loiret (Dondin-Payre et Cribellier, 2011).

Sans beaucoup de points de comparaison en Gaule, surtout en ce qui concerne le double enclos fossoyé et son bâtiment sur poteaux (E2), il est possible de voir dans cet établissement, non seulement un élément fixant les limites du sanctuaire, mais aussi marquant une évolution d'un péribole fossoyé vers une ou des structures utilitaires souvent maçonnées à l'image du sanctuaire d'Authevernes dans l'Eure (Michel, 2014; Provost, Archéo 27, 2019, p. 126-127) ou de Saint-Denis-du-Maine en Mayenne (Séris, 2015). À titre d'hypothèse, il est envisageable que le bâtiment B1 marque l'angle sud-est de la zone sacrée.

\section{CONCLUSION}

Seule la fraction sud d'un sanctuaire, en plus ou moins bon état de conservation et affecté par des phénomènes de récupération, d'érosion et de déplacement des matériaux a pu être examinée. Un autre point faible est l'indigence du mobilier céramique, réduit à moins d'un millier de tessons.

Cette fouille distingue une succession de temples. Ceux des premières occupations sont mal caractérisés, tandis que ceux élevés à partir de l'époque flavienne le sont mieux, même s'ils sont incomplets. Au sein d'un vaste péribole, se succèdent le temple B5 puis l'ensemble E3/B4. Le premier, avec ses contreforts, présente un plan original régionalement. Le second pose quelques problèmes de restitution de son plan d'origine, notamment en ce qui concerne l'ensemble E3.

Pour autant, ce sanctuaire, dans son état le mieux perçu, couvre une surface assez importante suggérant plutôt un usage collectif, voire public. 
Les monnaies des $\mathrm{I}^{\mathrm{er}}$ et $\mathrm{II}^{\mathrm{e}}$ s., peu nombreuses, signeraient non une faiblesse de la fréquentation du site (Golosetti, 2019), mais l'indice de nettoyages du sanctuaire. D'autres hypothèses sont aussi évoquées, par exemple celle lié à la récupération des dépositions, désormais mieux encadrées et matérialisées par des troncs monétaires (Izri, 2011).

Celles plus tardives peuvent être mises en parallèle avec une enquête récente (Aubin et al., 2014, p. 222-231) qui détaille l'utilisation des monnaies en tant que fossile directeur sur les sanctuaires du $\mathrm{III}^{\mathrm{e}}$ au $\mathrm{V}^{\mathrm{e}}$ s., tout en insistant sur les difficultés d'un tel exercice. Le site du Sablon relèverait de la phase 3 de la chronologie qui y est proposée. Il a été remarqué que quatre des cinq sanctuaires « ruraux » caractéristiques de cette phase 3 tardive (Aubin et al., 2014, p. 222, 231) présentant des monnaies s'échelonnant entre 378 et 388 , sont localisés en bord de Loire (Chênehutte-les-Tuffeaux), et surtout en bord de Seine (La Londe, Oissel et Criquebeuf-sur-Seine), sans que l'on sache si cela est dû à un déterminisme religieux, géographique ou autre. Le site d'Yville-sur-Seine ajoute un point complémentaire à cette concentration de sites cultuels occupés tardivement dans les boucles de la Seine.

Est-il également possible de relever, dans ces monnaies tardives (Aubin et al., 2014, p. 231), avec un lot de monnaies de Valens et de Gratien (voir de Valentinien II), datable des années 367-375 jusqu'en 392 (avec des dates estimatives de perte de 367-420 à 388-450), d'ultimes témoins de pratiques cultuelles possiblement contemporaines de l'abandon officiel et de la destruction du temple (Bertrand, 2018, p. 997-998; Golosetti, 2019) ou même postérieures à sa destruction? Ou bien faut-il y voir les marques d'activités plus profanes, récupération des matériaux, réutilisation des lieux comme habitat pérenne ou non... ? Quoi qu'il en soit, les 54 monnaies antiques découvertes, sont essentiellement de faibles dénominations, dupondius, as, semis, antoniniens (parfois de faible poids, jusqu'à $0,21 \mathrm{~g}$ : cat. $\mathrm{n}^{\circ} 24$ ), quelques nummi, des aes 3 ou 4 et enfin une maiorina et une demi-maiorina.

Enfin, dernier avatar de l'occupation antique du site du Sablon, le semis de fosses reprenant sensiblement le tracé du fossé 1013, pose la question ouverte de sa nature. Elles sont identifiées sur certains sanctuaires tel Pannes dans le Loiret (Dondin-Payre et Cribellier, 2011; Fauduet, 2014, p. 64), tandis que régionalement des parallèles sont mentionnés à Authevernes dans l'Eure (Michel, 2011; 2012; 2014; Provost, Archéo 27, 2019, p. 127) et à Nécy, La Martinière dans l'Orne (Besnard-Vauterin et al., 2013, p. 208 et 209). Ces semis de fosses matérialisent alors la dernière occupation structurée des sites. Est-il possible d'y déceler les dernières traces cultuelles, car elles recèlent des éléments de destruction mêlés à des reliefs de repas, des détritus d'habitat ou autres et parfois des offrandes (ainsi les monnaies issues des US de destruction) (Provost, Archéo 27, 2019, p. 126-127 et fig. 67), ces éléments matérialisant les derniers avatars cultuels avec des rites de clôture puis d'enfouissement? Ces dernières traces de manifestations religieuses trouveraient par exemple un écho, mais sous une forme différente, au sanctuaire du Gué-de-Sciaux, où les activités cultuelles, notamment matérialisées par des rejets de monnaies, sont contemporaines de la destruction du grand temple principal (Bertrand, 2018, V. 1, p. 479-481 et V. 2 p. 997-998). Cet auteur note la présence d'objets personnels dans ces couches tardives, à l'image de la plaquette à fard rejetée dans la fosse 1065 .

\section{Remerciements}

Nos remerciements vont en premier lieu aux agents du SRA de Normandie qui se sont investis pleinement pour nous aider, $\mathrm{M}^{\mathrm{me}}$ Éloi-Épailly, pour la documentation qu'elle a aimablement mise à notre disposition (Éloy-Épailly, 2008) et M. Fajon, qui a géré le dossier au SRA. Remercions aussi grandement les agents de terrain de l'Inrap qui se sont tout autant investis lors de la fouille, $\mathrm{M}^{\text {me }}$ Santiago et MM. Beugnet, Cottard, Chantreuil, Grancha, Le Borgne et Calduch pour la topographie. N'oublions pas R. Delage de l'Inrap qui a identifié la céramique sigillée.

\section{Bibliographie}

Adrian Y.-M., 2001 - « La céramique du Haut-Empire dans la région d'Évreux (Eure) : première approche du répertoire et de ses approvisionnements ", Revue archéologique de l'Ouest, 18, p. 95-143.

Adrian Y.-M., 2011 - Isneauville - Saint-Martin-du-Vivier "ZAC de la Plaine de la Ronce " (Seine-Maritime, Haute-Normandie) : une ferme gauloise puis gallo-romaine et une nécropole antique, rapport de fouilles, Cesson-Sévigné, Inrap Grand-Ouest, 3 vol.

Adrian Y.-M., Féret L., 2014 - « La céramique du Haut-Empire dans la région d'Évreux (Eure) : nouvelle approche ", dans RIVET L. (éd.), Actes du congrès de Chartres de la Société Française d'Étude de la Céramique Antique en Gaule, Marseille, SFECAG, p. 197-244.

Adrian Y.-M., Lukas D., 2015 - Val-de-Reuil "Le Chemin aux Errants »-zone C (Eure, Haute-Normandie), vol. II : Une villa à plan axial du Haut-Empire et un habitat tardo-antique entre Seine et Eure, textes et illustrations, rapport de fouille archéologique, Cesson-Sévigné, Inrap Grand-Ouest.

Aubin G., Monteil M., Éloy-Épailly L., Le Gaillard L., 2014 "Sanctuaires et pratiques religieuses du $\mathrm{III}^{\mathrm{e}}$ au v $\mathrm{v}^{\mathrm{e}}$ s. apr. J.-C. dans l'ouest de la province de Lyonnaise et de ses marges ", dans VAN ANDringa W. (dir.), La fin des dieux. Les lieux de culte du polythéisme dans la pratique religieuse du III au v's. apr. J.-C. (Gaules et provinces occidentales), Paris, CNRS Éditions (Gallia, 71, 1), p. 219-248. 
BASTIEN P., 1976 - Le monnayage de l'atelier de Lyon. De la réouverture de l'atelier par Aurélien à la mort de Carin (fin 274-mi 285), Wetteren, Édition Numismatique Romaine, 287 p., 63 pl.

Bayard D., Lemaire P., 2014 - «Les vestiges de l'Antiquité sur les grands tracés linéaires en Picardie ", dans Bayard D., Buchez N., Depaepe P. (dir.), Quinze ans d'archéologie préventive sur les grands tracés linéaires en Picardie, seconde partie, Paris, Société préhistorique française (Revue archéologique de Picardie, 3, 4), p. 7-232.

Ben Redjeb T., 1992 - "Production et consommation de la céramique gallo-belge en Picardie et en Champagne », dans Rivet L. (éd.), Actes du congrès de Tournai de la Société Française d'Étude de la Céramique Antique en Gaule, Marseille, SFECAG, p. 47-57.

Bertrand I. (dir.), 2018 - Le sanctuaire du Gué-de-Sciaux à Antigny (Vienne, FR) : genèse et évolution d'un lieu de culte picton ( $I^{r}$ s. av. J.-C.-IV s. apr. J.-C.), Chauvigny, Association des Publications Chauvinoises (Mémoire L), vol. I : p. 1-498, vol. II, p. 499-1025.

Besly E., Bland R., 1983 - The Cunetio Treasure. Roman Coinage of the Third Century AD, Londres, British Museum Publications, 199 p., 40 pl.

Besnard-Vauterin C.-C., Besnard M., Corde D., Féret L., Manson A.-L., Savary X., 2013 - «Un habitat de la fin de la période gauloise et un fanum du Haut-Empire à Nécy "La Martinière" (Orne) ", Revue archéologique de l'Ouest, 30, p. 187222.

Besson C., 2015 - «Un autre regard sur la bijouterie en or de Lyon (Rhône, France) », dans Raux S., Bertrand I., Feugère M. (dir.), Actualité de la recherche sur les mobiliers non céramiques de l'Antiquité et du haut Moyen Âge, actes de la table ronde européenne instrumentum, Lyon, Montagnac/Chauvigny, Éditions M. Mergoil/ Association des Publications Chauvinoises (Monographies instrumentum, 51), p. 555-576.

Beurion C., 2012 - Val-de-Reuil "Le Clos Saint-Cyr, La Cerisaie ", ZAC des Portes (Eure, Haute-Normandie). Une succession d'occupations rurales du Néolithique au Haut-Empire, rapport final d'opération, Cesson-Sévigné, Inrap Grand-Ouest, 2 vol.

Beurion C., 2013 - Yville-sur-Seine, Seine-Maritime. Le Sablon (carrière $C B N$ ), rapport de diagnostic, Cesson-Sévigné, Inrap GrandOuest, $67 \mathrm{p}$.

Blancquaert G., Rougier R., Desfosses Y., 1996 - Les gisements protohistoriques sur le tracé autoroutier A 29 (Le Havre-Saint-Saëns), document final de synthèse, Rouen, SRA de Haute-Normandie.

Blancquaert G., Adrian Y.-M., 2006 - « Les occupations multiples de la plaine du Bosc Renault à Hautot-le-Vatois (SeineMaritime) : la zone de stockage du premier âge du Fer et les vestiges antiques funéraires et domestiques ", Revue archéologique de l'Ouest, 23, p. 9-44.

Bland R., Burnett A., 1988 - "Normanby, Lincolnshire : 47909 Radiates to 289 ", dans Bland R., Burnett A. (dir.), The Normanby Hoard and Other Roman Coin Boards. Coin Hoards from Roman Britain, VIII, p. 114-215.
Blin O., 2000 - «Un sanctuaire de vicus : Jouars-Pontchartrain (Yvelines)", dans VAn Andringa W. (éd.), Archéologie des sanctuaires en Gaule romaine, Publications de l'université de SaintÉtienne, (Centre Jean-Palerme, Mémoires, XXII), p. 91-117.

Bossard S., 2019 - «La religion ", dans Provost M., Archéo 27, 2019 - L'Eure 27/2, Carte archéologique de la Gaule, Paris, Académie des Inscriptions et Belles-Lettres, p. 78-83.

Bourgeors L. (dir.), 1999 - Le sanctuaire rural de Bennecourt (Yvelines). Du temple celtique au temple gallo-romain, Paris, Éditions de la Maison des sciences de l'homme, 220 p. (Document d'Archéologie Française, 77).

BruUn P.-M., 1966 - The Roman Imperial Coinage, VII. Constantine to Licinius, Londres, Spink and Son Ltd, 778 p., 24 pl.

Burnett A., Amandry M., Ripollès P.-P., 1995 - The Roman Provincial Coinage, I. From the death of Caesar to the death of Vitellius (44 BC-AD 69), Londres/Paris, Bibliothèque nationale de France/The British Museum Press, vol. I : Introduction and Catalogue, 734 p.; vol. II : Indexes and Plates, 82 p., 195 pl.

Deschler-Erb E., 1999 - Ad Arma! Römisches Militär des 1. Jahrhunderts n. Chr. in Augusta Raurica, Augst, Römerstadt Augusta Raurica, 189 p., 46 pl. (Forschungen in Augst, 28).

Dondin-Payre M., Cribellier C., 2011 - «Un ex-voto oculaire inscrit trouvé au Clos du Détour à Pannes (Loiret), sanctuaire du territoire sénon ", Revue archéologique du Centre de la France, 50, p. $558-568$.

Duplessy J., 1989 - Les Monnaies Françaises Royales de Hugues Capet à Louis XVI (987-1793), Paris/Maastricht, Éditions Platt et A. G. Van der Dussen, t. 2, 350 p.

Duvauchelle A., 2005 - Les outils en fer du musée romain d'Avenches, Avenches, Association Pro Aventico, 232 p. (Documents du Musée romain d'Avenches, 11).

Elmer G., 1941 - « Die Münzprägung der gallischen Kaiser in Köln, Trier und Mailand ", Bonner Jahrbücher, 146, p. 1-106, pl. 1-12.

Éloy-Épailly L., 2008 - Sanctuaires et lieux de cultes, manuscrit rédigé à l'occasion des bilans régionaux des connaissances, $20 \mathrm{p}$.

ÉNEAU T., 2002 - Les objets en fer du sanctuaire gallo-romain du Gué-deSciaux (Antigny, Vienne), Chauvigny, Association des Publications Chauvinoises, 114 p. (Mémoire XXI).

Étienne R., Rachet M., 1984 - Le Trésor de Garonne. Essai sur la circulation monétaire en Aquitaine à la fin du règne d'Antonin le Pieux (159-161), Bordeaux, Fédération Historique du Sud-Ouest, 465 p., 78 pl.

FAuduet I., 1992 - Musée d'Évreux, collections archéologiques, bronzes gallo-romains, Instrumentum, Argenton-sur-Creuse, imprimerie Le Trépan, $171 \mathrm{p}$.

FAUdUET I., 1993 - Atlas des sanctuaires romano-celtiques de Gaule. Les fanums, Paris, Éditions Errance, 140 p. (Archéologie Aujourd'hui).

Fauduet I., 2010 - Les temples de tradition celtique, Paris, Éditions Errance, 351 p. (Hespérides). 
FAuduet I., 2014 - Dieux merci! Sanctuaires, dévots et offrandes en Gaule romaine, catalogue de l'exposition tenue à Argentomagus (Indre), musée d'Argentomagus, $112 \mathrm{p}$.

Feugère M., 1985 - Les fibules en Gaule méridionale, de la Conquête à la fin du vs. apr. J.-C., Paris, CNRS, suppl. à la Revue archéologique de Narbonnaise, 12, 509 p.

Flotté P., LÉOn G., Richard J.-M., Adrian Y.-M., 1996 - Le sanctuaire gallo-romain du Devant de la Garenne et son environnement - Guichainville (27306 005) Eure, document final de synthèse de fouille programmée, Rouen, SRA de Haute-Normandie, 105 p.

Foucray B., Hollard D., 1995 - « Le trésor multiple de deniers et d'antoniniens de Cravent (Yvelines) ", Trésors monétaires, XV, p. 71-114 et pl. VIII à XIII.

Golosetti R., 2019, « La stips des Alpes à la Méditerranée : interpréter la présence des monnaies dans les sanctuaires d'époque romaine ", Gallia, 76, 2, p. 121-163.

Gricourt D., 1998 - «Les émissions Victoriae Dd Auggq Nn de Trèves : séquence et chronologie ", Revue suisse de Numismatique, 77, p. 127-139.

GRICOURT D., 1999 - « La trouvaille de monnaies constantiniennes de La Chapelle-lès-Luxeuil (ensemble 1) », Trésors monétaires, XVIII, 140 p., 13 pl.

Gricourt D., 2000 - Ripostiglio della Venèra. Nuovo catalogo illustrato IV. Caro - Diocleziano, Rome, Éditions L'Erma di Bretschneider, 4, 262 p., $60 \mathrm{pl}$.

Gruel K., Brouquier-Reddé V., 2003 - Le sanctuaire de Mars Mullo, Allonnes (Sarthe), Le Mans, Éditions de La Reinette, 191 p.

Guillier G., 2013 - Neuville-sur-Sarthe (72) «Le Chapeau » : le sanctuaire gaulois et gallo-romain du Chapeau à Neuville-sur-Sarthe, rapport d'opération de fouille préventive, Cesson-Sévigné, Inrap Grand-Ouest, vol. I, 430 p., vol. II, 397 p.

Guillier G. (dir.), 2020 - Le sanctuaire du Chapeau (Neuville-surSarthe). Evolution d'un complexe cultuel en territoire cénoman du If s. av. J.-C. au IIt s. apr. J.-C. Paris, Inrap/CNRS Éditions 304 p. (Recherches Archéologiques, 19).

Guillier G., Biard M., ChÉrel A.-F., 2005 - «Un atelier augustéen de taille de meules en poudingue au "Clos des Forges " à Avrilly (Eure) ", Revue archéologique de l'Ouest, 22, p. 199-220.

Guillier G., Beurion C., Brossard L., Delage R., Féret L., Pilon F., 2016 - Yville-sur-Seine (76). Un sanctuaire rural galloromain au cour d'une boucle de la Seine, rapport d'opération de fouille préventive, Cesson-Sévigné, Inrap Grand-Ouest, 242 p.

Guiraud H., 1989 - «Bagues et anneaux à l'époque romaine en Gaule », Gallia, 46, p. 173-211.

Guyard L., Lepert T., 1999 - « Renaissance d'une ville sanctuaire gallo-romaine : Le Vieil-Évreux ", Archaeologia, 359, p. 20-29.

Guyard L., Bertaudière S., Cormier S., Hartz C., CarvalheiroFereira F., Wech P., Fontaine C., 2015 - « Le Vieil-Évreux (Eure), ville-sanctuaire? ", dans Dechezleprêtre T., Gruel K., Joly M. (dir.), Agglomérations et sanctuaires, réflexions à partir de l'exemple de Grand, actes du colloque de Grand (20-23 octobre 2011),
Épinal, conseil départemental des Vosges, (Archéologie et territoire, 2), p. 191-238.

Halbout P., Pilet C., Vaudour C., 1987 - Corpus des objets domestiques et des armes en fer de Normandie. Du I $^{r}$ au XV s., Caen, Centre archéologique de Normandie, 255 p. (Cahier des Annales de Normandie, 20).

Hartley B. R., Dickinson B. M., 2008-2012 - Names on Terra Sigillata. An index of makers' stamps and signatures on gallo-roman terra sigillata (samian ware), Londres, Institute of Classical Studies, 9 vol.

Hollard D., Pilon F., 2007 - « Le trésor et les monnaies de site de l'"Espace du Palais" à Rouen (Seine-Maritime) ", Trésors monétaires, XXII, p. 57-118, 6-10.

IZRI S., 2011 - «Usages rituels de la monnaie », dans ReDDÉ M., Barral P., Favory F., Guillaumet J.-P., Joly M., Marc J.-Y., Nouvel P., Nuninger L., Petit C., Aspects de la romanisation dans l'est de la Gaule. Glux-en-Glenne, Bibracte, Centre archéologique européen, «Bibracte, 21 », vol. 2, p. 639-654.

Kent J. P. C., 1981 - The Roman Imperial Coinage, VIII. The family of Constantine I, Londres, Spink \& Son, 605 p., 28 pl.

LAÜT L., 2012 - «Premier bilan des recherches au sanctuaire des Petits Jardins à Isle-et-Bardais, en forêt domaniale de Tronçais (Allier) ", dans Cazanove O. (de), Méniel P. (dir.), Etudier les lieux de culte de Gaule romaine, actes de la table ronde de Dijon (18-19 septembre 2009), Montagnac, Éditions M. Mergoil (Archéologie et Histoire romaine, 24), p. 181-196.

Le Cloirec G., 2001 - Les bronzes antiques de Corseul (Côtes-d'Armor), Montagnac, Éditions M. Mergoil, 173 p. (Monographies Instrumentum, 18).

Leconte L., 2013 - «L'instrumentum métallique lié à la cuisine en Gaule romaine ", dans Mauné S., Monterx N., Poux M. (dir.), Cuisines et boulangeries en Gaule romaine, Paris, CNRS Éditions (Gallia, 70, 1), p. 233-251.

LEJARs T., 1989 - « Les armes des sanctuaires poitevins d'époque préromaine de Faye-l'Abbesse (Deux-Sèvres) et de Nalliers (Vendée) ", Gallia, 46, p. 1-41.

Le Maнo J., 1995 - «Le fanum de l'abbaye Saint-Georges à SaintMartin-de-Boscherville (Seine-Maritime) », Haute-Normandie archéologique, III, p. 75-89.

Lukas D., 2014 - Val-de-Reuil "Le Chemin aux Errants " zone A, "Les Sablons", "La Salle " (Eure, Haute-Normandie) : du sanctuaire à l'habitat gallo-romain, rapport de fouille, Cesson-Sévigné, Inrap Grand-Ouest, 2 vol.

Mangard M., 2008 - Le sanctuaire gallo-romain du Bois l'Abbé à Eu (Seine-Maritime), Revue du Nord, hors-série (Art et Archéologie), $12,301 \mathrm{p}$.

Mantel E. (dir.), 1997 - Le sanctuaire de Fesques « Le Mont du Val aux Moines » (Seine-Maritime), Berck-sur-Mer, CRADC, Nord-Ouest Archéologie, 8, 359 p.

Mattingly H., Sydenham E. A., 1926 - The Roman Imperial Coinage, vol. II.: Vespasian to Hadrian, Londres, Spink \& Son, 565 p., 16 pl. 
Mattingly H., Sydenham E. A., 1930 - The Roman Imperial Coinage, vol. III.: Antoninus Pius to Commodus, Londres, Spink \& Son, 514 p., 16 pl.

Mattingly H., Sydenham E. A., Sutherland C. H. V., 1936, 1938, 1949 - The Roman Imperial Coinage, IV. Pertinax to Uranius Antoninus, Londres, Spink \& Son, 1936, 399 p., 16 pl. (1); 1938, 215 p., 13 pl. (2); 1949, 246 p., 16 pl. (3).

Mermet C., 1993 - « Le sanctuaire gallo-romain de Châteauneuf (Savoie) ", Gallia, 50, p. 95-138.

Michel M., 2011 - Authevernes "Les Mureaux ». Haute-Normandiel Eure (27), rapport de fouilles d'archéologique préventive, Le Petit Quevilly, Archéopole, vol. 1 : Texte; vol. 2 : Annexes.

Michel M., 2012 - «Authevernes "Les Mureaux” (Eure) : le sanctuaire antique, approche chronologique et pratiques cultuelles ", Journées archéologiques de Haute-Normandie, Évreux, 6-8 mai 2011, Mont-Saint-Aignan, Presses universitaires de Rouen et du Havre, p. 91-106.

Michel M., 2014 - « Pratiques religieuses dans un sanctuaire véliocasse. Les Mureaux à Authevernes (Eure) ", Gallia, 71-2, p. 189259.

Monteil M., Maligorne Y., Aubin G., Besombes P.-A., Bouvet J.-P., Guitton D., Levillayer A., Mortreau M., Thébaud S., Saget Y., 2009 - « Le sanctuaire gallo-romain de Vieille-Cour à Mauves-sur-Loire (Loire-Atlantique) : bilan des connaissances ", Revue archéologique de l'Ouest, 26, p. 153-188.

Mouquin E., Rossier E., 2011 - «Les haches miniatures du canton de Fribourg ", Cahiers d'Archéologie Fribourgeoise, 13, p. 112-125.

PAez-Rezende L., Adrian Y.-M., 2014 - « Le sanctuaire gallo-romain de La Pièce des Côtelets à Saint-Martin-des-Entrées (Calvados) ", Revue archéologique de l'Ouest, 31, p. 251-287.

Pearce J. W. E., 1933 - The Roman Imperial Coinage, IX. Valentinian I - Theodosius I, Londres, Spink \& Son, 334 p., 16 pl.

Pilon F., 2011 - «La "Date Estimative de Perte" d'une monnaie : une aide à la datation des contextes archéologiques et de leurs mobiliers ", dans VAN Ossel P. (dir.), Bertin P. (collab.), SÉGuier J.-M. (collab.), Les céramiques de l'Antiquité tardive en Île-de-France et dans le Bassin parisien, vol. II : Synthèses (Diœcesis Galliarum, Document de travail, 9), Nanterre, p. 1-12.

PILON F., 2012 - " L'occupation aux abords nord et sud de l'ensemble cultuel central gallo-romain de Châteaubleau (Seineet-Marne) : structuration de l'espace et périodisation ", Revue archéologique d'Île-de-France, 5, p. 99-124.

Poey d'Avant F., 1858-1862 - Monnaies féodales de France, Paris, Chez Camille Rollin, t. I, 368 p., t. 2, 419 p., t. 3, 471 p., 163 pl.

Pommeret C. (dir.), 2001 - Le sanctuaire antique des Bolards à NuitsSaint-Georges (Côte-d'Or), Revue archéologique de l'Est, 16 suppl., $410 \mathrm{p}$.

Poux M., Demierre M. (dir.), 2015 - Le sanctuaire de Corent (Puy-deDôme, Auvergne). Vestiges et rituels, Paris, CNRS Éditions (Gallia, $62^{\mathrm{e}}$ suppl.), $707 \mathrm{p}$.
Prou M., 1892 - Catalogue des monnaies françaises de la bibliothèque nationale. Les monnaies mérovingiennes, Paris, Rollin et Feuardent, 630 p., 36 pl.

Provost M., Archéo 27, 2019 - L'Eure 27/2, Carte archéologique de la Gaule, Paris, Académie des Inscriptions et Belles-Lettres, 832 p.

Rıна E., 1980 - «Der gallorömische Tempel auf der Flühweghalde bei Augst ", Augst, Augster Museumshefte, 3, 65 p.

RıнA E., 1986 - " Römische Toilettgerät und medizinische Instrumente aus Augst und Kaiseraugst ", Augst, Forschungen in Augst, 6, 187 p.

Riнa E., 1990 - " Der römische Schmuck aus Augst und Kaiseraugst ", Augst, Forschungen in Augst, 10, 91 pl., 245 p.

Roth-Zehner M., Le Martret A., 2008 - « Le sanctuaire galloromain de Sierentz - ZAC Hoell (Haut-Rhin, F) ", dans Castella D., Meylan Krause M.-F. (dir.), Topographie sacrée et rituels. Le cas d'Aventicum, capitale des Helvètes, actes du colloque international d'Avenches (2-4 novembre 2006), Antiqua, 43, p. 298-303.

SANGnier P., 1968 - Notice de la carte géologique au 1/50000, Rouen (ouest), XIX-11, Orléans, Bureau de Recherches Géologiques et Minières, $12 \mathrm{p}$.

SaraH G., 2009 - "Analyses élémentaires de monnaies de Charlemagne et de Louis le Pieux du Cabinet des Médailles : le cas de Melle ", dans Clairand A., Hollard D. (dir.), Numismatique et archéologie en Poitou-Charentes, Actes du colloque de Niort 7-8 décembre 2007, Musée Bernard d'Agesci, Paris, SENA (Recherches et Travaux de la Société d'Études Numismatiques et Archéologiques, 2), p. 63-83, pl. VII-VIII.

SÉris D., 2015 - " La Grillère, Saint-Denis-du-Maine, Mayenne ", dans Raux S., Brouquier-Reddé V., Monteil M., Van Andringa W., Des dieux et des hommes. Cultes et sanctuaires en Sarthe et Mayenne dans l'Antiquité, Catalogue d'exposition (Le Mans, 21 mars au 21 septembre 2015), Le Mans, p. 127-130.

Sutherland C. H. V., 1967 - The Roman Imperial Coinage, VI. From Diocletian's reform (A.D. 294) to the death of Maximinus (AD 313), Londres, Spink \& Son, 727 p., 16 pl.

Sutherland C. H. V., 1984 - The Roman Imperial Coinage, I'. From 31 BC to $A D$ 69, Londres, Spink \& Son, 305 p., 32 pl. (revised edition).

Tisserand G., 1980 - "Les ex-voto du site de Flavier à Mouzon (08210) ", Revue archéologique de l'Est et du Centre-Est, XXXI, fasc. 1 et 2, p. 61-73, 16 fig.

Verneau F., 2014 - «Évolution des espaces et des pratiques dans le sanctuaire de la Fontaine de l'Étuvée à Orléans/Cenabum ", dans Van Andringa W. (dir.), La fin des dieux. Les lieux de culte du polythéisme dans la pratique religieuse du IIt au ve s. apr. J.-C. (Gaules et provinces occidentales), Paris, CNRS Éditions (Gallia, 71, 1), p. 97-108.

Weвв P. H., 1927, 1933 - The Roman Imperial Coinage, V. Valerian to Amandus, Londres, 1927, 424 p., 12 pl. (1); Probus to Amandus, Londres, Spink \& Son, 1933, 701 p., 20 pl. (2). 